Check for updates

Cite this: Mater. Adv., 2021, 2, 598

Received 9th March 2020 Accepted 18th November 2020

DOI: $10.1039 / \mathrm{d} 0 \mathrm{ma} 00087 \mathrm{f}$

rsc.li/materials-advances

\section{Carbon based materials: a review of adsorbents for inorganic and organic compounds}

\author{
Mohammad Mehdi Sabzehmeidani, (D) a Sahar Mahnaee, ${ }^{\mathrm{b}}$ Mehrorang Ghaedi, ${ }^{\mathrm{b}}$ \\ Hadi Heidari $\mathbb{B D}^{c}$ and Vellaisamy A. L. Roy ${ }^{c}$
}

\begin{abstract}
This review presents the adsorptive removal process of hazardous materials onto carbon-based materials comprising activated carbon, graphene, carbon nanotubes, carbon nanofibers, biochar and carbon aerogels. Particular emphasis is placed on the fabrication of various carbon-based substances and their characteristics. As a ubiquitous phenomenon, dangerous compounds originating from industrial wastewater lead to damage to the environment and water resources. Therefore, among conventional technologies, adsorption is highly effective and the most extensively used method owing to its simplicity of performance and fairly low cost of application for the removal of hazardous pollutants. This paper comprehensively reviews a multitude of aspects regarding the chemical and physical nature of various carbon materials and their adsorption ability by increasing their surface area or their possible modification. Based on the properties of nano-carbon materials, adsorptive elimination mechanisms for antibiotics, dyes, heavy metals, pesticides, oils, phenolic and volatile organic compounds and gas pollutants are highlighted. The advantageous characteristics of nano-carbon materials assigned to their unique adsorptive removal of common hazardous substances will be pointed out.
\end{abstract}

\section{Introduction}

Nowadays, the increasing demand for fresh water along with the development of industrialization, multiyear droughts and rapid human population growth are leading to a deficiency in clean water resources and urgent water treatment is highly recommended. The issue of the lower extent of water resources is proportional to the adoption of different practical methods to yield more useable water. Also, industrial and agricultural wastewaters are classified as the largest feasible water resources. Among the diverse treatment processes developed for water treatment, every process has intrinsic limitations in applicability, cost and effectiveness. One attractive option is the treatment of wastewater from industry or other activities with an adsorption process to improve its quality for further use in industrial and agricultural operations. In past decades, much research effort has been devoted to understanding the properties of materials as adsorbents for the removal of dangerous and hazardous compounds. The water quality is important to avoid long term consequences of human health and it is obtained by adsorption of pollutants such as dyes, heavy metals, phenolic, and pharmaceuticals from the liquid phase, to purify products and

\footnotetext{
${ }^{a}$ Chemical Engineering Department, Yasouj University, Yasouj, Iran

${ }^{b}$ Chemistry Department, Yasouj University, Yasouj 75918l-74831, Iran.

E-mail: m_ghaedi@yu.ac.ir; Fax:+98-74-33223048; Tel: +98-74-33223048

c James Watt School of Engineering, University of Glasgow, Glasgow G12 8QQ, UK
}

recover valuable compounds. This review will focus on an investigation of the removal of conventional inorganic and organic compound hazardous substances that exist in gas or liquid media using carbon-based materials (CBMs), to describe properties assigned to adsorbent and adsorbate interaction. Over past several decades, much progress has been made on and attention has been paid to a better understanding of the adsorption, mechanisms and isotherms of CBMs. This review mainly addresses the methods of CBM synthesis and modification using various materials and the corresponding summary mechanisms and adsorption capacity for the removal of pollutants from aqueous solution.

\subsection{Adsorbents}

Various factors are involved in adsorption processes, such as adsorbent structures, fluid properties and contaminant structures, operating conditions, and system configuration. Various materials, including alumina, activated carbon (AC), clays, silica gel, composites, zeolites, biomasses, and biological and polymeric matters have been employed as adsorbents for the elimination of contaminants in environmental water. ${ }^{1}$ The study of carbon-based nanomaterials as adsorbents is a research issue that has expanded quickly over the past decade. The motivation for the development of this field stems mainly from the unique properties and diversities of carbon-based structures and the creation of new opportunities in many subfields of chemistry, physics and engineering. A great variety of water contaminants, like toxic 
metal ions, pharmaceuticals, pesticides, metalloids and other inorganic and organic substances, have the ability to be adsorbed by carbon-based material in a combination of various process. ${ }^{2,3}$ Absorption as a water treatment technology merely concentrates the common pollutants and transfers them to other phases. The adsorption phenomena are characterized by and depend on the interactions between adsorbate molecules and adsorbent. The absorption capacity of a carbon-based adsorbent for chemical compounds depends on the nature of the adsorbate $\left(\mathrm{p} K_{\mathrm{a}}\right.$, polarity, functionality, size and molecular weight), the adsorbent (functional groups and pore size and structure) and solution conditions $(\mathrm{pH}$, ionic strength and temperature). ${ }^{4,5}$ In the aqueous phase, the van der Waals, induced-dipole, dipole-dipole, and hydrogen-bonding donoracceptor forces are responsible for the binding and accumulation of chemical compounds on various adsorbents. Among the various interactions, hydrogen and $\pi-\pi$ bonds and also covalent and electrostatic interactions and the hydrophobic effect play important roles in the adsorption. ${ }^{6-8} \mathrm{CBMs}$ comprise $\mathrm{AC}$, graphene, carbon nanotubes (CNTs), carbon nanofibers (CNFs), biochar (BC) and carbon aerogels (CAs). Fig. 1 shows some different types of CBMs used for the adsorption process.

\subsection{Adsorption equilibrium isotherm}

The equilibrium isotherms give the adsorption capacity of an adsorbent and the thermodynamic parameters and provide the means to find the interaction between adsorbent and adsorbate. Equilibrium isotherms correlate the amount of adsorption by the adsorbent $\left(q_{\mathrm{e}}\right)$ and the equilibrium concentration of the adsorbate $\left(C_{\mathrm{e}}\right)$, which are good indexes for representation of the adsorption system. Also, liquid-solid adsorption isotherms are used to diagnose the adsorption mechanism to obtain information about adsorbent surface properties and the nature of the adsorbate. ${ }^{9}$ The $\mathrm{S}, \mathrm{L}, \mathrm{H}$, and $\mathrm{C}$ curves represent the four types of equilibrium curves that are

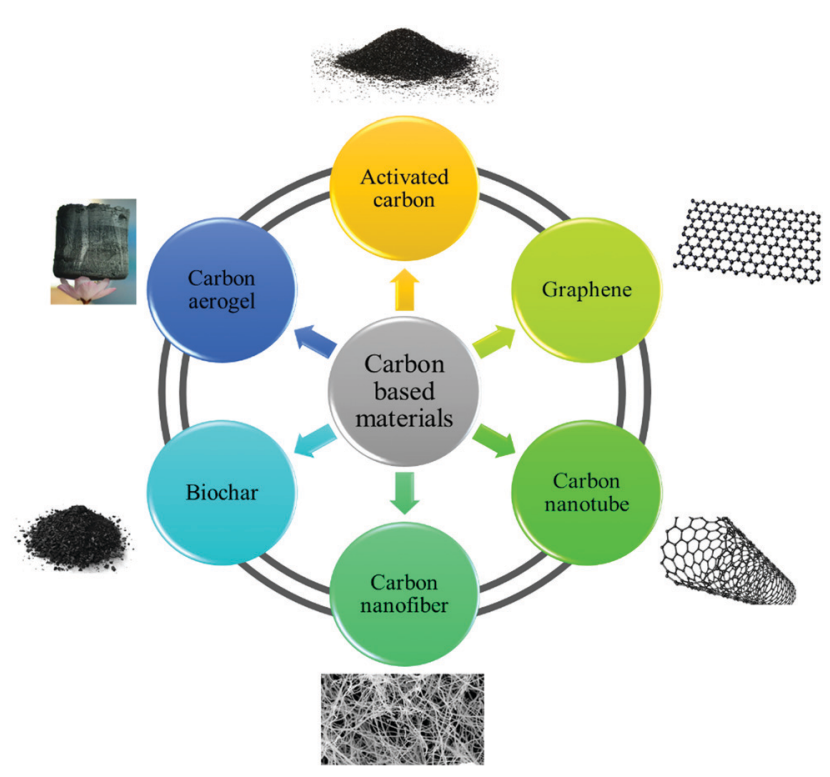

Fig. 1 Various applicable CBMs in adsorption processes. identified according to the initial slope. ${ }^{10}$ The adsorption data can be simulated through several isotherm models, including Henry's law, Langmuir (monolayer), Temkin, Freundlich, Dubinin-Radushkevich (D-R), Redlich-Peterson (R-P), the BET isotherm (multilayer) and statistical physics models. ${ }^{11}$ The adsorption isotherm models used to describe the adsorbent and adsorbate are presented in Table 1.

\subsection{Adsorption kinetics model}

The nature of adsorption will depend on an evaluation of the adsorption kinetics that were applied to investigate the rate and mechanism of adsorption, which can occur through physical or chemical phenomena, and the possibility of their application. In a batch adsorption process, the more utilized traditional models are tabulated in Table 2.

The pseudo-first-order equations are formed based on five assumptions: adsorption only occurs on localized sites and the interactions between adsorbates are not considered; the energy of adsorption is not dependent on surface coverage; maximum adsorption corresponds to a saturated mono-layer of adsorbates on the adsorbent surface; the concentrations of adsorbates are considered to be constant; and the adsorbate uptake obeys the pseudo-first-order rate. ${ }^{13}$ For pseudo-second-order kinetics, the assumptions are almost the same as for the pseudo-first-order model except the metal ion uptake on the ACs is governed by a second-order rate equation. ${ }^{14}$ The Elovich model plus a consideration of interactions between adsorbed elements employs some assumptions, including: a linear relationship between energy and surface coverage; adsorbate concentration is constant; and the ion uptake on the activated carbons is negligible before the exponential. ${ }^{15}$

The intra-particle diffusion model is the so-called WeberMorris intra-particle model. The straight-line form of $q_{t}$ versus $t^{1 / 2}$ shows that the adsorption process is only controlled by intra-particle diffusion. However, multi-linear plots suggest that two or more parameters influence the sorption process. It is assumed that the external resistance to mass transfer surrounding the particles is only significant in the early stages of adsorption: this is represented by the first sharper stage. The second linear portion is the gradual adsorption stage with control over intraparticle diffusion. ${ }^{16}$ According to the shrinking-core model, an adsorption process occurs into three sequential steps: diffusion through an external liquid film, diffusion through a saturated shell, and adsorption at the surface of the sorbate-free core. In this model, the two parameters $\tau_{1}$ and $\tau_{2}$ are the characteristic diffusion times for diffusion through the external liquid film and diffusion through the saturated shell, respectively. ${ }^{18}$ In a continuous adsorption process, the various experimental models for calculation of breakthrough curves that can analyze the mass balance of a fixed bed include Bohart-Adams, Thomas, Wolborska, and Yoon-Nelson. ${ }^{11}$

\subsection{Adsorption mechanisms}

The mechanisms governing the removal by carbon-based adsorbent materials of aqueous pollutants are outlined in the summary. Generally, the interactions between the functional 
Table 1 Expressions of adsorption isotherm models ${ }^{11,12}$

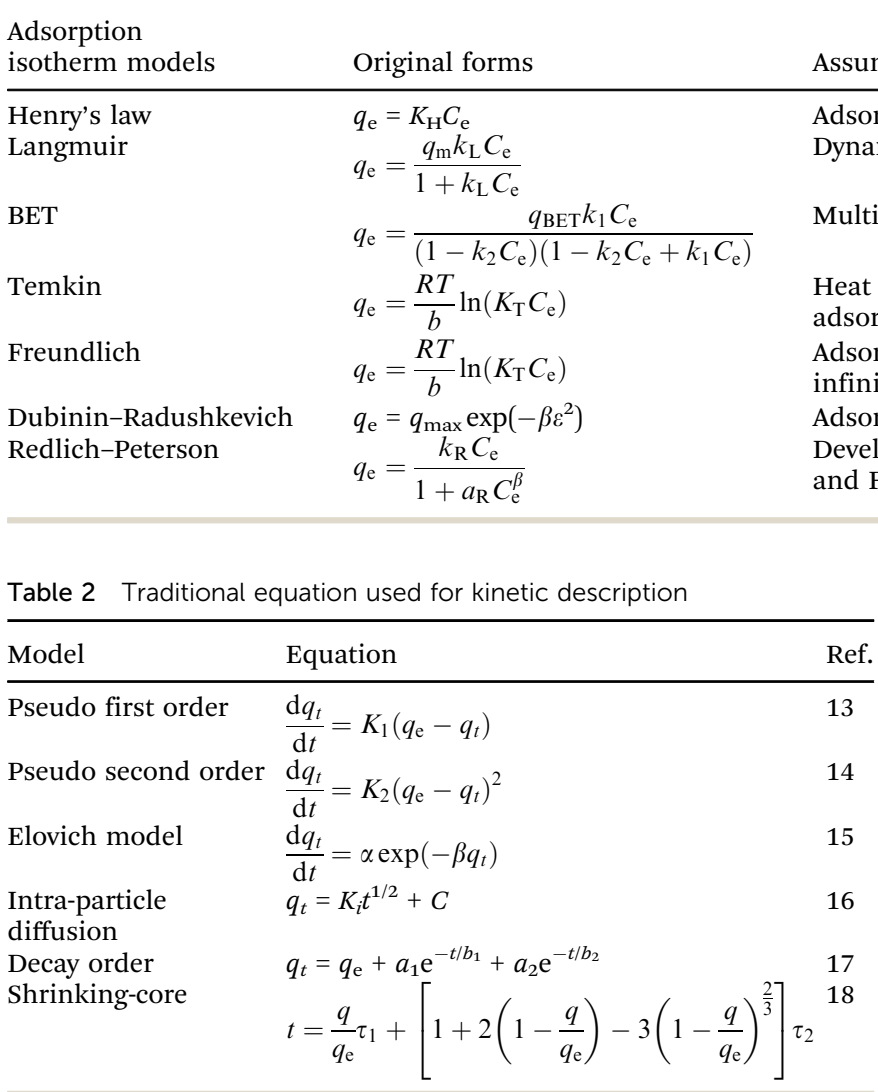

groups of CBMs and pollutants are complicated. The adsorption performance depends on the physics and chemistry of the carbon-containing material surface, the properties of the aqueous solution, and the nature of the adsorbate. The adsorption mechanisms onto carbon adsorbents could involve physisorption (physical adsorption and electrostatic interaction) and chemisorption (surface complexation, ion exchange and precipitation).$^{19}$ In general, chemisorption has a more remarkable influence than physisorption for the removal of pollutants from aqueous solution. Under particular conditions, the surface functional groups are effective in some mechanisms that comprise ion exchange, electrostatic interaction, and surface complexation. ${ }^{20,21}$

\section{Adsorption by carbon-based material}

The existence of carbon in different forms can be attributed to its unique electronic structure which allows the formation of stable chemical bonds in various configurations. The uniqueness of carbon comes from the fact that it can form single, double or triple bonds; it has an exceptional ability to catenate (bond with one another), forming cyclic or acyclic chains; it can form straight or branched chains; it can also bond with other non-metallic elements. ${ }^{22,23}$ The four valence electrons (two s and two $\mathrm{p}$ electrons) of carbon occupy the $\mathrm{L}$ shell, while the inner $\mathrm{K}$ shell is occupied by two electrons. The $2 \mathrm{~s}$ and $2 \mathrm{p}$ orbitals of carbon can be hybridized to enable single, double or triple bonds formation via $\mathrm{sp}^{3}, \mathrm{sp}^{2}$ or $\mathrm{sp}$ hybridization, respectively. The formation of various structures for carbon in one-dimension, two-dimensions and three-dimensions is due to the linear combination of valence carbon orbitals. Carbon atoms with $\mathrm{sp}^{2}$ hybridization give rise to an impressive number of different materials, such as CNTs, graphene nanoribbons, porous carbon and fullerene. As in any crystalline phase, the crystal structures of natural carbon allotropes (i.e. graphite and diamond) contain various types of imperfections. These so-called lattice defects can be classified by their dimensions into 0D (point), 1D (line), 2D (planar) and 3D (volume) defects. Lattice defects control the physical properties of crystals and are often a fingerprint of the geological environment in which they formed and were modified.

By convention, carbon naturally has three allotropes: amorphous carbon, crystalline graphite and diamond. There are various kinds of amorphous carbon allotropes like coal, charcoal, lampblack, carbon black and coke, which have not been observed in the pure (100\% carbon) state. They possess different properties and therefore each deserves to be considered as an allotrope, but for preference they are grouped as one: the amorphous allotropes. ${ }^{24}$ The amorphous forms of carbon are usually not desirable choices for a researcher because their structures cannot be manipulated like crystalline allotropes; hence, they do not appeal to the interest of researchers. The use of carbon-based adsorbents goes so far back in time that its origin is impossible to determine exactly. Prior to the use of what we call today carbon-based adsorbents, either wood char, or coal char or simply a partially devolatilized carbonaceous material was employed as an adsorbent. Up to now, there have been many works related to the application of carbon-based adsorbents in the refining of pollutants from air, soil, water, and synthesized materials. AC, GO, CNTs, CNFs, BC and CAs are the common abbreviations which are used to classify these adsorbents. In different adsorption processes, both in gas and liquid phases, the molecules or atoms (adsorbable) are fixed (adsorbed) on the carbon (adsorbent) surface by physical interaction (electrostatic or dispersive forces) and/or chemical bonds. Therefore, a relatively large specific surface area is one of the most important properties 
that characterize CBM adsorbents. Hence, we have tried to review the achieved advances in the application of these materials, their structural modification and their properties in various fields of industry.

\subsection{Activated carbon}

AC generally refers to highly porous carbonaceous materials, and is the most popular amongst adsorbents owing to its large surface area which ranges from 500 to $3000 \mathrm{~m}^{2} \mathrm{~g}^{-1}$, low cost and good charge-holding capacity and the ability for various functional groups to be generated, which may be responsible for the effective elimination of a variety of contaminants from aqueous or gaseous media. ${ }^{25} \mathrm{AC}$ has different structures like granular, powdery and fibrous physical forms which are generally applied for water cleanup procedures. ${ }^{26}$

2.1.1 Synthesis and activation. AC preparation is composed of four basic steps: raw material preparation, pelletizing, carbonization and activation. ${ }^{27,28}$ Thermal and chemical activation are two kinds of activation approaches applied to supply a porous structure from a material with a low surface area. ${ }^{29}$ Physical (thermal) activation after initial treatment and pelletizing involves carbonization at $400-500{ }^{\circ} \mathrm{C}$ that is used for the removal of volatile matter and subsequent partial gasification by an oxidizing gas like carbon monoxide, steam or flue gas $\left(800-1000{ }^{\circ} \mathrm{C}\right)$ leads to the generation of porosity, surface area and functional groups. ${ }^{30,31}$ Another method is chemical activation that involves the incorporation of additive materials into the synthesis approach before carbonization. $^{32}$ The present additives degrade and dehydrate the cellulosic substance in carbonization at $250-650{ }^{\circ} \mathrm{C}$. Lignin present in a raw substance is blended with activators like phosphoric acid, sulfuric acid or others following carbonization at temperatures up to $900{ }^{\circ} \mathrm{C} .{ }^{33}$ In fact, according to the material sources and activation process, different structure and functional groups and activities can be supplied. ${ }^{34}$

A rotary kiln and a fluidized bed are two important processes for large-scale production of AC materials. The rotary kiln is a pyro-processing device to increase the temperature of raw materials. The kiln is a cylindrical vessel, inclined slightly on a horizontal axis, which is rotated slowly around its axis. The main part of this system is a refractory-lined cylinder that rotates at a horizontal angle of 5-10 degrees or less at a speed of 1-5 rpm. Auxiliary heating is also another way to achieve the desired temperature for kiln systems. As the kiln rotates, the material gradually moves down to the lower end, and may undergo a certain amount of stirring and mixing. For better heat transfer, hot gases pass along the kiln. AC manufacture (using a rotary kiln) is generally considered to be a threestage process consisting of pre-activation, activation and postactivation: ${ }^{35,36}$

- Pre-activation refers to checking the quality and obtaining desirable size properties for the material prior to activation (so-called kiln-feed).

- Activation is a process in which the kiln-feed is turned into AC. According to the properties of the kiln-feed, the rotary kiln uses high temperatures and steam within special designs.

- The post-activation consists of quality checking the parameters of the kiln output material.

With regard to using a fluidized bed reactor for AC production, the effect of various process parameters, such as particle size, fluidizing velocity, process time, static bed height, activation temperature and fluidizing medium can also be well studied.

2.1.2 Source of AC. Lignocelluloses from biomass, wood, anthracite and bituminous coal are considerable routes for producing AC, while nowadays more precursor materials are available and widespread with which it is possible to make low-cost carbons. ${ }^{37,38}$ General waste materials, including agricultural by-products and plastics, are potential sources of AC. Also, several important and highly abundant agricultural by-products are indicated in Table 3 that can be applied as natural sources for AC that can subsequently be used for the adsorption of various pollutants from aqueous solutions.

2.1.3 Modification of AC. The effectiveness of ACs in an adsorption process for various pollutants is identified based on

Table 3 Summary of maximum adsorption capacities by AC

\begin{tabular}{|c|c|c|c|c|c|}
\hline AC natural source & Pollutants & $\begin{array}{l}\text { Initial dye concentration } \\
\left(\mathrm{mg} \mathrm{L}^{-1}\right)\end{array}$ & Isotherm model & $\begin{array}{l}\text { Adsorbent capacity } \\
\left(\mathrm{mg} \mathrm{g}^{-1}\right)\end{array}$ & Ref. \\
\hline Acorn tree & Brilliant Green & 25 & Langmuir & 2.11 & 39 \\
\hline Limon wood & Acid Yellow 199 & 8 & Langmuir & 85.51 & 40 \\
\hline Rice husks & Safranin-T & $50 \mathrm{mM}$ & Langmuir & $3.183 \mathrm{~mol} \mathrm{~g}^{-1}\left(40{ }^{\circ} \mathrm{C}\right)$ & 41 \\
\hline Cherry tree & $\mathrm{MB}$ & $5-30$ & Langmuir & 41.49 & 42 \\
\hline Apple tree wood & $\begin{array}{l}\text { Janus Green B } \\
\text { Methylene Blue (MB) }\end{array}$ & $9-33$ & Langmuir & $\begin{array}{l}28.01 \\
21.79\end{array}$ & 43 \\
\hline Fruit stones & Astrazon Yellow 7GL & $50-300$ & Langmuir & 221.23 & 44 \\
\hline Pomegranate & Congo Red (CR) & $5-200$ & Langmuir & 19.23 & 45 \\
\hline Pistacia & $\mathrm{MB}$ & - & Langmuir & 185 & 46 \\
\hline Bagasse & Acid Blue & $20-1050 \mathrm{mg} \mathrm{dm}{ }^{-3}$ & Langmuir & 391 & 47 \\
\hline Date palm & Ciprofloxacin & $50-300$ & Langmuir & 133.3 & 48 \\
\hline Plum kernels & $\begin{array}{l}\text { MB } \\
\text { Acid Blue } 74 \\
\text { Basic Brown } 1 \\
\text { Phenol }\end{array}$ & $0-300 \mathrm{~g} \mathrm{~m}^{-3}$ & Langmuir & $\begin{array}{l}828 \mathrm{~g} \mathrm{~kg}^{-1} \\
567 \mathrm{~g} \mathrm{~kg}^{-1} \\
1848 \mathrm{~g} \mathrm{~kg}^{-1} \\
277 \mathrm{~g} \mathrm{~kg}^{-1}\end{array}$ & 49 \\
\hline Siris seed pods & Metronidazole & $20-100$ & Langmuir & 53.194 & 50 \\
\hline Sawdust & $\begin{array}{l}\text { Direct Blue 2B } \\
\text { Direct Green B }\end{array}$ & - & Langmuir & $\begin{array}{l}518 \\
327.9\end{array}$ & 51 \\
\hline
\end{tabular}


the conduct of research into AC modification, which is gaining prominence owing to the generation of extra sites on ACs to progress the affinity for certain contaminants to accelerate their efficient removal from various types of industries, especially wastewater effluents. Therefore, it is necessary to understand the most important effective variables that influence AC adsorption capacity prior to their application or appropriate modification via specific physical and chemical reactions which are assigned to enhance affinities toward metal, inorganic and/or organic compounds in aqueous media. ${ }^{52}$ The main and distinguished features of $\mathrm{AC}$ which have critical roles in adsorption efficiency are specific surface area (SSA), pore-size distribution (PS), pore volume (PV) and the presence of surface functional groups ${ }^{53}$ which may be progressed and improved following their modification with other nano-structured materials or even their size reduction to the nano-scale. Generally, the adsorption capacity rises with specific surface area owing to the availability of adsorption sites while the PS is closely attributed to the composition of the $\mathrm{AC}$, the kind of initial raw substance, the degree of activation during the production stage and the iteration of regeneration. Much emphasis is given to synthesizing surface-modified carbons by various methods to increase the potential of $\mathrm{AC}$ for the removal of specific pollutants. The surface of AC is generally modified after the activation stage. The modification could be classified into three classes: physical, chemical, and biological modification. Furthermore, oxidative ${ }^{54}$ and non-oxidative ${ }^{55}$ methods of AC treatment have been reported in the literature. Various techniques, including acid, base, impregnation, ozone, surfactant, plasma and microwave treatment have been suggested to develop surfacemodified ACs.

2.1.4 Application. The main areas of AC application in industry are water treatment, decolorizing, solvent recovery, military usage to protect against attack by toxic gases such as mustard gas, nuclear reactors, and air treatment. ${ }^{34}$ Domestic activities include cooker hoods, fridge deodorizers, air purifiers, deep fat fryer cartridges, and cigarette filters. Precious metal recovery includes gold and silver from a cyanide solution. ACs can also be used as catalysis supports. Owing to their inert porous structure, ACs can absorb chemicals on their large hydrophobic internal surface, making them accessible to reactants. AC is synthesized in various shapes and sizes depending on the application for which it is to be applied, such as extruded AC (EAC), granular AC (GAC), powdered AC (PAC), $\mathrm{AC}$ fibers and AC-molecular sieves. The application of carbon molecular sieves in gas separation, in particular oxygen and nitrogen, has grown progressively over the last decades. ${ }^{56-60}$ These carbons are characterized by a high adsorption capacity and micropore size which may be of the same order of magnitude as the adsorbate molecules. The ability of the molecule to penetrate into the pore volumes dictates the ability and efficiency of carbon molecular sieves in the separation of various species, especially gas mixtures. Efficiency of separation increased following the application of AC fibers as molecular sieves in gas filtration, which emerged from the fact that AC fiber shapes often have a greater adsorption rate and a larger capacity
Table 4 Summary of maximum adsorption capacities by nanostructures on $\mathrm{AC}$

\begin{tabular}{|c|c|c|c|}
\hline $\begin{array}{l}\text { Nanostructures } \\
\text { on AC }\end{array}$ & Pollutants & $\begin{array}{l}\text { Adsorbent capacity } \\
\left(\mathrm{mg} \mathrm{g}^{-1}\right)\end{array}$ & Ref. \\
\hline \multirow{2}{*}{$\mathrm{Bi}_{2} \mathrm{~S}_{3}-\mathrm{Ag}_{2} \mathrm{~S}$} & Auramine-O & 202.43 & 61 \\
\hline & Ponceau-4R & 191.57 & \\
\hline \multirow{2}{*}{$\begin{array}{l}\mathrm{CrFeO}_{3} \\
\mathrm{ZnO}\end{array}$} & Methyl Violet (MV) & 65.67 & 62 \\
\hline & Safranin $\mathrm{O}$ & 32.06 & 63 \\
\hline \multirow{2}{*}{$\mathrm{Au}-\mathrm{Fe}_{3} \mathrm{O}_{4}$} & Rhodamine123 & 71.46 & 64 \\
\hline & Disulfine Blue & 76.38 & \\
\hline \multirow[t]{2}{*}{$\mathrm{ZnS}: \mathrm{Cu}$} & Methyl Orange (MO) & 44.65 & 65 \\
\hline & Sunset Yellow (SY) & 50.54 & \\
\hline $\mathrm{Pt}$ & $\mathrm{CR}$ & 43.478 & 66 \\
\hline \multirow{3}{*}{$\mathrm{Cu}_{2} \mathrm{O}$} & SY & 113.0 & 67 \\
\hline & Eosin B & 137.0 & \\
\hline & MB & 110.0 & \\
\hline $\mathrm{Cu}: \mathrm{ZnS}$ & SY & 85.397 & 68 \\
\hline \multirow{3}{*}{$\mathrm{Fe}_{3} \mathrm{O}_{4}$} & SY & 76.37 & 69 \\
\hline & Eosin B & 78.76 & \\
\hline & $\mathrm{MB}$ & 102.0 & \\
\hline \multirow{2}{*}{$\mathrm{TiO}_{2}$} & $\mathrm{Cu}(\mathrm{II})$ & 105.26 & 70 \\
\hline & $\operatorname{Cr}(\mathrm{III})$ & 93.46 & \\
\hline \multirow[t]{3}{*}{$\mathrm{Cu}(\mathrm{OH})_{2}$} & Eosin $Y$ & 32.9 & 71 \\
\hline & MB & 26.4 & \\
\hline & Phenol Red & 38.5 & \\
\hline CdSe & Muroxide & 333 & 72 \\
\hline CdTe & SY & 181.81 & 73 \\
\hline $\mathrm{Cd}(\mathrm{OH})_{2}$ & SY & 76.923 & 74 \\
\hline $\mathrm{Pd}$ & $\mathrm{CR}$ & 76.923 & 75 \\
\hline $\mathrm{Ag}$ & & 66.667 & \\
\hline $\mathrm{ZnO}$ & & 142.57 & \\
\hline
\end{tabular}

than typical granular ACs. Also, several research studies on the modification of AC by nanoparticle (NP) surfaces have been carried out for the creation of specific surfaces to enhance the removal of chemical species, including $\mathrm{Bi}_{2} \mathrm{~S}_{3}-\mathrm{Ag}_{2} \mathrm{~S}^{61}{ }^{61} \mathrm{CrFeO}_{3},{ }^{62}$ $\mathrm{ZnO},{ }^{63} \mathrm{Au}-\mathrm{Fe}_{3} \mathrm{O}_{4}{ }^{64} \mathrm{ZnS}: \mathrm{Cu},{ }^{65} \mathrm{Pt},{ }^{66} \mathrm{Cu}_{2} \mathrm{O},{ }^{67} \mathrm{Cu}: \mathrm{ZnS},{ }^{68} \mathrm{Fe}_{3} \mathrm{O}_{4},{ }^{69}$ $\mathrm{TiO}_{2},{ }^{70} \mathrm{Cu}(\mathrm{OH})_{2},{ }^{71} \mathrm{CdSe},{ }^{72} \mathrm{CdTe},{ }^{73} \mathrm{Cd}(\mathrm{OH})_{2}{ }^{74}$ and $\mathrm{Pd}^{75}$ nanostructures on AC. The adsorption capacities of pollutants by nanostructures on AC are presented in Table 4.

From another viewpoint, the various application of ACs can mostly be split into two main sorts: liquid-phase and gas-phase applications. Gas-phase applications of AC include separation, gas storage and catalysis supports, while ACs in gas-phase applications are granular or shaped. Daneshyar et al. ${ }^{76}$ synthesized nanocomposites $\mathrm{Cu}-\mathrm{Zn}-\mathrm{Ni}-\mathrm{NPs}-\mathrm{AC}$ and Ni-Co-NPs- $\gamma \mathrm{Al}_{2} \mathrm{O}_{3}$ and used them for the elimination of $\mathrm{H}_{2} \mathrm{~S}$ molecules from natural gas with maximum removal by $\mathrm{Cu}-\mathrm{Zn}-\mathrm{Ni} / \mathrm{AC}$ (Fig. 2).

ACs for use in the liquid-phase differ from gas-phase carbons primarily in their pore size distribution, where liquid-phase carbons have much greater pore volume in the macropore range which permits liquids to diffuse more rapidly into the pores. The pores with a higher size also promote the higher adsorption of large-size molecules (either impurities or products) in many liquid-phase applications. Zhang et al. ${ }^{77}$ studied the performance of powdered AC (PAC) for the removal of representative groups of 28 antibiotics: namely, tetracyclines (TCs), macrolides (MCs), chloramphenicols (CPs), penicillins (PNs), sulfonamides (SAs) and quinolones (QNs) from wastewater. Under optimum conditions, the removal efficiency was up to $99.9 \%$ (deionized water) and $99.6 \%$ (surface water) with a 

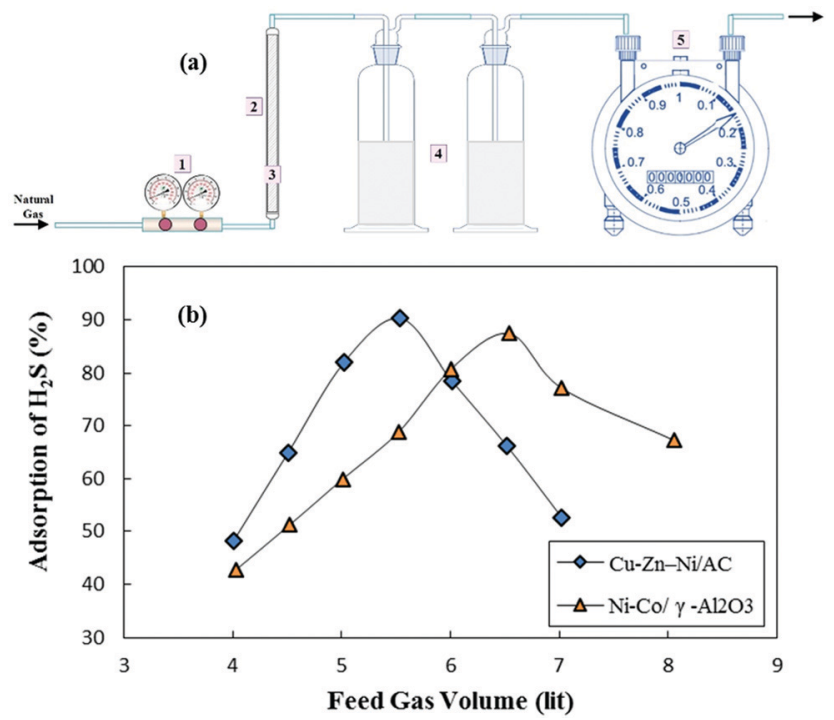

Fig. 2 (a) The experimental set-up used for the adsorptive removal of hydrogen sulfide; (b) influence of feed gas volume on the adsorption of $\mathrm{H}_{2} \mathrm{~S}^{76}$

PAC dosage of $20 \mathrm{mg} \mathrm{L}^{-1}$ in a contact time of $120 \mathrm{~min}$ and these results indicated superior adsorption capacity for all others antibiotics. It has been reported that metal ions like $\mathrm{Co},{ }^{78} \mathrm{Cu},{ }^{79}$ $\mathrm{Mn},{ }^{80} \mathrm{Hg},{ }^{81} \mathrm{Pd},{ }^{82} \mathrm{Cd},{ }^{83} \mathrm{~V}^{84}$ and $\mathrm{Pb}^{85,86}$ have an adsorption capability for ACs via various interaction formations. The adsorption of lead $\left(\mathrm{Pb}^{2+}\right)$ onto $\mathrm{AC}$ originating from cow bones and chemically modified with $\mathrm{HNO}_{3}$ was investigated. ${ }^{87}$ The solution $\mathrm{pH}$ is a highly significant factor in $\mathrm{Pb}^{2+}$ adsorption onto $\mathrm{AC}$, and at $\mathrm{pH}>6.0$ the precipitation of metal hydroxides is the predominant process in the solution. The metal $\left(\mathrm{Pb}^{2+}\right)$ recovery remained constant at around $50 \%$ in all cycles. The $\mathrm{Cr}(\mathrm{vI})$ adsorption in both the absence and the presence of humic acid (HA) most appropriately followed the pseudosecond-order kinetic model and the adsorption isotherm is well fitted to the Freundlich equation. ${ }^{77}$ The increased $\mathrm{Cr}(\mathrm{vI})$ removal can be related to the binding interactions between $\mathrm{Cr}(\mathrm{vI})$ and $\mathrm{HA}$, and the reduction of $\mathrm{Cr}(\mathrm{VI})$ induced by HA, while $\mathrm{Cr}(\mathrm{III})$ is complexed by the surface-bound HA and subsequently the adsorption of $\mathrm{Cr}(\mathrm{III})-\mathrm{HA}$ complexes takes place. Phenolic compounds are used in many industrial chemical products because of their unique properties, while they are classified as a priority contaminants owing to their toxicity to organisms even at low concentrations. Gupta et al. ${ }^{88}$ fabricated ACs from waste rubber tires by a microwave-induced chemical impregnation (RTACMC) and physical activation (RTAC) technique for the adsorption of phenolic compounds from solution. RTACMC has greater porosity and total pore volume compared to fairly acidic RTAC. The microwave method thus helped in the development of an increased porous morphology in a shorter time and an improvement in the cost-effectiveness of the process. $\mathrm{NH}_{4} \mathrm{Cl}$-induced $\mathrm{AC}$ (NAC) was used for the adsorptive removal of diazinon pesticide from wastewater. ${ }^{89}$ The maximum adsorption was $97.5 \%$ for $20 \mathrm{mg} \mathrm{L}^{-1}$ of diazinon adsorbed onto NAC at a low solution concentration of $0.3 \mathrm{~g} \mathrm{~L}^{-1}$ and a short contact time of $30 \mathrm{~min}$ at neutral $\mathrm{pH}$. The effect of $\mathrm{NaCl}$ addition on the diazinon solution caused a slight reduction in humic acid, and ammonia content slightly improved the adsorption process, while the maximum adsorption capacity was $250 \mathrm{mg} \mathrm{g}^{-1}$ for diazinon using NAC.

Activated sludge was used for the elimination of triadimenol pesticide from water. ${ }^{89}$ The experimental adsorption data had the best fitness with the Freundlich model and the maximum adsorption capacity was $42.9 \mathrm{mg} \mathrm{g}^{-1}$ (298 K). Dyes are colored materials and it is known that their adsorption depends on a substrate that is generally applied in an aqueous solution. The use of synthetic dyes has led to an increasing worldwide awareness of the harmful consequences of pollution. Synthetic dyes even in low concentrations influence environmental aquatic and human safety. ${ }^{90}$ Thus, dye removal from wastewater becomes environmentally important and accordingly ACs are the most conventional adsorbent extensively applied for the adsorption of various dyes. ${ }^{91-94}$ Sayğılı et al. ${ }^{95}$ prepared AC under optimum production conditions from tomato waste, activated in the presence of $\mathrm{ZnCl}_{2}$ and they subsequently applied it for the adsorption of methylene blue (MB) and metanil yellow dyes. The optimal conditions to produce AC, including a (6:1) impregnation ratio at $600{ }^{\circ} \mathrm{C}$ over 1 hour of carbonization, led to the achievement of $\mathrm{AC}$ with a carbon content of $53.92 \%$ and a yield of $38.20 \%$, while it supplied a surface area of $1093 \mathrm{~m}^{2} \mathrm{~g}^{-1}$ with a total pore volume of $1.569 \mathrm{~cm}^{3} \mathrm{~g}^{-1}$, mesoporosity of $91.78 \%$ and average pore diameter of $5.92 \mathrm{~nm}$. The maximum adsorption capacities for $\mathrm{MB}$ and metanil yellow were $400 \mathrm{mg} \mathrm{g}^{-1}$ and $385 \mathrm{mg} \mathrm{g}^{-1}$, respectively. The AC was synthesized and subsequently chemically activated using $\mathrm{KOH}$ via hydrothermal treatment (HT) of sucrose. ${ }^{96}$ The AC was a microporous material with $S_{\mathrm{BET}}$ and $V_{\mathrm{T}}$ of $1534 \mathrm{~m}^{2} \mathrm{~g}^{-1}$ and $0.765 \mathrm{~cm}^{3} \mathrm{~g}^{-1}$, respectively. The highest adsorption capacity monolayer was $704.2 \mathrm{mg} \mathrm{g}^{-1}$ in a low MB concentration (300 $\left.\mathrm{mg} \mathrm{L}^{-1}\right)$.

\subsection{Carbon nanotubes}

CNTs, so-called buckytubes, are cylindrical allotropes of carbon molecules with distinctive properties that make them potentially applicable in a large variety of industrial applications. CNTs exhibit amazing strength as well as unique electrical, mechanical and thermal properties and are famous members of the fullerene family, initially produced via an arc-discharge method by Ijima in 1991. ${ }^{97}$ They have superior properties, such as wide band gap, high melting point, high tensile strength and thermal conductivity. ${ }^{98,99}$ CNTs are normally categorized into three types on the basis of the number of tubes present in their structures: ${ }^{99,100}$ single-walled CNTs (SWCNTs), double-walled CNTs (DWCNTs) and multi-walled CNTs (MWCNTs).

SWCNTs can be made from a single graphene sheet rolled up on itself (diameter of 1-2 $\mathrm{nm}$ ), while their length can be significantly changed by the preparation method. ${ }^{101}$ SWCNTs can usually come together to form bundles (ropes) which in such bundle structures are hexagonally organized to form a crystal-like construction. ${ }^{102}$ DWCNTs are made of two concentric CNTs in which the outer tube encloses the inner tube. They provide a 
combination of distinguished properties of SWNTs which are superior to those of SWNTs in terms of greater stability and stiffness or independent doping of inner and outer tubes. ${ }^{103}$ MWNTs consist of multiple layers of graphene rolled up on itself with diameters between 2 and $50 \mathrm{~nm}$ related to the number of graphene tubes, and these tubes have an approximate inter-layer distance of $0.34 \mathrm{~nm}^{104}$

2.2.1 Synthesis and modification. CNTs could be produced in sizeable quantities using different methods which are commonly categorized in five types: carbon arc-discharge technique, laser ablation, ${ }^{105}$ sonochemical or hydrothermal methods, ${ }^{106,107}$ electrolysis, ${ }^{108}$ and chemical vapor deposition (CVD). ${ }^{105}$ By employing any of these techniques different types of CNT can be produced. Carbon arc-discharge and laser ablation were the first methods used for SWCNT synthesis in large scales (gram). Both methods are suitable for SWCNT and MWCNT synthesis and are based on the condensation of hot gaseous carbon atoms generated from the evaporation of solid carbon. ${ }^{109,110}$ The arc-discharge system is based on using a metal catalyst to grow SWCNTs. About 1-10 g of high-quality SWCNTs can also be produced using the laser ablation method. ${ }^{110}$ Difficulties such as high energy consumption and expensive equipment requirements limit this approach and mean that these methods are less favorable for nanotube production. The main disadvantages for arc discharge are the high temperature and purification required and tangled nanotubes, while the laser based approach is limited to the lab scale and subsequent purification of the crude product is necessary. The sonochemical/hydrothermal technique is another synthesis method for the preparation of different carbonaceous nanoarchitectures, such as nano-onions, nano-rods, nanowires, nanobelts, and MWNTs. ${ }^{107}$ This process can be highly commended and satisfactory compared with other approaches due to its advantages of easy preparation of starting materials and their stability in ambient temperature and also their performance at low temperature (about $150-180{ }^{\circ} \mathrm{C}$ ) without the requirements of hydrocarbons or carrier gas for the operation. ${ }^{111}$ The main point of the electrolysis method is the electro-winning of alkali ( $\mathrm{Li}, \mathrm{Na}, \mathrm{K})$ or alkaline-earth $(\mathrm{Mg}, \mathrm{Ca})$ metals from their chloride salts on a graphite cathode followed by the formation of carbon tubes by the interaction of the metal being deposited with the cathode, which leads to the formation of MWCNTs. The advantages of the electrolytic method are simplicity, the possibility of controlling the process by electrolysis mode, low energy consumption, use of cheap raw substances, and the feasibility of controlling product morphologies and structures by means of optimization of the electrolysis and electrolytic bath composition. ${ }^{111}$ This method encounters challenges such as the cracking and destruction of the graphite cathode during electrolysis, the accumulation of electrolysis products, chlorine gas (anode), alkaline metal (cathode) and carbon nano-materials (cathode) formation in the bath. ${ }^{108}$ Nowadays the abovementioned methods have been replaced by low-temperature chemical vapour deposition (CVD) techniques $\left(<800{ }^{\circ} \mathrm{C}\right)$, which supply the conditions for greater control over the orientation, alignment, nanotube length, diameter, purity and density of CNTs.
There are many different kinds of CVD, such as catalytic chemical vapor deposition (CCVD), either thermal or plasma enhanced (PE) oxygen assisted $\mathrm{CVD},{ }^{112}$ water assisted $\mathrm{CVD}$, microwave plasma (MPECVD), ${ }^{113}$ radiofrequency CVD (RF-CVD), ${ }^{114}$ or hot-filament (HFCVD). ${ }^{115}$ Among these methods, catalytic chemical vapor deposition (CCVD) is the standard method for the preparation of CNTs. The nanotube growth in the CVD process includes the dissociation of hydrocarbon materials catalyzed by the transition metal, and the saturation of carbon atoms in the metal nanoparticle. The presence of metal particles leads to the production of tubular carbon solids in an $\mathrm{sp}^{2}$ hybrid structure. ${ }^{116}$ The properties of the CNTs synthesized by the CVD approach rely on operational factors like pressure and temperature, the type, volume and concentration of hydrocarbons, the nature and size of the catalyst and the nature of the support and the reaction time. ${ }^{117}$

2.2.2 Application. Applications of nanotubes include various areas and disciplines like medicine, nanotechnology, manufacturing, construction, electronics including high-strength composites, ${ }^{98}$ actuators, ${ }^{118}$ energy storage and energy conversion devices, ${ }^{119}$ nano-probes and sensors, ${ }^{101}$ hydrogen storage media, ${ }^{118}$ electronic devices, adsorbents and catalysts. The high surface area, scalable production, tunable surface chemistry, non-corrosive property and the presence of surface oxygen containing functional groups corresponding to CNTs and graphene nanomaterials lead to an improvement in their adsorption performance with respect to conventional adsorbents such as zero-valent iron, iron oxide, zeolite, silica, titanium dioxide, chitosan, and polymers. Accordingly, nowadays CNTs as an adsorbent have been applied for pollutant adsorption as bare CNTs or their modified form from aqueous or gaseous environments. MWCNTs are synthesized by the CVD approach in a fluidized bed reactor under a flow of $\mathrm{CH}_{4}$ and $\mathrm{H}_{2}$ gases in the presence of a Co-Mo/MgO nanocatalyst. ${ }^{120}$ MWCNTs have been modified to produce allylamide-grafted multiwall CNTs which are applicable for efficient $\mathrm{H}_{2} \mathrm{~S}$ removal. It was reported that this material has high capacity for $\mathrm{H}_{2} \mathrm{~S}$ removal due to its effective nitrogen functionalities. Duman et $a .^{121}$ subsequently synthesized oxidized multiwalled CNT (OMWCNT) $-\mathrm{Fe}_{3} \mathrm{O}_{4}$ and OMWCNT-k-carrageenan- $\mathrm{Fe}_{3} \mathrm{O}_{4}$ nanocomposites using CVD, and these materials were applied as adsorbents for the removal of $\mathrm{MB}$ from aqueous solution. Antibiotics like tetracyclines, sulfonamides, macrolides, and quinolones were eliminated by the adsorption process. ${ }^{122}$ The ultrasound-assisted adsorptive removal of dyes such as SY and azur(II) (AZ) onto MWCNT and MWCNT-Pd-NPs was shown and the experimental results revealed that MWCNT-Pd-NPs are superior to MWCNTs in terms of lower contact time and adsorbent mass for the removal of some quantity of SY and AZ. ${ }^{123}$ A summary of pollutant adsorption capacities by CNTs is presented in Table 5.

\subsection{Graphene}

Graphene as single layer of carbon atoms supplies a twodimensional (2D) tightly packed honeycomb crystal lattice. The hexagonal structure of graphene is known as an elementary building block for the $\mathrm{sp}^{2}$ hybridization of the $2 \mathrm{~s}$ orbital and 
Table 5 Summary of adsorption capacities by CNT

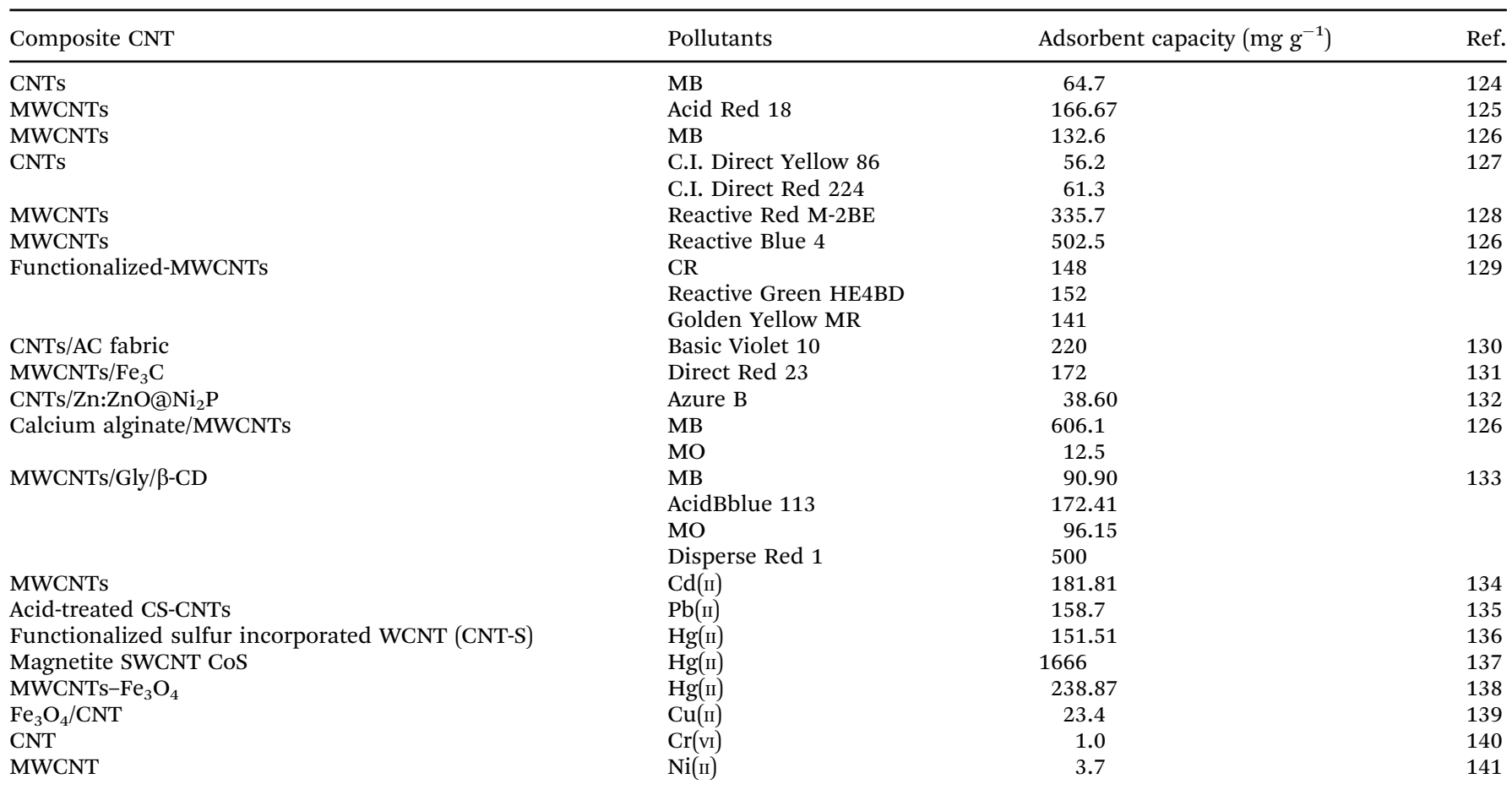

two $2 \mathrm{p}$ orbitals of the carbon atom. Also, graphene is a monolayered 2D hexagonal crystal which indicates a conventional quantum Hall effect due to the electrons being confined in 2D substances. ${ }^{142,143}$

2.3.1 Synthesis and modification. The interesting properties of graphene, including high surface area, high thermal conductivity, strong Young's modulus and fast charge carrier mobility, are well described in the literature. ${ }^{144}$ Graphenes can be mainly prepared by various methods, including exfoliation and cleavage, thermal chemical vapor deposition (CVD), plasma enhanced chemical vapor deposition (PECVD), chemical methods, thermal decomposition on substrates, and unzipping CNTs. Different dimensions have also been obtained, such as zero-dimensional (OD) graphene quantum dots (GQDs), one-dimensional (1D) graphene nanoribbons (GNRs), and two-dimensional (2D) graphene nanosheets (GNSs). MWCNT unzipping methods for the production of graphene can be classified into four major types: the reductive-intercalationassisted approach, oxidative unzipping, electrochemical unzipping, and a fourth miscellaneous group of methods. The first approach is based on the well-known ability of alkali metals to intercalate graphite with expansion in the $Z$-axis direction. Such lattice expansion induces extreme stress within the concentric walls, resulting in the bursting, or longitudinal opening, of the tubes. The resulting GNRs are highly conductive, but they remain multi-layered and foliated. Due to the attraction between the surfaces, they do not exfoliate to single-layer ribbons. The oxidative approach involves treatment of MWCNTs in acidic oxidative media with a formulation almost identical to that used in the production of graphene oxide (GO) from graphite by the Hummers' method. The resulting product is GO nanoribbons (GONRs). Unlike GNRs obtained by the reductive-intercalation method, GONRs easily exfoliate in aqueous solution, and they can be obtained as single-layered structures.

CVD is regarded as having the most potential as a promising way to synthesize high-quality, huge-area and single-layer graphene. Graphene growth via the CVD process remains a reliable way to produce graphene due to its scalability and potential to produce high-quality graphene film. However, it is also an inefficient method because it requires high temperature. Therefore, incorporating plasma into the CVD can transfer it to a lower process temperature. ${ }^{7}$ Laser methods for graphene synthesis can be classified into laser exfoliation, intercalation and exfoliation in liquid nitrogen, pulsed laser deposition (PLD), laser-induced ultrafast CVD, laser-induced catalyst-free growth of graphene from solid carbon sources, epitaxial graphene growth on an Si-rich surface of an SiC substrate by laser sublimation, reduction of GO, and unzipping of CNTs. ${ }^{8}$ PLD is commonly used to deposit graphene on various substrate materials because it provides a high growth rate, good control over the thickness and morphology of graphene, and is low cost. PLD of graphene on a substrate, including graphite and highly oriented pyrolytic graphite (HOPG), with or without a metal layer, involves the irradiation of a solid target in a high vacuum and can also be used as a post-process treatment to selectively convert carbon to graphene. ${ }^{9}$ Overall, carbon clusters of different sizes form on the irradiated graphite surface during laser ablation. By placing the laser focal point at the graphite surface and adjusting the values of important process parameters (i.e., laser energy, ablation volume, focal length, background gas, working pressure, and target-substrate distance) to their desired amounts, the graphite 
can be evaporated in the form of carbon nanoparticles and can then be deposited on the substrate surface to form a restructured thin graphene layer.

2.3.2 Application. Graphenes have plentiful potential applications, including transistors, transparent electrodes, ultracapacitors, fuel cells, gas sensors, biosensors, batteries, hydrogen storage, drug delivery, extraction, photocatalysts and adsorbants. One of the most highly discussed applications of graphene in chemistry is its potential applicability in the adsorption of organic compounds, especially common hazardous materials. Graphene compounds have also been broadly investigated for the adsorptive elimination of different hazardous substances, such as antibiotics, ${ }^{145-147}$ gases, ${ }^{148}$ metals, ${ }^{2,149-151}$ VOCs, ${ }^{152,153}$ phenolic compounds, ${ }^{154-156}$ oil, ${ }^{157-159}$ pesticides ${ }^{160-162}$ and dyes ${ }^{163-165}$ from water solution. A summary of pollutant adsorption capacities by graphenes and composite graphenes is presented in Table 6.

$\mathrm{GO} /$ cellulose membranes could be used for the effective removal of metal ions like $\mathrm{Co}(\mathrm{II}), \mathrm{Ni}(\mathrm{II}), \mathrm{Cu}(\mathrm{II}), \mathrm{Zn}$ (II), $\mathrm{Cd}(\mathrm{II})$ and $\mathrm{Pb}$ (II) ions. ${ }^{171}$ Adsorption isotherms and kinetics showed that the sorption of understudy metal ions on membranes happens in a monolayer coverage. The maximum adsorption capacities corresponding to $\mathrm{Co}$ (II), $\mathrm{Ni}$ (II), $\mathrm{Cu}$ (II), $\mathrm{Zn}$ (II), $\mathrm{Cd}(\mathrm{II})$ and $\mathrm{Pb}$ (II) ions at a $\mathrm{pH}$ of 4.5 were 15.5, 14.3, 26.6, 16.7, 26.8, $107.9 \mathrm{mg} \mathrm{g}^{-1}$, respectively. Yu et al. ${ }^{184}$ fabricated a GO nanosheet and in the next stage applied it for the removal of four typical antibiotic resistant genes (ARGs) with two various molecular structures (i.e., cyclic (c)- and double-stranded (ds)-ARGs). The highest adsorption equilibrium was achieved within 15 mins which strongly denoted the high efficiency of GO for the removal of ARGs. The removal of four ARGs was as high as 3.11 logs toward c-ARGs and $2.88 \log$ s toward ds-ARGs in $300 \mu \mathrm{g} \mathrm{mL} \mathrm{m}^{-1} \mathrm{GO}$ solution, which was attributed to high-energy adsorption sites, including conjugate $\mathrm{p}$ region sites and oxygen-containing groups. Fig. 3 shows the adsorption kinetics of c-ARGs (a) and ds-ARGs (b) on a GO nanosheet and the schematics of c- and ds-ARG adsorption.

The adsorption and removal of volatile organic compounds (VOCs) such as benzene and butanone by GO/carbon composite nanofibers was studied by Guo et al. ${ }^{185}$ The highest benzene and butanone adsorption capacities onto the GO/carbon composite nanofibers at $20{ }^{\circ} \mathrm{C}$ reached 83.2 and $130.5 \mathrm{~cm}^{3} \mathrm{~g}^{-1}$, respectively. Therefore, GO simultaneously improves the adsorption capacities of the nanofibers for polar VOCs. Xu et al. ${ }^{174}$ prepared graphene and applied it for the removal of bisphenol A (BPA) from aqueous solution by adsorption. At $302.15 \mathrm{~K}$, the highest adsorption capacity of graphene for BPA achieved from a Langmuir isotherm was $182 \mathrm{mg} \mathrm{g}^{-1}$. The adsorption of BPA on graphene occurs with the involvement of $\pi-\pi$ interaction and hydrogen bonds. Brodie's method and grafting with poly$\left(N\right.$-isopropylacrylamide) (PNIPAM) was used by Gong et al. ${ }^{186}$

Table 6 Summary of adsorption capacities by graphenes, graphene analogues and composite graphene

\begin{tabular}{|c|c|c|c|}
\hline Graphenes & Pollutants & Adsorbent capacity $\left(\mathrm{mg} \mathrm{g}^{-1}\right)$ & Ref. \\
\hline Graphene-like layered molybdenum disulfide & Antibiotic doxycycline & 310 & 166 \\
\hline$\left(\mathrm{Fe}_{3} \mathrm{O}_{4}\right)$ modified graphene nanoplatelets & Antibiotic amoxicillin & 14.10 & 167 \\
\hline \multirow[t]{3}{*}{ GO } & $\mathrm{Au}(\mathrm{III})$ & 108.34 & \multirow[t]{3}{*}{168} \\
\hline & $\operatorname{Pd}(\mathrm{II})$ & 80.78 & \\
\hline & $\operatorname{Pt}($ Iv) & 71.38 & \\
\hline \multirow{3}{*}{ EDTA-magnetic GO } & $\mathrm{Cu}(\mathrm{II})$ & 301.2 & \multirow[t]{3}{*}{169} \\
\hline & $\operatorname{Hg}(\mathrm{II})$ & 268.4 & \\
\hline & $\mathrm{Pb}(\mathrm{II})$ & 508.4 & \\
\hline Polyamide-graphene & $\mathrm{Sb}($ III) & 158.2 & 170 \\
\hline \multirow[t]{6}{*}{ GO/cellulose membranes } & $\operatorname{Co(II)~}$ & 15.5 & \multirow[t]{6}{*}{171} \\
\hline & $\mathrm{Ni}(\mathrm{II})$ & 14.3 & \\
\hline & $\mathrm{Cu}(\mathrm{II})$ & 26.6 & \\
\hline & $\mathrm{Zn}(\mathrm{II})$ & 16.7 & \\
\hline & $\mathrm{Cd}(\mathrm{II})$ & 26.8 & \\
\hline & $\mathrm{Pb}(\mathrm{II})$ & 107.9 & \\
\hline \multirow[t]{2}{*}{ Chitosan/GO } & $\mathrm{Au}(\mathrm{III})$ & 1076.65 & \multirow[t]{2}{*}{172} \\
\hline & $\operatorname{Pd}(\mathrm{II})$ & 216.92 & \\
\hline \multirow[t]{2}{*}{$\mathrm{GO} / \mathrm{NiFe}_{2} \mathrm{O}_{4}$} & $\mathrm{Cr}($ III) & 25.0 & \multirow[t]{2}{*}{173} \\
\hline & $\mathrm{Pb}(\mathrm{II})$ & 45.4 & \\
\hline Graphene & Bisphenol A & 182 & 174 \\
\hline \multirow[t]{4}{*}{$\mathrm{GO}$} & $\mathrm{Cu}(\mathrm{II})$ & 294 & \multirow[t]{4}{*}{175} \\
\hline & $\mathrm{Zn}(\mathrm{II})$ & 345 & \\
\hline & Cd(II) & 530 & \\
\hline & $\mathrm{Pb}(\mathrm{II})$ & 1119 & \\
\hline $\mathrm{Fe}_{3} \mathrm{O}_{4} / \mathrm{rGO}$ nanocomposite & Ametryn & 57.64 & 176 \\
\hline GO & $\mathrm{Co}(\mathrm{II})$ & 21.28 & 177 \\
\hline \multirow[t]{2}{*}{ GO } & Acid Orange 8 & 29.0 & \multirow[t]{2}{*}{178} \\
\hline & Direct Red 23 & 15.3 & \\
\hline \multirow[t]{2}{*}{ GO } & Basic Yellow 28 & 68.5 & \multirow[t]{2}{*}{179} \\
\hline & Basic Red 46 & 76.9 & \\
\hline GO/iron oxide & $\mathrm{MB}$ & 39 & 180 \\
\hline GO & $\mathrm{Pb}(\mathrm{II})$ & 250 & 181 \\
\hline GO & $\mathrm{Ni}(\mathrm{II})$ & 38.61 & 182 \\
\hline GO & Th(IV) & 58.59 & 183 \\
\hline
\end{tabular}



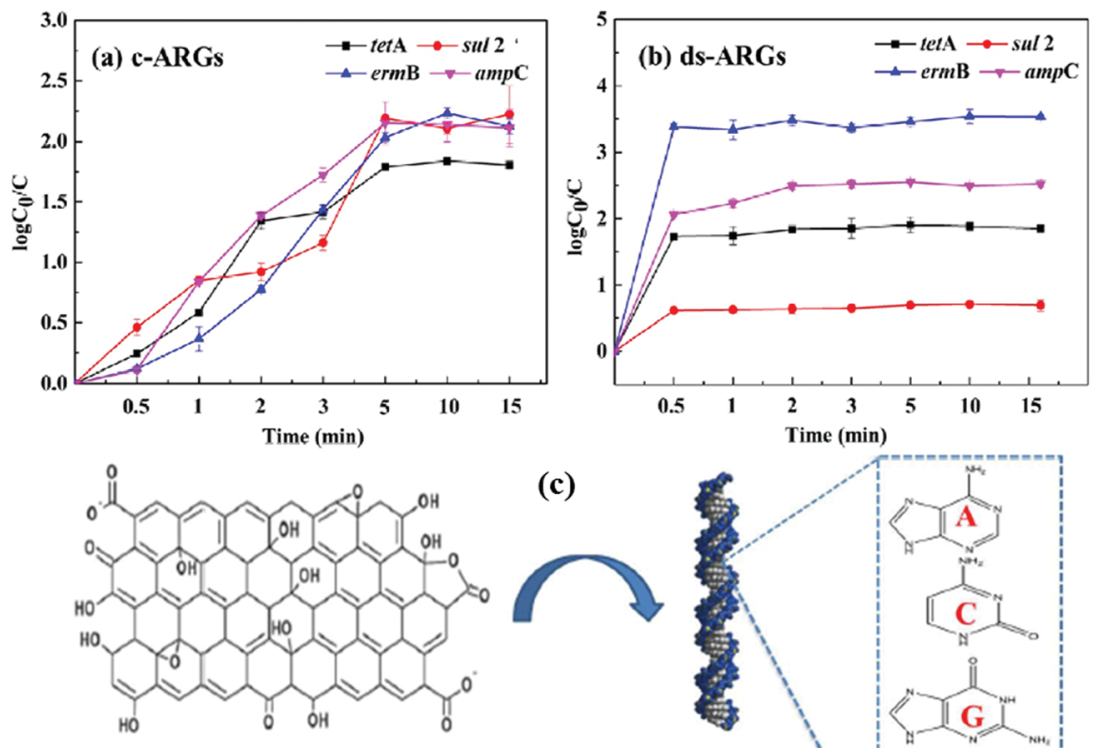

(c)
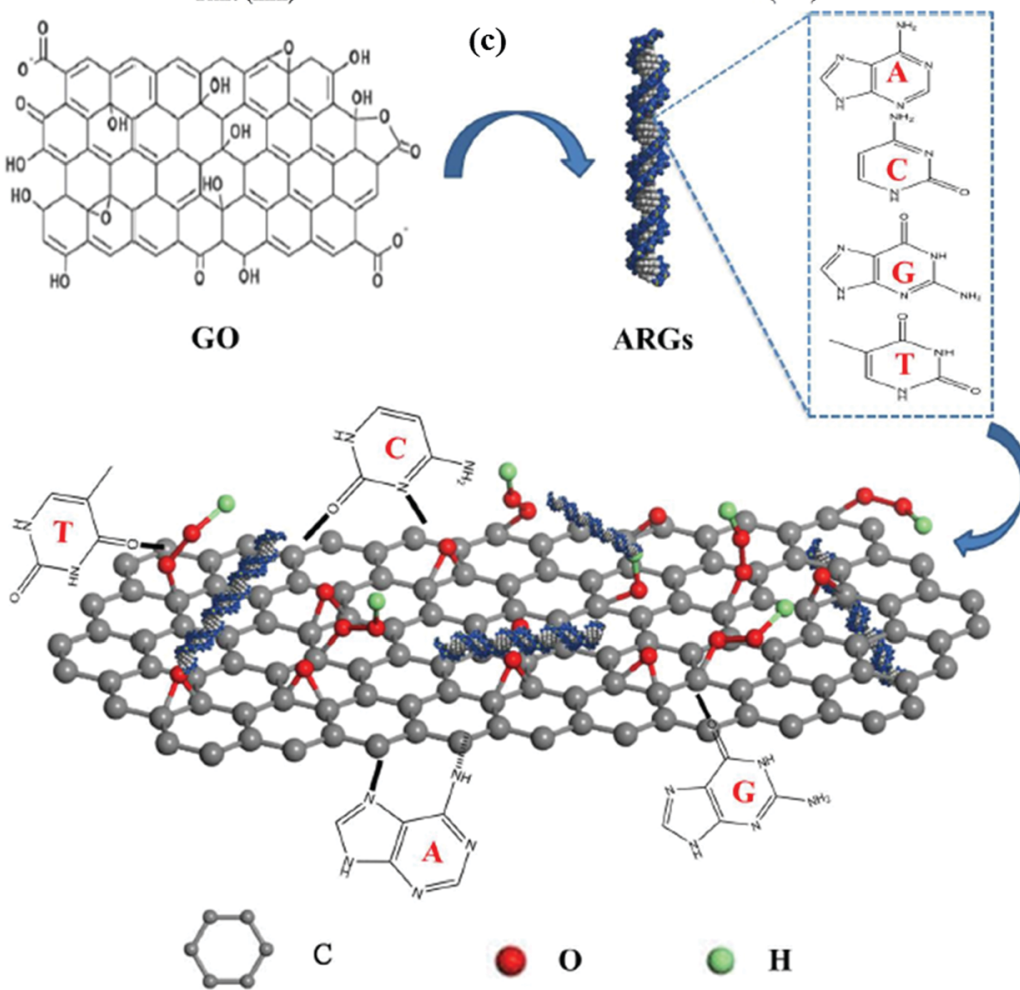

Fig. 3 Adsorption kinetics of c-ARGs (a), ds-ARGs (b) on a GO nanosheet and (c) representation of c- and ds-ARGs adsorbed onto GO nanosheets (A, adenine; C, cytosine; G, guanine; T, thymine). ${ }^{184}$

to synthesize PNIPAM grafted GO (GO-PNIPAM) for the selective adsorption of phenol pollutants. The results indicate selective adsorption of phenol owing to the contribution of different interactions like hydrogen bonds, so that the adsorption performance depends significantly on temperature. The adsorption of oil and organic solvents from a water solution using magnetic graphene foam loaded with magnetite $\left(\mathrm{Fe}_{3} \mathrm{O}_{4}\right)$ nanoparticles was studied. ${ }^{187}$ The magnetic foam with porous and hierarchical structures illustrates a high capability to adsorb oil and different organic solvents. The magnetic graphene foam revealed great reusability and durability under cyclic operations. Sharif et al. reported that $\mathrm{GO} /$ iron oxide (rGO-IO) nanocomposites were fabricated using a solvothermal method and used for the removal of $\mathrm{MB}$ with an adsorption capacity of $39 \mathrm{mg} \mathrm{g}^{-1}$ for the composite containing $60 \mathrm{wt} \%$ IO, while increasing the fraction of IO to $75 \mathrm{wt} \%$ was associated with a large reduction of the adsorptive capacity to $26 \mathrm{mg} \mathrm{g}^{-1}$. The magnetic
$\beta$-cyclodextrin-chitosan/GO material (MCCG) adsorbents were used for the removal of MB. ${ }^{188}$ MCCG indicated remarkable removal capacity and quick adsorption rates due to the high surface area of GO, the hydrophobicity of $\beta$-cyclodextrin and the presence of functional groups and reactive centers like amino and hydroxyl groups of chitosan.

\subsection{Carbon nanofibers}

2.4.1 Fabrication and modification. CNFs were prepared by electrospinning technology and subsequently applied as interesting substance in various fields. ${ }^{189-192}$ CNFs with average diameters of 50-200 $\mathrm{nm}$ can fabricated by two methods: vapor deposition growth ${ }^{193,194}$ and electrospinning, ${ }^{195-197}$ where electrospinning has more extensive applications for the preparation of CNFs. In this technique, the precursors of CNFs are generally fabricated from polymer nanofibers. PAN (polyacrylonitrile), ${ }^{198}$ pitches, poly(vinyl alcohol) (PVA), ${ }^{199-201}$ polyimides (PIs), ${ }^{202-204}$ 
polybenzimidazole (PBI), ${ }^{205-207}$ poly(vinylidene fluoride) (PVDF), ${ }^{208-210}$ phenolic resin ${ }^{211-213}$ and lignin ${ }^{201,214}$ are used as polymers. The major properties of CNF composites include satisfactory electrical, thermal conductivity and mechanical properties and their mechanical and thermal transport phenomena are widely studied. ${ }^{215-217}$ Subsequently the polymer synthesis of nanofibers successfully exposed to thermal treatment to carbonize them (up to $1000{ }^{\circ} \mathrm{C}$ ) under various atmospheric conditions and temperatures were demonstrated to form CNFs. Subsequently, the volume and weight change generally happen within the carbonization protocol, which causes a decrease in the diameter of these nanofibers. ${ }^{218,219}$

2.4.2 Application. CNFs and their derivatives indicated great efficiency in environmental contaminant elimination like metals $^{220}$ dyes, ${ }^{221,222}$ volatile organic compounds, ${ }^{223,224}$ organic pollutants (phenolic compounds ${ }^{225}$ and pesticides ${ }^{226}$ ), gaseous persistent organic pollutants, ${ }^{227}$ toxic industrial chemicals $^{228}$ and organic solvents. ${ }^{229}$ AC nanofibers are applied with high efficiency to remove various pollutants owing to their large surface area, functional groups and electron transfer that supply conditions for their consideration as excellent adsorbents and the best catalytic materials. ${ }^{230,231}$ Table 7 summarizes the adsorption capacities of CNFs for the removal of various pollutants from wastewater.

The nitrogen contents on AC nanofibers (ACNFs) by electrospinning PAN nanofibers play a great role in formaldehyde adsorption. $^{243}$ The carbonization of nanofibers occurs in the presence of steam with many nitrogen-containing functional groups. The ACNFs show higher capability compared to the normal thick ACFs for formaldehyde adsorption even in a humid atmosphere. CNFs were synthesized from electrospun PAN polymer followed by thermal treatments of stabilization, carbonization and activation and were subsequently applied for the adsorption of organic chemicals, such as ciprofloxacin
(CIP), bisphenol (BPA) and 2-chlorophenol (2-CP). ${ }^{244}$ The high surface area of these CNTs was $2326 \mathrm{~m}^{2} \mathrm{~g}^{-1}$, and the micro/ mesoporous structure and also the maximum adsorption capacities $\left(q_{\mathrm{m}}\right)$ of the obtained CNFs can be arranged in the order CIP $>$ BPA $>$ 2-CP. Accordingly, the maximum adsorption capacities of these CNFs for pollutants can be arranged in the order CIP $>$ BPA $>2$-CP and show enhancements of 2.6 for CIP, 1.6 for BPA and 1.1 for 2-CP in comparison with commercial powdered $\mathrm{AC}$. $\mathrm{Fe}_{3} \mathrm{O}_{4} / \mathrm{PAN}$ composite NFs are synthesized by a two-step process composed of electrospinning and solvothermal approaches. ${ }^{245}$ The characterization exhibited the formation of uniform nanoparticles coated on the PAN nanofibers. The removal of tetracycline (TC) as an antibiotic onto $\mathrm{Fe}_{3} \mathrm{O}_{4} / \mathrm{PAN}$ composite NFs well fitted a pseudosecond-order kinetics model, while the maximum adsorption capacity corresponding to a Langmuir isotherm model was $257.07 \mathrm{mg} \mathrm{g}^{-1}(\mathrm{pH}=6)$. In addition, these nanofibers indicate good regenerability in adsorption/desorption cycles with low cost and an acceptable environmentally-friendly relationship. Fig. 4 indicates the preparation procedures for $\mathrm{Fe}_{3} \mathrm{O}_{4} / \mathrm{PAN}$ composite NFs and also their adsorption capacities and kinetics.

The adsorption equilibrium isotherms corresponding to volatile organic compounds (VOCs) comprising benzene and ethanol by AC nanofibers (ACNFs) were studied in detail. ${ }^{246}$ The ACNFs (PAN/DMF $10 \mathrm{wt} \%$ ) were synthesized by electrospinning and subsequently activated with steam, and due to their much smaller diameter and the presence of micro-pores on the ACNFs are expected to supply more available adsorption sites. According to the results, ACNFs show higher adsorption capacities for VOCs than does AC fiber at extremely low relative pressures. The same group also fabricated AECNFs in oxidative acid $\left(\mathrm{HNO}_{3}\right.$ and $\left.\mathrm{H}_{2} \mathrm{SO}_{4}\right)$ to achieve surface oxidation. ${ }^{247}$ The results indicate that the amount of oxygen functional groups on the nanofibers enhances the degree of acid oxidation, which

Table 7 Comparison of various types of CNFs

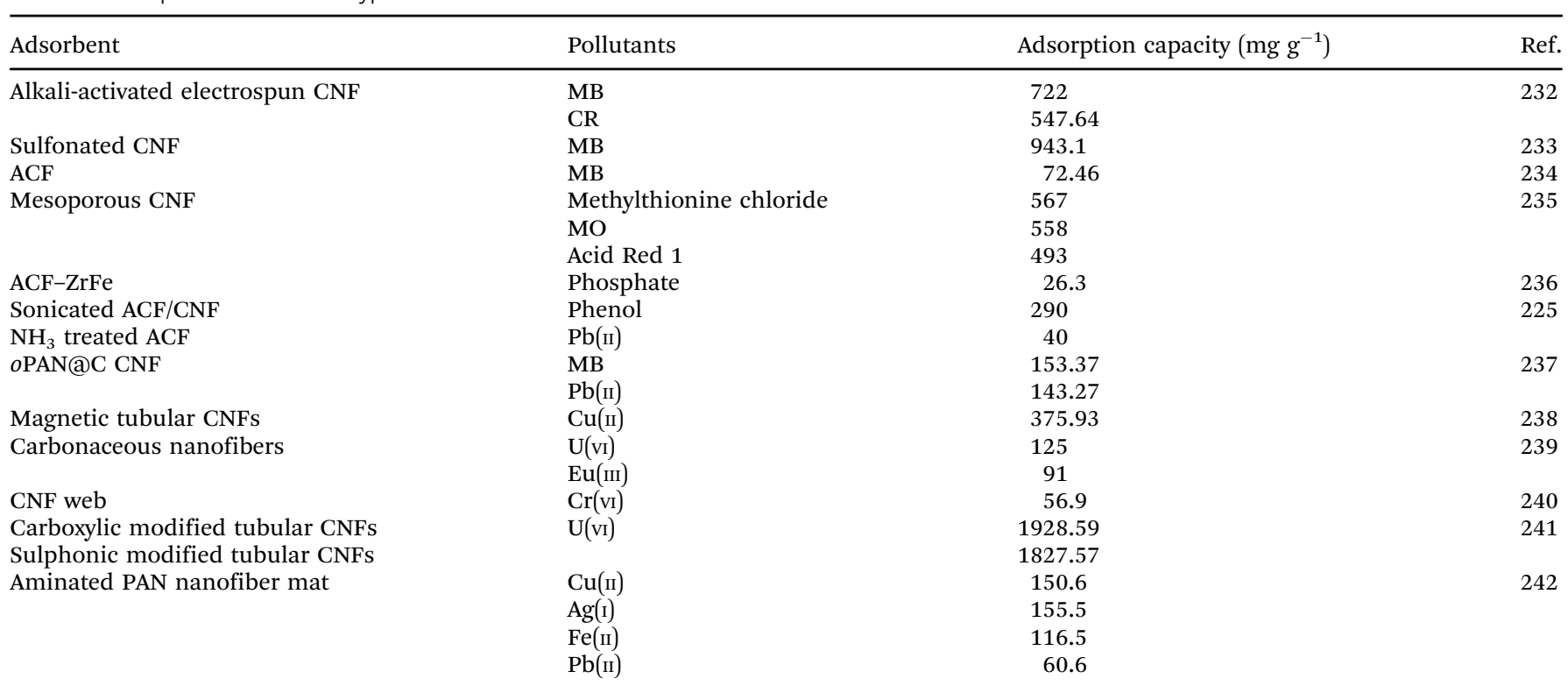




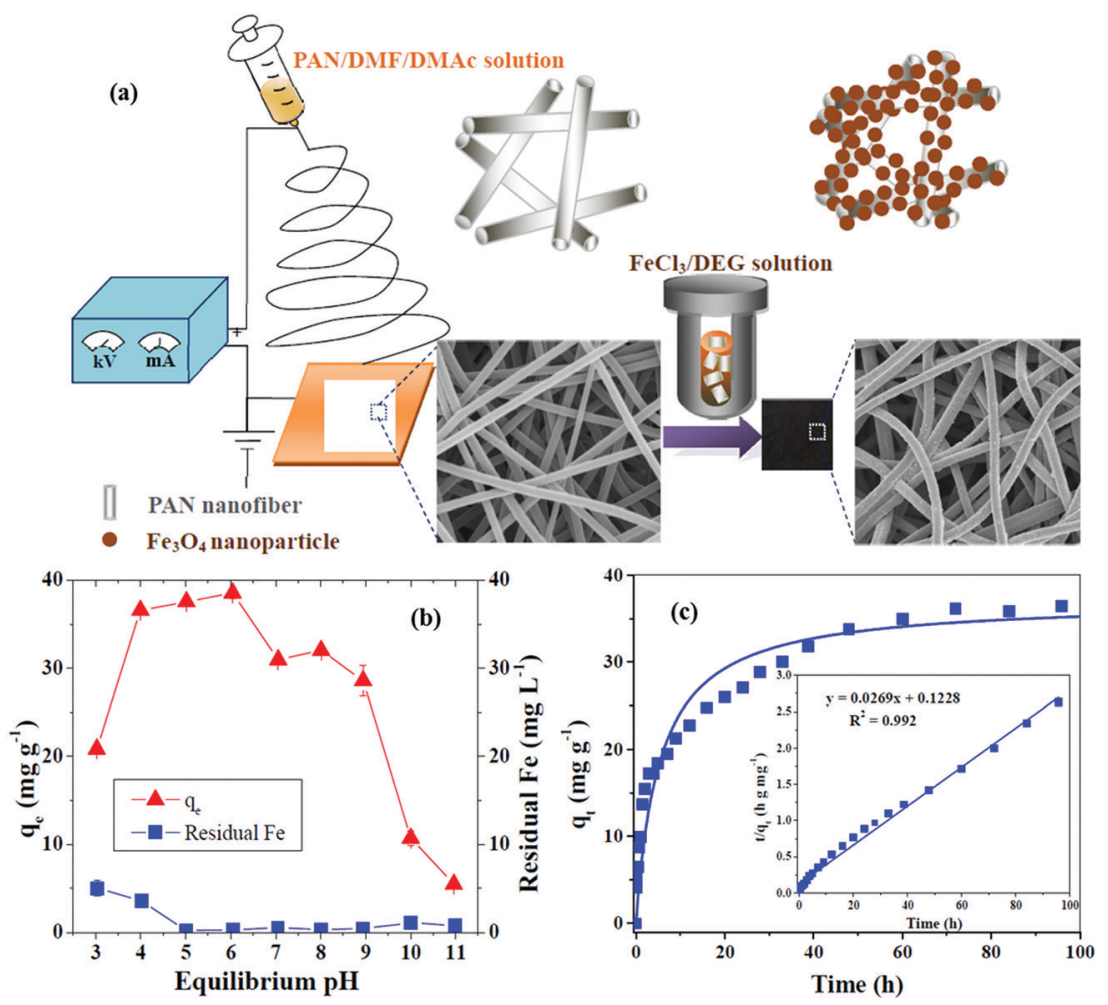

Fig. 4 (a) Preparation of $\mathrm{Fe}_{3} \mathrm{O}_{4} / \mathrm{PAN}$ composite NFs, (b) pollutant $\mathrm{TC}$ adsorption capacities onto $\mathrm{Fe}_{3} \mathrm{O}_{4} / \mathrm{PAN}$ composite NFs and residual Fe in solution with varying $\mathrm{pH}$ and (c) adsorption kinetics of $\mathrm{TC}$ on $\mathrm{Fe}_{3} \mathrm{O}_{4} / \mathrm{PAN}$ composite NFs. ${ }^{245}$

leads to enhancement of the adsorption tendency on oxidized nanofibers. The adsorption performance of pure and oxidized CNFs for organic compounds like benzene (non-polar), butanone and ethanol (polar) were evaluated by the isotherms model. Also, the AECNFs exhibit the highest water adsorption capacities and increase the adsorption tendency for butanone and ethanol relative to benzene on nanofibers. Schneiderman $e t$ al. $^{248}$ fabricated PAN nanofibers by combining the electrospinning technique and subsequent chemical surface-functionalization with weak acid (carboxylic acid) to act as an active adsorption material, which was subsequently applied to protein (i.e., lysozyme adsorption). In addition, the presence of a surfactant additive is associated with a significant reduction in non-specific binding of unintended impurities and leads to an improvement in the selectivity of electrospun CNF mats as solid adsorption substances for biotherapeutic processes. The specific surface area and average micro-pore volume of ACNFs have a positive relationship with activation temperatures over 800 to $1000{ }^{\circ} \mathrm{C} .{ }^{249}$ An excellent toluene adsorption capacity of $65 \mathrm{~g}$ (toluene)/100 g (ACNFs) was obtained using CNFs activated at $1000{ }^{\circ} \mathrm{C}$. The same group also prepared manganese embedded PAN-based ACNFs in various Mn loadings for toluene adsorption ${ }^{250}$ and their unique ability for such adsorption is related to micropore ACNFs embedding Mn particles which leads to the formation of pores by catalytic activation during the burn-off process. PAN CNFs synthesized by Shim et $a l^{251}$ were shown to be microporous substances with small amounts of mesopore regions and higher adsorption capacity for benzene compared to commercial ACFs. The sublimation method is used to prepare electrospun macroporous CNF film (MCNFF) by the electrospinning technique and during the carbonization of PTA-PAN nanofibers, PTA sublimed and generated macropores within the CNFs. ${ }^{252}$ The MCNFFs illustrated excellent oil adsorption with maximum capacities of 62.6, 73.8, 64.0, 94.0 and $138.4 \mathrm{~g} \mathrm{~g}^{-1}$ for ethanol, pump oil, mineral oil, corn oil and silicone oil. Also, the MCNFFs exhibited selective absorption of oil from water due to their superhydrophobic and superoleophilic properties.

\subsection{Biochar}

$\mathrm{BC}$ is a carbonaceous solid residue which can be produced from a variety of agricultural and industrial biomasses via pyrolysis at various temperatures under oxygen-limited conditions. ${ }^{253,254}$ $\mathrm{BC}$, charcoal, and $\mathrm{AC}$ are three forms of carbon that can be produced from organic material. They have a lot of overlap, with similar compositions and production approaches, but they also differ in terms of their practical applications. Charcoal is typically prepared from wood and used as a fuel whereas BC is attributed with soil conditioning and water remediation properties, whereas AC almost is attributed with filter treatment. ${ }^{255}$ It has been said in some literature that BC generally lacks an activation process in comparison with $\mathrm{AC}$ and it is fabricated at relatively lower temperatures than AC. ${ }^{256}$ BC has attracted much attention due to its promising benefits for soil improvement and the removal of pollutants from the environment. ${ }^{257,258}$ In particular, $\mathrm{BC}$ as a low-cost adsorbent can be used as a substitute for AC, which is applied as a conventional adsorbent owing to its ability to adsorb 
various pollutants. ${ }^{259}$ Recently, the field of $\mathrm{BC}$ research has begun to grow as a technology for the recycling and reduction of organic waste resources.

2.5.1 Synthesis of BC. The raw materials used as a source for the preparation of $\mathrm{BC}$ include agricultural residues, forestry waste, the organic fraction of municipal solid waste, industrial biomass by-products, and animal manures. BC as biomassderived materials are fabricated from different biomass feedstock types via pyrolysis $\left(300-700{ }^{\circ} \mathrm{C}\right)$ under oxygen-free or oxygen-limited conditions. ${ }^{254,260}$ The adsorption capacity of $\mathrm{BC}$ is affected by its own physicochemical properties like specific surface area, special functional groups, pore properties, and surface charges. Generally, the properties of BC depend on the type of materials, and the pyrolysis conditions, including pyrolysis time and temperature, heating rate and pyrolysis furnace. ${ }^{261}$ Generally, various BC modification methods have been used, including impregnation with mineral elements, the assistance of nanoscale-metals, surface oxidation and surface reduction. ${ }^{259}$

2.5.2 Application. The abilities of as-fabricated BC emerged from their special properties for the adsorptive removal of various pollutants, such as metals, ${ }^{262,263}$ dyes, ${ }^{264}$ pesticides, ${ }^{265}$ and antibiotics. ${ }^{266}$ A summary of pollutant adsorption capacities by $\mathrm{BC}$ as adsorbent is indicated in Table 8 .

\subsection{Carbon aerogel}

Aerogels are solid materials which are interconnected by colloidal particles to make a network structure and filled with gas phase. Another definition of an aerogel is a gel including a microporous solid that is dispersed in a gas phase. ${ }^{279,280}$ Until now, aerogels have been divided based on matrix type into oxide aerogels, carbide aerogels, organic aerogels and CAs. ${ }^{281}$ CAs as new form of mesoporous carbon material were considered to be highly attractive materials for adsorbents, catalyst supports, electrochemical capacitors and insulation materials. ${ }^{282-284}$ In addition, CAs have very low thermal conductivity owing to their nano-sized pores and particle structures. ${ }^{281}$ Carbonbased aerogels as three-dimensional (3D) structures includes CNT aerogels, graphene aerogels, carbon micro-belt aerogels and carbon fiber aerogels. ${ }^{285,286}$

2.6.1 Synthesis of CAs. The prominent properties of carbon-based aerogels include high specific surface area, low density, high porosity, good electrical conductivity and excellent hydrophobicity. ${ }^{285}$ Conventionally, CAs can be synthesized from a polymer/monomer polymerization reaction and subsequent acetone exchange and supercritical carbon dioxide drying and pyrolysis under vacuum. ${ }^{287}$ One method of preparation of CAs is the polycondensation of organic materials, including: resorcinol/formaldehyde, ${ }^{288}$ cresol/formaldehyde, ${ }^{289}$ phenol/ formaldehyde, ${ }^{290}$ phloroglucinol/formaldehyde, ${ }^{291}$ 5-methylresorcinol/formaldehyde, ${ }^{292}$ and cresol/resorcinol/formaldehyde. ${ }^{293}$ Generally, CAs have been fabricated according to the same recipe and there are several main steps that include: gelation and subsequent curing, solvent exchange, drying of the wet gel and the carbonization or pyrolysis of the dried gel. ${ }^{281,294}$ In summary, drying of the wet gel by environmental drying, supercritical drying or freeze-drying, results in an organic xerogel, aerogel or cryogel, respectively. ${ }^{294}$ In addition, CAs

Table 8 Summary of maximum adsorption capacities by various BC

\begin{tabular}{|c|c|c|c|c|}
\hline Adsorbent & Source & Pollutants & Adsorbent capacity $\left(\mathrm{mg} \mathrm{g}^{-1}\right)$ & Ref. \\
\hline & \multirow{2}{*}{ Frass of yellow mealworms } & Crystal Violet (CV) & 175.6 & \multirow{2}{*}{267} \\
\hline & & $\mathrm{CR}$ & 86.9 & \\
\hline \multirow[t]{3}{*}{ BC } & \multirow[t]{3}{*}{ Sludge-rice husk } & Direct Red 4BS & 59.77 & \multirow[t]{3}{*}{269} \\
\hline & & Acid Orange II & 42.12 & \\
\hline & & React Blue 19 & 38.46 & \\
\hline \multirow{2}{*}{$\mathrm{BC}$} & \multirow{2}{*}{ Switchgrass (Panicum virgatum L.) } & Orange G & 38.2 & \multirow{2}{*}{270} \\
\hline & & $\mathrm{CR}$ & 22.6 & \\
\hline \multirow[t]{2}{*}{$\mathrm{BC}$} & \multirow[t]{2}{*}{ Litchi peel } & CR & 404.4 & \multirow[t]{2}{*}{271} \\
\hline & & MG & 2468 & \\
\hline \multirow[t]{3}{*}{$\mathrm{BC}$} & \multirow[t]{3}{*}{ Cladodes of Opuntia ficus-indica } & MG & 1341 & \multirow[t]{3}{*}{272} \\
\hline & & $\mathrm{Cu}(\mathrm{II})$ & 49 & \\
\hline & & $\mathrm{Ni}(\mathrm{II})$ & 44 & \\
\hline \multirow[t]{4}{*}{$\mathrm{BC}$} & \multirow[t]{4}{*}{ Discarded mushroom-stick } & $\mathrm{Pb}(\mathrm{II})$ & 21.0 & \multirow[t]{4}{*}{276} \\
\hline & & $\mathrm{Cu}(\mathrm{II})$ & 18.8 & \\
\hline & & $\mathrm{Cd}(\mathrm{II})$ & 11.2 & \\
\hline & & $\mathrm{Ni}(\mathrm{II})$ & 9.8 & \\
\hline \multirow{2}{*}{ Chitosan/magnetic loofah BC } & \multirow[t]{2}{*}{ Loofah sponges } & $\mathrm{Cr}(\mathrm{vI})$ & 30.14 & \multirow[t]{2}{*}{277} \\
\hline & & $\mathrm{Cu}(\mathrm{II})$ & 54.68 & \\
\hline \multirow[t]{2}{*}{ N-Doping BC } & \multirow[t]{2}{*}{ Crop straws } & $\mathrm{Cu}(\mathrm{II})$ & $1.63 \mathrm{mmol} \mathrm{g}^{-1}$ & \multirow[t]{2}{*}{278} \\
\hline & & $\mathrm{Cd}(\mathrm{II})$ & $1.76 \mathrm{mmol} \mathrm{g}^{-1}$ & \\
\hline
\end{tabular}


derived from biomass materials due to their low cost, environmental friendliness and renewability have attracted much attention. Usable materials for the production of CAs include chitosan, ${ }^{295}$ lignin, ${ }^{296}$ watermelon, ${ }^{297}$ bagasse, ${ }^{298}$ bamboo, ${ }^{299}$ cotton, ${ }^{300}$ starch $^{301}$ glucose, ${ }^{302}$ and cellulose. ${ }^{303}$ Various applications of CAs comprising supercapacitors, ${ }^{304}$ sensors, ${ }^{305}$ hydrogen storage, ${ }^{306}$ batteries, ${ }^{307}$ electro-Fenton oxidation, ${ }^{308}$ purification, ${ }^{309}$ and adsorbents ${ }^{310}$ have been studied.

2.6.2 Application. The ability to prepare CAs emerges from their unique properties for the adsorptive removal of various organic and inorganic substances, including metals, ${ }^{311,312}$ dyes, ${ }^{313,314}$ antibiotics, ${ }^{315,316}$ volatile organic compounds, ${ }^{317}$ organic solvents, ${ }^{318}$ oils, ${ }^{285,319} \mathrm{CO}_{2},{ }^{320}$ and $\mathrm{H}_{2} \mathrm{~S} .{ }^{321}$ One of the highly discussed applications of CA in chemistry is its potential applicability in the adsorption of organic compounds, especially common hazardous materials. Generally, the presence of oxygen, nitrogen, and sulfur groups on the surface of the CBMs, especially CAs, can increase the porosity, hydrophilicity and selectivity of the adsorbents. ${ }^{322,323}$ Typically, a variety of derivatives of CAs have been studied for the adsorption of organic and inorganic pollutants. Magnetic mesoporous Fe/CA structures with a high specific surface area of $487 \mathrm{~m}^{2} \mathrm{~g}^{-1}$ were prepared through the carbonization of composite $\mathrm{Fe}_{3} \mathrm{O}_{4}$ / phenol-formaldehyde resin structures using a hydrothermal process with the addition of phenol. ${ }^{324}$ The Fe/CA were further applied for the adsorption of $\operatorname{As}(\mathrm{v})$ with a maximum $\operatorname{As}(\mathrm{v})$

Table 9 Summary of adsorption capacities by various CAs

\begin{tabular}{|c|c|c|c|}
\hline Adsorbent & Pollutants & Adsorbent capacity $\left(\mathrm{mg} \mathrm{g}^{-1}\right)$ & Ref. \\
\hline \multirow[t]{3}{*}{ CA } & $\mathrm{CV}$ & 1515 & \multirow[t]{3}{*}{301} \\
\hline & MV & 1423 & \\
\hline & $\mathrm{MB}$ & 1181 & \\
\hline CA & Ibuprofen & 7.43 & 329 \\
\hline CA & Reactive Brilliant Red X-3B & 565 & 330 \\
\hline Konjac glucomannan/AC & $\mathrm{MB}$ & 416.67 & 325 \\
\hline \multirow[t]{2}{*}{ Activated CA } & $\mathrm{MB}$ & 249.6 & \multirow[t]{2}{*}{287} \\
\hline & MG & 245.3 & \\
\hline \multirow[t]{8}{*}{ Activated CA } & Phenol & 204.26 & \multirow[t]{8}{*}{331} \\
\hline & P-nitrophenol & 613.34 & \\
\hline & Resorcinol & 194.07 & \\
\hline & Tetracycline & 1030.05 & \\
\hline & Oxytetracycline & 813.80 & \\
\hline & Doxycycline & 922.93 & \\
\hline & Sulfamethazine & 834.92 & \\
\hline & $\mathrm{MB}$ & 754.1 & \\
\hline \multirow[t]{5}{*}{$3 \mathrm{D} \mathrm{CA}$} & Oxytetracycline & 1729 & \multirow[t]{5}{*}{327} \\
\hline & Diethyl phthalate & 680 & \\
\hline & MB & 685 & \\
\hline & $\mathrm{Cd}(\mathrm{II})$ & 235 & \\
\hline & Diesel & $421 \mathrm{~g} \mathrm{~g}^{-1}$ & \\
\hline N-Doped activated mesoporous CA & MO & $\sim 400$ & 313 \\
\hline \multirow[t]{2}{*}{ 3D N-doped CA } & MG & 238.2 & \multirow[t]{2}{*}{323} \\
\hline & $\mathrm{MB}$ & 230.4 & \\
\hline N-Doped CA & Rhodamine B & 250 & 332 \\
\hline N/S doped magnetic CA & Bisphenol-A & 199.8 & 322 \\
\hline \multirow[t]{2}{*}{ Cellulose-based hydrophobic CA } & $\mathrm{MG}$ & 1947 & \multirow[t]{2}{*}{333} \\
\hline & $\mathrm{Cu}(\mathrm{II})$ & 801 & \\
\hline \multirow[t]{7}{*}{$\mathrm{CA}$} & $\mathrm{Pb}(\mathrm{II})$ & 0.75 & \multirow[t]{7}{*}{334} \\
\hline & $\mathrm{Hg}(\mathrm{II})$ & 45.62 & \\
\hline & $\mathrm{Cd}(\mathrm{II})$ & 400.8 & \\
\hline & $\mathrm{Cu}(\mathrm{II})$ & 561.7 & \\
\hline & $\operatorname{Mn}(\mathrm{II})$ & 1.275 & \\
\hline & $\mathrm{Zn}(\mathrm{II})$ & 1.843 & \\
\hline & $\mathrm{Ni}(\mathrm{II})$ & 12.875 & \\
\hline \multirow[t]{3}{*}{$\mathrm{CA}$} & $\mathrm{Hg}(\mathrm{II})$ & 34.96 & \multirow[t]{3}{*}{335} \\
\hline & $\mathrm{Pb}(\mathrm{II})$ & 34.72 & \\
\hline & $\mathrm{Ni}(\mathrm{II})$ & 2.80 & \\
\hline \multirow[t]{3}{*}{ CA } & $\mathrm{Pb}(\mathrm{II})$ & 34.72 & \multirow[t]{3}{*}{311} \\
\hline & $\mathrm{Hg}(\mathrm{II})$ & 34.96 & \\
\hline & Cd(II) & 15.53 & \\
\hline CA & $\mathrm{Cu}(\mathrm{II})$ & 55.25 & 312 \\
\hline CA & Cd(II) & 15.53 & 336 \\
\hline CA & $\mathrm{Pb}(\mathrm{II})$ & 34.72 & 337 \\
\hline $\mathrm{CA}$ & $\operatorname{Sr}(\mathrm{II})$ & 24.63 & 338 \\
\hline \multirow{2}{*}{$\mathrm{CA} / \mathrm{Na}_{2} \mathrm{Ti}_{3} \mathrm{O}_{7}$} & $\mathrm{Rb}(\mathrm{I})$ & $1.11 \mathrm{mmol} \mathrm{g}^{-1}$ & \multirow[t]{2}{*}{339} \\
\hline & $\operatorname{Cs}(\mathrm{I})$ & $1.45 \mathrm{mmol} \mathrm{g}^{-1}$ & \\
\hline \multirow[t]{3}{*}{$\mathrm{CA}$} & $\mathrm{Cd}(\mathrm{II})$ & 18.6 & 340 \\
\hline & $\operatorname{Cr}(\mathrm{VI})$ & 35.5 & \\
\hline & $\mathrm{Ni(II)}$ & 32.2 & \\
\hline $\mathrm{Zn}-\mathrm{Al} \mathrm{LDH} / \mathrm{AC}$ & $\mathrm{Te}(\mathrm{Iv})$ & 132 & 341 \\
\hline
\end{tabular}


uptake evaluated as $216.9 \mathrm{mg} \mathrm{g}^{-1}$. Magnetic $\mathrm{Fe}$ and $\mathrm{Mn}$ oxide loaded CA based on konjac glucomannan (KGM), which is a type of natural polysaccharide from the tubers of the amorphophallus konjac plant. The performances of a KGM-based magnetic CA matrix for the adsorption of anionic MO and cationic MB were studied. ${ }^{325}$ The maximum MO and MB uptake capacities of this CA reached $7.42 \mathrm{mg} \mathrm{g}^{-1}$ and $9.37 \mathrm{mg} \mathrm{g}^{-1}$, respectively, according to the Langmuir isotherm (303 K). A flexible carbon fiber aerogel material prepared from cotton using an air-limited calcination approach was used for the adsorption of $\mathrm{MB}$ from aqueous solution. ${ }^{326}$ The morphology of the cotton consisted of a regular smooth fibrous structure and the carbon fiber aerogels still retained an elongated fibrous morphology after calcination. Based on the Langmuir isotherm model, the maximum monolayer adsorption capacity was calculated to be $102.23 \mathrm{mg} \mathrm{g}^{-1}$. The 3D CAs prepared from 1D CNTs and 2D GO showed a highly porous and stable structure and their adsorption performances were promising for emerging pollutants. ${ }^{327}$ The using of waste paper helps to save resources and protect the environment. Li et al. ${ }^{328}$ used a combination of waste office paper and chitosan to synthesize CA as an adsorbent for the removal of $\mathrm{Cu}$ (II). The maximum $\mathrm{Cu}(\mathrm{II})$ capacity of this $\mathrm{CA}$ reached $156.3 \mathrm{mg} \mathrm{g}^{-1}$ according to the Langmuir isotherm. A summary of pollutant adsorption capacities by CA based materials is presented in Table 9.

\subsection{Other carbon based materials}

Besides AC, graphene, CNTs, CNFs, BC, and CAs, there are other materials containing carbon that can used in the adsorption of pollutants from the environment. Metal-organic frameworks (MOFs) and covalent organic frameworks (COFs) are porous organic frameworks derived from carbon materials. MOFs and COFs are two classes of adsorbent for the efficient removal of various pollutants. These materials have attracted much attention due to their unusual structures and properties, such as massive porosity and the simple tunability of their pore size from the microporous to the mesoporous scale. ${ }^{342,343}$

\section{Conclusion and perspectives}

In summary, this review highlights the potential prospects for using carbon-based materials like activated carbon, graphene, carbon nanotubes, carbon nanofibers, biochar and carbon aerogels to remove hazardous materials from aqueous media. The influence of various preparation methods on the physicochemical properties of the carbon-based adsorbent were summarized, along with the related effects on pollutant adsorption. Overall, the rapid growth of this field shows that CBMs seem to be the best candidates for contaminant management with prominent capacities and easy production. CBMs with designed structures, morphologies and functional groups are promising adsorbents for various environmental applications. These materials indicate extremely good potential for the adsorptive removal of inorganic and organic pollutants, such as antibiotics, dyes, heavy metals, pesticides, oils, phenolic and volatile organic compounds and gas pollutants from various media. The high adsorption capacity and robust selectivity make carbon nano-materials supreme carriers for separating both inorganic and organic pollutants by adsorption. Carbonbased adsorbents for the removal of pollutants has been a key area of research in order to improve and optimize the preparation process. Clearly, the interactions between the functional groups of carbon materials play key roles in the removal of various pollutants from aqueous solutions. The physicochemical adsorption properties of carbon nano-materials are dominated by the synthesis, functionalization and/or decoration approaches. The present review is forecast to enlighten more future studies to push forward the synthesis and preparation and subsequent usage of carbon-based nano-materials for the adsorptive elimination of common hazardous compounds. Therefore, it is necessary to develop the preparation of carbon-based adsorbents to efficiently remove different pollutants. Despite efforts by researchers to prepare various CBMs as adsorbents, it is generally believed that various profound and comprehensive methods for the synthesis of carbon adsorbents are required. In addition, for the reduction and removal of secondary pollution that is caused by the physicochemical preparation of CBMs, materials synthesis using various approaches should be studied in depth. Most research only examines CBMs under laboratory conditions, while actual water generally contains different pollutants in complex combinations; therefore, further information is required in largescale practical environments.

\section{Conflicts of interest}

There are no conflicts to declare.

\section{References}

1 M. Rafatullah, O. Sulaiman, R. Hashim and A. Ahmad, Adsorption of methylene blue on low-cost adsorbents: A review, J. Hazard. Mater., 2010, 177, 70-80, DOI: 10.1016/j.jhazmat.2009.12.047.

2 P. Liu, T. Yan, J. Zhang, L. Shi and D. Zhang, Separation and recovery of heavy metal ions and salt ions from wastewater by 3D graphene-based asymmetric electrodes: Via capacitive deionization, J. Mater. Chem. A, 2017, 5, 14748-14757, DOI: 10.1039/c7ta03515b.

3 K. Björklund and L. Y. Li, Adsorption of organic stormwater pollutants onto activated carbon from sewage sludge, J. Environ. Manage., 2017, 197, 490-497, DOI: 10.1016/j.jenvman.2017.04.011.

4 Y. S. Al-Degs, M. I. El-Barghouthi, A. H. El-Sheikh and G. M. Walker, Effect of solution $\mathrm{pH}$, ionic strength, and temperature on adsorption behavior of reactive dyes on activated carbon, Dyes Pigm., 2008, 77, 16-23, DOI: 10.1016/j.dyepig.2007.03.001.

5 F. Haghseresht, S. Nouri, J. J. Finnerty and G. Q. Lu, Effects of surface chemistry on aromatic compound adsorption 
from dilute aqueous solutions by activated carbon, J. Phys. Chem. B, 2002, 106, 10935-10943, DOI: 10.1021/jp025522a.

$6 \mathrm{~K}$. Yang and B. Xing, Adsorption of organic compounds by carbon nanomaterials in aqueous phase: Polanyi theory and its application, Chem. Rev., 2010, 110, 5989-6008, DOI: 10.1021/cr100059s.

7 K. Yang, W. Wu, Q. Jing and L. Zhu, Aqueous adsorption of aniline, phenol, and their substitutes by multi-walled carbon nanotubes, Environ. Sci. Technol., 2008, 42, 7931-7936, DOI: 10.1021/es801463v.

8 Z. Dehgani, M. Sedghiasl, M. Ghaedi, M. M. Sabzehmeidani and E. Adhami, Removal of paraquat from aqueous solutions by a bentonite modified zero-valent iron adsorbent, New J. Chem., 2020, 44, 13368-13376, DOI: 10.1039/d0nj02259d.

9 J. U. Keller and R. Staudt, Gas adsorption equilibria: Experimental methods and adsorptive isotherms, Springer Science \& Business Media, 2005, DOI: 10.1007/b102056.

10 C. H. Giles, T. H. MacEwan, S. N. Nakhwa and D. Smith, Studies in adsorption. Part XI. A system of classification of solution adsorption isotherms, and its use in diagnosis of adsorption mechanisms and in measurement of specific surface areas of solids, J. Chem. Soc., 1960, 3973-3993, DOI: 10.1039/jr9600003973.

11 A. Bonilla-Petriciolet, D. I. Mendoza-Castillo and H. E. Reynel-Ávila, Adsorption processes for water treatment and purification, Adsorpt. Process. Water Treat. Purif., 2017, 1-256, DOI: 10.1007/978-3-319-58136-1.

12 W. Kast, Principles of adsorption and adsorption processes, John Wiley \& Sons, 1985, DOI: 10.1016/0255-2701(85)80013-1.

13 H. Wang, H. Shen, C. Shen, Y. N. Li, Z. Ying and Y. Duan, Kinetics and Mechanism Study of Mercury Adsorption by Activated Carbon in Wet Oxy-Fuel Conditions, Energy Fuels, 2019, 33, 1344-1353, DOI: 10.1021/acs.energyfuels.8b03610.

14 Z. Harrache, M. Abbas, T. Aksil and M. Trari, Thermodynamic and kinetics studies on adsorption of Indigo Carmine from aqueous solution by activated carbon, Microchem. J., 2019, 144, 180-189, DOI: 10.1016/j.microc. 2018.09.004.

15 L. Largitte and R. Pasquier, A review of the kinetics adsorption models and their application to the adsorption of lead by an activated carbon, Chem. Eng. Res. Des., 2016, 109, 495-504, DOI: 10.1016/j.cherd.2016.02.006.

16 R. El-Sharkawy and H. A. El-Ghamry, Multi-walled carbon nanotubes decorated with $\mathrm{Cu}(\mathrm{II})$ triazole Schiff base complex for adsorptive removal of synthetic dyes, J. Mol. Liq., 2019, 282, 515-526, DOI: 10.1016/j.molliq.2019.02.137.

17 H. Zhang, W. Gu, M. J. Li, Z. Y. Li, Z. J. Hu and W. Q. Tao, Experimental study on the kinetics of water vapor sorption on the inner surface of silica nano-porous materials, Int. J. Heat Mass Transfer, 2014, 78, 947-959, DOI: 10.1016/ j.ijheatmasstransfer.2014.07.047.

18 S. G. Pakdehi, S. Babaee and H. R. Azizi, Kinetic study and optimization of dehydration of dimethyl amino ethyl azide (DMAZ) using response surface methodology, Bull. Chem. Soc. Jpn., 2017, 90, 1325-1332, DOI: 10.1246/bcsj.20170253.
19 X. Yang, Y. Wan, Y. Zheng, F. He, Z. Yu, J. Huang, H. Wang, Y. S. Ok, Y. Jiang and B. Gao, Surface functional groups of carbon-based adsorbents and their roles in the removal of heavy metals from aqueous solutions: A critical review, Chem. Eng. J., 2019, 366, 608-621, DOI: 10.1016/j.cej. 2019.02.119.

20 L. Zhang, F. Pan, X. Liu, L. Yang, X. Jiang, J. Yang and W. Shi, Multi-walled carbon nanotubes as sorbent for recovery of endocrine disrupting compound-bisphenol $\mathrm{F}$ from wastewater, Chem. Eng. J., 2013, 218, 238-246, DOI: 10.1016/j.cej.2012.12.046.

21 V. K. Gupta, O. Moradi, I. Tyagi, S. Agarwal, H. Sadegh, R. Shahryari-Ghoshekandi, A. S. H. Makhlouf, M. Goodarzi and A. Garshasbi, Study on the removal of heavy metal ions from industry waste by carbon nanotubes: Effect of the surface modification: A review, Crit. Rev. Environ. Sci. Technol., 2016, 46, 93-118, DOI: 10.1080/10643389. 2015.1061874.

22 M. Loos, Allotropes of Carbon and Carbon Nanotubes, Carbon Nanotub Reinf. Compos. CNR Polym. Sci. Technol., 2015, 73-101, DOI: 10.1016/B978-1-4557-3195-4.00003-5.

23 S. Nasir, M. Z. Hussein, Z. Zainal and N. A. Yusof, Materials, 2018, 11, 1-24.

24 O. S. Okwundu, E. U. Aniekwe and C. E. Nwanno, Unlimited potentials of carbon: different structures and uses (a Review), Metall, Mater. Eng., 2018, 24, 145-171, DOI: 10.30544/388.

25 O. Ioannidou and A. Zabaniotou, Agricultural residues as precursors for activated carbon production-A review, Renewable Sustainable Energy Rev., 2007, 11, 1966-2005, DOI: 10.1016/j.rser.2006.03.013.

26 A. Dąbrowski, P. Podkościelny, Z. Hubicki and M. Barczak, Adsorption of phenolic compounds by activated carbon - A critical review, Chemosphere, 2005, 58, 1049-1070, DOI: 10.1016/j.chemosphere.2004.09.067.

27 H. Deng, G. Li, H. Yang, J. Tang and J. Tang, Preparation of activated carbons from cotton stalk by microwave assisted $\mathrm{KOH}$ and K2CO3 activation, Chem. Eng. J., 2010, 163, 373-381, DOI: 10.1016/j.cej.2010.08.019.

28 T. M. Alslaibi, I. Abustan, M. A. Ahmad and A. A. Foul, A review: Production of activated carbon from agricultural byproducts via conventional and microwave heating, J. Chem. Technol. Biotechnol., 2013, 88, 1183-1190, DOI: 10.1002/jctb.4028.

29 M. Jafari, M. R. Rahimi, M. Ghaedi and K. Dashtian, ZnO nanoparticles loaded different mesh size of porous activated carbon prepared from Pinus eldarica and its effects on simultaneous removal of dyes: Multivariate optimization, Chem. Eng. Res. Des., 2017, 125, 408-421, DOI: 10.1016/j.cherd.2017.07.011.

30 A. Yamashita, J. Shikada, T. Oshima and Y. Baba, Preparation of activated carbon with high surface area using biomass wastes and its application to methane storage technology, Kagaku Kogaku Ronbunshu, 2014, 40, 98-103, DOI: 10.1252/kakoronbunshu.40.98.

31 J. L. Figueiredo, M. F. R. Pereira, M. M. A. Freitas and J. J. M. Órfão, Modification of the surface chemistry of 
activated carbons, Carbon, 1999, 37, 1379-1389, DOI: 10.1016/S0008-6223(98)00333-9.

32 J. M. Dias, M. C. M. Alvim-Ferraz, M. F. Almeida, J. RiveraUtrilla and M. Sánchez-Polo, Waste materials for activated carbon preparation and its use in aqueous-phase treatment: A review, J. Environ. Manage., 2007, 85, 833-846, DOI: 10.1016/j.jenvman.2007.07.031.

33 D. Prahas, Y. Kartika, N. Indraswati and S. Ismadji, Activated carbon from jackfruit peel waste by $\mathrm{H} 3 \mathrm{PO} 4$ chemical activation: Pore structure and surface chemistry characterization, Chem. Eng. J., 2008, 140, 32-42, DOI: 10.1016/j.cej.2007.08.032.

34 S. J. Allen, L. Whitten and G. McKay, The production and characterisation of activated carbons: a review, Asia-Pac. J. Chem. Eng., 1998, 6, 231-261.

35 J. Andas, M. L. A. Rahman and M. S. M. Yahya, Preparation and Characterization of Activated Carbon from Palm Kernel Shell, IOP Conf. Ser.: Mater. Sci. Eng., 2017, 226, 251-264, DOI: 10.1088/1757-899X/226/1/012156.

36 K. Promdee, J. Chanvidhwatanakit, S. Satitkune, C. Boonmee, T. Kawichai, S. Jarernprasert and T. Vitidsant, Characterization of carbon materials and differences from activated carbon particle (ACP) and coal briquettes product (CBP) derived from coconut shell via rotary kiln, Renewable Sustainable Energy Rev., 2017, 75, 1175-1186, DOI: 10.1016/ j.rser.2016.11.099.

37 M. Shoaib and H. M. Al-Swaidan, Optimization and characterization of sliced activated carbon prepared from date palm tree fronds by physical activation, Biomass Bioenergy, 2015, 73, 124-134, DOI: 10.1016/j.biombioe.2014.12.016.

38 J. M. V. Nabais, C. E. C. Laginhas, P. J. M. Carrott and M. M. L. Ribeiro, Carrott, Production of activated carbons from almond shell, Fuel Process. Technol., 2011, 92, 234-240, DOI: 10.1016/j.fuproc.2010.03.024.

39 M. Ghaedi, H. Hossainian, M. Montazerozohori, A. Shokrollahi, F. Shojaipour, M. Soylak and M. K. Purkait, A novel acorn based adsorbent for the removal of brilliant green, Desalination, 2011, 281, 226-233, DOI: 10.1016/j.desal.2011.07.068.

40 H. Jamshidi, M. Ghaedi, M. M. Sabzehmeidani and A. R. Bagheri, Comparative study of acid yellow 119 adsorption onto activated carbon prepared from lemon wood and $\mathrm{ZnO}$ nanoparticles loaded on activated carbon, Appl. Organomet. Chem., 2018, 32, e4080, DOI: 10.1002/aoc.4080.

41 V. K. Gupta, A. Mittal, R. Jain, M. Mathur and S. Sikarwar, Adsorption of Safranin-T from wastewater using waste materials- activated carbon and activated rice husks, J. Colloid Interface Sci., 2006, 303, 80-86, DOI: 10.1016/ j.jcis.2006.07.036.

42 P. S. Ardekani, H. Karimi, M. Ghaedi, A. Asfaram and M. K. Purkait, Ultrasonic assisted removal of methylene blue on ultrasonically synthesized zinc hydroxide nanoparticles on activated carbon prepared from wood of cherry tree: Experimental design methodology and artificial neural network, J. Mol. Liq., 2017, 229, 114-124, DOI: 10.1016/j.molliq.2016.12.028.
43 H. Z. Khafri, M. Ghaedi, A. Asfaram and M. Safarpoor, Synthesis and characterization of ZnS:Ni-NPs loaded on AC derived from apple tree wood and their applicability for the ultrasound assisted comparative adsorption of cationic dyes based on the experimental design, Ultrason. Sonochem., 2017, 38, 371-380, DOI: 10.1016/j.ultsonch.2017.03.033.

44 E. Demirbas, M. Kobya and M. T. Sulak, Adsorption kinetics of a basic dye from aqueous solutions onto apricot stone activated carbon, Bioresour. Technol., 2008, 99, 5368-5373, DOI: 10.1016/j.biortech.2007.11.019.

45 M. Ghaedi, H. Tavallali, M. Sharifi, S. N. Kokhdan and A. Asghari, Preparation of low cost activated carbon from Myrtus communis and pomegranate and their efficient application for removal of Congo red from aqueous solution, Spectrochim. Acta, Part A, 2012, 86, 107-114, DOI: 10.1016/j.saa.2011.10.012.

46 M. Ghaedi, A. M. Ghaedi, F. Abdi, M. Roosta, A. Vafaei and A. Asghari, Principal component analysis- adaptive neurofuzzy inference system modeling and genetic algorithm optimization of adsorption of methylene blue by activated carbon derived from Pistacia khinjuk, Ecotoxicol. Environ. Saf., 2013, 96, 110-117, DOI: 10.1016/j.ecoenv.2013.05.015.

47 M. Valix, W. H. Cheung and G. McKay, Preparation of activated carbon using low temperature carbonisation and physical activation of high ash raw bagasse for acid dye adsorption, Chemosphere, 2004, 56, 493-501, DOI: 10.1016/ j.chemosphere.2004.04.004.

48 E. S. I. El-Shafey, H. Al-Lawati and A. S. Al-Sumri, Ciprofloxacin adsorption from aqueous solution onto chemically prepared carbon from date palm leaflets, J. Environ. Sci., 2012, 24, 1579-1586, DOI: 10.1016/S1001-0742(11)60949-2.

49 R. L. Tseng, Physical and chemical properties and adsorption type of activated carbon prepared from plum kernels by $\mathrm{NaOH}$ activation, J. Hazard. Mater., 2007, 147, 1020-1027, DOI: 10.1016/j.jhazmat.2007.01.140.

50 M. J. Ahmed and S. K. Theydan, Microporous activated carbon from siris seed pods by microwave-induced $\mathrm{KOH}$ activation for metronidazole adsorption, J. Anal. Appl. Pyrolysis, 2013, 99, 101-109, DOI: 10.1016/j.jaap.2012. 10.019.

51 P. K. Malik, Dye removal from wastewater using activated carbon developed from sawdust: Adsorption equilibrium and kinetics, J. Hazard. Mater., 2004, 113, 81-88, DOI: 10.1016/j.jhazmat.2004.05.022.

52 A. Sari and M. Tuzen, Kinetic and equilibrium studies of biosorption of $\mathrm{Pb}(\mathrm{II})$ and $\mathrm{Cd}(\mathrm{II})$ from aqueous solution by macrofungus (Amanita rubescens) biomass, J. Hazard. Mater., 2009, 164, 1004-1011, DOI: 10.1016/j.jhazmat. 2008.09.002.

53 M. C. Ribas, M. A. Adebayo, L. D. T. Prola, E. C. Lima, R. Cataluña, L. A. Feris, M. J. Puchana-Rosero, F. M. Machado, F. A. Pavan and T. Calvete, Comparison of a homemade cocoa shell activated carbon with commercial activated carbon for the removal of reactive violet 5 dye from aqueous solutions, Chem. Eng. J., 2014, 248, 315-326, DOI: 10.1016/j.cej.2014.03.054. 
54 M. Santiago, F. Stüber, A. Fortuny, A. Fabregat and J. Font, Modified activated carbons for catalytic wet air oxidation of phenol, Carbon, 2005, 43, 2134-2145, DOI: 10.1016/ j.carbon.2005.03.026.

55 S. Sato, K. Yoshihara, K. Moriyama, M. Machida and H. Tatsumoto, Influence of activated carbon surface acidity on adsorption of heavy metal ions and aromatics from aqueous solution, Appl. Surf. Sci., 2007, 253, 8554-8559, DOI: 10.1016/j.apsusc.2007.04.025.

56 A. R. Mohamed, M. Mohammadi and G. N. Darzi, Preparation of carbon molecular sieve from lignocellulosic biomass: A review, Renewable Sustainable Energy Rev., 2010, 14, 1591-1599, DOI: 10.1016/j.rser.2010.01.024.

57 M. G. Buonomenna, W. Yave and G. Golemme, Some approaches for high performance polymer based membranes for gas separation: Block copolymers, carbon molecular sieves and mixed matrix membranes, $R S C$ Adv., 2012, 2, 10745-10773, DOI: 10.1039/c2ra20748f.

58 A. Wahby, J. M. Ramos-Fernández, M. Martínez-Escandell, A. Sepúveda-Escribano, J. Silvestre-Albero and F. RodríguezReinoso, High-surface-area carbon molecular sieves for selective CO2 adsorption, ChemSusChem, 2010, 3, 974-981, DOI: $10.1002 /$ cssc.201000083.

59 M. S. Shafeeyan, W. M. A. W. Daud, A. Houshmand and A. Arami-Niya, Ammonia modification of activated carbon to enhance carbon dioxide adsorption: Effect of preoxidation, Appl. Surf. Sci., 2011, 257, 3936-3942, DOI: 10.1016/j.apsusc.2010.11.127.

60 Z. Zhang, M. Xu, H. Wang and Z. Li, Enhancement of $\mathrm{CO} 2$ adsorption on high surface area activated carbon modified by N2, H2 and ammonia, Chem. Eng. J., 2010, 160, 571-577, DOI: 10.1016/j.cej.2010.03.070.

61 K. Dashtian, S. Porhemat, A. R. Rezvani, M. Ghaedi and M. M. Sabzehmeidani, Adsorption of semisoft pollutants onto Bi2S3/Ag2S-AC under the influence of ultrasonic waves as external filed, J. Ind. Eng. Chem., 2018, 60, 390-400, DOI: 10.1016/j.jiec.2017.11.026.

62 A. A. Bazrafshan, S. Hajati, M. Ghaedi and A. Asfaram, Synthesis and characterization of antibacterial chromium iron oxide nanoparticle-loaded activated carbon for ultrasound-assisted wastewater treatment, Appl. Organomet. Chem., 2018, 32, e3981, DOI: 10.1002/aoc.3981.

63 E. Sharifpour, M. Ghaedi, F. Nasiri Azad, K. Dashtian, H. Hadadi and M. K. Purkait, Zinc oxide nanorod-loaded activated carbon for ultrasound-assisted adsorption of safranin O: Central composite design and genetic algorithm optimization, Appl. Organomet. Chem., 2018, 32, e4099, DOI: 10.1002/aoc.4099.

64 S. Bagheri, H. Aghaei, M. Ghaedi, A. Asfaram, M. Monajemi and A. A. Bazrafshan, Synthesis of nanocomposites of iron oxide/gold ( $\mathrm{Fe} 3 \mathrm{O} 4 / \mathrm{Au})$ loaded on activated carbon and their application in water treatment by using sonochemistry: Optimization study, Ultrason. Sonochem., 2018, 41, 279-287, DOI: 10.1016/j.ultsonch.2017.09.031.

65 H. Askari, M. Ghaedi and K. Dashtian, Comparative studies on removal of methyl orange and sunset yellow dyes using
ZnS:Cu-NPs-AC: Optimization, equilibrium, kinetic and thermodynamic studies, Desalin. Water Treat., 2017, 77, 355-365, DOI: 10.5004/dwt.2017.20360.

66 M. Ghaedi, S. J. Hossaini and S. Ramezani, Platinum nanoparticles loaded on activated carbon as novel adsorbent for the removal of congo red, E-J. Chem., 2012, 9, 63-74, DOI: $10.1155 / 2012 / 257584$.

67 S. Agarwal, I. Tyagi, V. K. Gupta, A. R. Bagheri, M. Ghaedi, A. Asfaram, S. Hajati and A. A. Bazrafshan, Rapid adsorption of ternary dye pollutants onto copper (I) oxide nanoparticle loaded on activated carbon: Experimental optimization via response surface methodology, J. Environ. Chem. Eng., 2016, 4, 1769-1779, DOI: 10.1016/j.jece.2016.03.002.

68 S. Agarwal, I. Tyagi, V. K. Gupta, M. Dastkhoon, M. Ghaedi, F. Yousefi and A. Asfaram, Ultrasound-assisted adsorption of Sunset Yellow CFC dye onto Cu doped $\mathrm{ZnS}$ nanoparticles loaded on activated carbon using response surface methodology based on central composite design, J. Mol. Liq., 2016, 219, 332-340, DOI: 10.1016/j.molliq.2016.02.100.

69 A. R. Bagheri, M. Ghaedi, A. Asfaram, A. A. Bazrafshan and R. Jannesar, Comparative study on ultrasonic assisted adsorption of dyes from single system onto $\mathrm{Fe} 3 \mathrm{O} 4$ magnetite nanoparticles loaded on activated carbon: Experimental design methodology, Ultrason. Sonochem., 2017, 34, 294-304, DOI: 10.1016/j.ultsonch.2016.05.047.

70 A. R. Bagheri, M. Ghaedi, K. Dashtian, S. Hajati and A. A. Bazrafshan, Simultaneous removal of $\mathrm{Cu} 2+$ and $\mathrm{Cr} 3+$ ions from aqueous solution based on Complexation with Eriochrome cyanine- $\mathrm{R}$ and derivative spectrophotometric method, Appl. Organomet. Chem., 2018, 32, e3918, DOI: $10.1002 /$ aoc.3918.

71 S. Dashamiri, M. Ghaedi, A. Asfaram, F. Zare and S. Wang, Multi-response optimization of ultrasound assisted competitive adsorption of dyes onto $\mathrm{Cu}(\mathrm{OH}) 2$-nanoparticle loaded activated carbon: Central composite design, Ultrason. Sonochem., 2017, 34, 343-353, DOI: 10.1016/ j.ultsonch.2016.06.007.

72 H. Tavallali and A. Daneshyar, Cadmium selenide nanoparticles loaded on activated carbon and its efficient application for removal of fluoride from aqueous solution, Int. J. ChemTech Res., 2012, 4, 1178-1181.

73 M. Ghaedi, A. Hekmati Jah, S. Khodadoust, R. Sahraei, A. Daneshfar, A. Mihandoost and M. K. Purkait, Cadmium telluride nanoparticles loaded on activated carbon as adsorbent for removal of sunset yellow, Spectrochim. Acta, Part A, 2012, 90, 22-27, DOI: 10.1016/j.saa.2011.12.064.

74 M. Ghaedi, S. Haghdoust, S. N. Kokhdan, A. Mihandoost, R. Sahraie and A. Daneshfar, Comparison of activated carbon, multiwalled carbon nanotubes, and cadmium hydroxide nanowire loaded on activated carbon as adsorbents for kinetic and equilibrium study of removal of safranine O, Spectrosc. Lett., 2012, 45, 500-510, DOI: 10.1080/00387010.2011.641058.

75 M. Ghaedi, M. N. Biyareh, S. N. Kokhdan, S. Shamsaldini, R. Sahraei, A. Daneshfar and S. Shahriyar, Comparison of the efficiency of palladium and silver nanoparticles loaded 
on activated carbon and zinc oxide nanorods loaded on activated carbon as new adsorbents for removal of Congo red from aqueous solution: Kinetic and isotherm study, Mater. Sci. Eng., C, 2012, 32, 725-734, DOI: 10.1016/j.msec. 2012.01.015.

76 A. Daneshyar, M. Ghaedi, M. M. Sabzehmeidani and A. Daneshyar, H2S adsorption onto $\mathrm{Cu}-\mathrm{Zn}-\mathrm{Ni}$ nanoparticles loaded activated carbon and Ni-Co nanoparticles loaded $\gamma$-Al2O3: Optimization and adsorption isotherms, J. Colloid Interface Sci., 2017, 490, 553-561, DOI: 10.1016/ j.jcis.2016.11.068.

77 X. Zhang, W. Guo, H. H. Ngo, H. Wen, N. Li and W. Wu, Performance evaluation of powdered activated carbon for removing 28 types of antibiotics from water, J. Environ. Manage., 2016, 172, 193-200, DOI: 10.1016/j.jenvman. 2016.02.038.

78 M. Abbas, S. Kaddour and M. Trari, Kinetic and equilibrium studies of cobalt adsorption on apricot stone activated carbon, J. Ind. Eng. Chem., 2014, 20, 745-751, DOI: 10.1016/j.jiec.2013.06.030.

79 T. M. Alslaibi, I. Abustan, M. A. Ahmad and A. A. Foul, Kinetics and equilibrium adsorption of iron (II), lead (II), and copper (II) onto activated carbon prepared from olive stone waste, Desalin. Water Treat., 2014, 52, 7887-7897, DOI: $10.1080 / 19443994.2013 .833875$.

80 N. Esfandiar, B. Nasernejad and T. Ebadi, Removal of $\mathrm{Mn}$ (II) from groundwater by sugarcane bagasse and activated carbon (a comparative study): Application of response surface methodology (RSM), J. Ind. Eng. Chem., 2014, 20, 3726-3736, DOI: 10.1016/j.jiec.2013.12.072.

81 P. G. González and Y. B. Pliego-Cuervo, Adsorption of $\mathrm{Cd}(\mathrm{II}), \mathrm{Hg}$ (II) and $\mathrm{Zn}$ (II) from aqueous solution using mesoporous activated carbon produced from Bambusa vulgaris striata, Chem. Eng. Res. Des., 2014, 92, 2715-2724, DOI: $10.1016 /$ j.cherd.2014.02.013.

82 H. Sharififard, M. Soleimani and F. Z. Ashtiani, Evaluation of activated carbon and bio-polymer modified activated carbon performance for palladium and platinum removal, J. Taiwan Inst. Chem. Eng., 2012, 43, 696-703, DOI: 10.1016/ j.jtice.2012.04.007.

83 S. Hydari, H. Sharififard and M. Nabavinia, M. reza Parvizi, A comparative investigation on removal performances of commercial activated carbon, chitosan biosorbent and chitosan/activated carbon composite for cadmium, Chem. Eng. J., 2012, 193-194, 276-282, DOI: 10.1016/ j.cej.2012.04.057.

84 H. Sharififard and M. Soleimani, Performance comparison of activated carbon and ferric oxide-hydroxide-activated carbon nanocomposite as vanadium(v) ion adsorbents, RSC Adv., 2015, 5, 80650-80660, DOI: 10.1039/c5ra14493k.

85 E. A. Dil, M. Ghaedi, A. Asfaram, S. Hajati, F. Mehrabi and A. Goudarzi, Preparation of nanomaterials for the ultrasound-enhanced removal of $\mathrm{Pb} 2+$ ions and malachite green dye: Chemometric optimization and modeling, Ultrason. Sonochem., 2017, 34, 677-691, DOI: 10.1016/ j.ultsonch.2016.07.001.
86 E. Sharifpour, H. Z. Khafri, M. Ghaedi, A. Asfaram and R. Jannesar, Isotherms and kinetic study of ultrasoundassisted adsorption of malachite green and $\mathrm{Pb} 2+$ ions from aqueous samples by copper sulfide nanorods loaded on activated carbon: Experimental design optimization, Ultrason. Sonochem., 2018, 40, 373-382, DOI: 10.1016/ j.ultsonch.2017.07.030.

87 M. A. P. Cechinel, S. M. A. G. Ulson De Souza and A. A. Ulson, De Souza, Study of lead (II) adsorption onto activated carbon originating from cow bone, J. Cleaner Prod., 2014, 65, 342-349, DOI: 10.1016/j.jclepro.2013.08.020.

88 V. K. Gupta, A. Nayak, S. Agarwal and I. Tyagi, Potential of activated carbon from waste rubber tire for the adsorption of phenolics: Effect of pre-treatment conditions, J. Colloid Interface Sci., 2014, 417, 420-430, DOI: 10.1016/j.jcis. 2013.11.067.

89 G. Moussavi, H. Hosseini and A. Alahabadi, The investigation of diazinon pesticide removal from contaminated water by adsorption onto $\mathrm{NH} 4 \mathrm{Cl}$-induced activated carbon, Chem. Eng. J., 2013, 214, 172-179, DOI: 10.1016/j.cej. 2012.10.034.

90 P. K. Malik, Use of activated carbons prepared from sawdust and rice-husk for adsoprtion of acid dyes: A case study of acid yellow 36, Dyes Pigm., 2003, 56, 239-249, DOI: 10.1016/S0143-7208(02)00159-6.

91 M. Ghaedi, J. Tashkhourian, A. A. Pebdani, B. Sadeghian and F. N. Ana, Equilibrium, kinetic and thermodynamic study of removal of reactive orange 12 on platinum nanoparticle loaded on activated carbon as novel adsorbent, Korean J. Chem. Eng., 2011, 28, 2255-2261, DOI: 10.1007/ s11814-011-0142-1.

92 M. Ghaedi, H. Khajesharifi, A. Hemmati Yadkuri, M. Roosta, R. Sahraei and A. Daneshfar, Cadmium hydroxide nanowire loaded on activated carbon as efficient adsorbent for removal of Bromocresol Green, Spectrochim. Acta, Part A, 2012, 86, 62-68, DOI: 10.1016/j.saa. 2011.09.064.

93 M. Ghaedi, M. Ghayedi, S. N. Kokhdan, R. Sahraei and A. Daneshfar, Palladium, silver, and zinc oxide nanoparticles loaded on activated carbon as adsorbent for removal of bromophenol red from aqueous solution, J. Ind. Eng. Chem., 2013, 19, 1209-1217, DOI: 10.1016/ j.jiec.2012.12.020.

94 G. Jethave, U. Fegade, S. Attarde, S. Ingle, M. Ghaedi and M. M. Sabzehmeidani, Exploration of the adsorption capability by doping $\mathrm{Pb} @ \mathrm{ZnFe} 2 \mathrm{O} 4$ nanocomposites (NCs) for decontamination of dye from textile wastewater, Heliyon, 2019, 5, e02412, DOI: 10.1016/j.heliyon.2019.e02412.

95 H. Sayğili and F. Güzel, High surface area mesoporous activated carbon from tomato processing solid waste by zinc chloride activation: Process optimization, characterization and dyes adsorption, J. Cleaner Prod., 2016, 113, 995-1004, DOI: 10.1016/j.jclepro.2015.12.055.

96 R. A. Rashid, A. H. Jawad, M. A. M. Ishak and N. N. Kasim, $\mathrm{KOH}$-activated carbon developed from biomass waste: adsorption equilibrium, kinetic and thermodynamic studies 
for Methylene blue uptake, Desalin. Water Treat., 2016, 57, 27226-27236, DOI: 10.1080/19443994.2016.1167630.

97 S. Iijima, Helical microtubules of graphitic carbon, Nature, 1991, 354, 56-58, DOI: 10.1038/354056a0.

98 V. N. Popov, Carbon nanotubes: Properties and application, Mater. Sci. Eng., $R$, 2004, 43, 61-102, DOI: 10.1016/ j.mser.2003.10.001.

99 L. S. Ying, M. A. Bin Mohd Salleh, H. B. Mohamed Yusoff, S. B. Abdul Rashid and J. B. Abd Razak, Continuous production of carbon nanotubes - A review, J. Ind. Eng. Chem., 2011, 17, 367-376, DOI: 10.1016/j.jiec.2011.05.007.

100 E. N. Ganesh, Single Walled and Multi Walled Carbon Nanotube Structure, Synth. Appl., 2013, 2, 311-320, http:// www.ijitee.org/attachments/File/v2i4/D0561032413.pdf.

101 A. Eatemadi, H. Daraee, H. Karimkhanloo, M. Kouhi, N. Zarghami, A. Akbarzadeh, M. Abasi, Y. Hanifehpour and S. W. Joo, Carbon nanotubes: properties, synthesis, purification, and medical applications, Nanoscale Res. Lett., 2014, 9, 393.

102 R. L. Vander Wal, G. M. Berger and T. M. Ticich, Carbon nanotube synthesis in a flame using laser ablation for in situ catalyst generation, Appl. Phys. A: Mater. Sci. Process., 2003, 77, 885-889, DOI: 10.1007/s00339-003-2196-3.

103 K. S. Ibrahim, Carbon nanotubes? properties and applications: a review, Carbon Lett., 2013, 14, 131-144.

104 T. Pichler, Molecular Nanostructures: Carbon ahead, Nat. Mater., 2007, 6, 332-333, DOI: 10.1038/nmat1898.

105 J. Prasek, J. Drbohlavova, J. Chomoucka, J. Hubalek, O. Jasek, V. Adam and R. Kizek, Methods for carbon nanotubes synthesis - Review, J. Mater. Chem., 2011, 21, 15872-15884, DOI: 10.1039/c1jm12254a.

106 S. Manafi, H. Nadali and H. R. Irani, Low temperature synthesis of multi-walled carbon nanotubes via a sonochemical/hydrothermal method, Mater. Lett., 2008, 62, 4175-4176, DOI: 10.1016/j.matlet.2008.05.072.

107 S. H. Jeong, J. H. Ko, J. B. Park and W. Park, A sonochemical route to single-walled carbon nanotubes under ambient conditions, J. Am. Chem. Soc., 2004, 126, 15982-15983, DOI: $10.1021 / \mathrm{ja0451867.}$

108 I. A. Novoselova, N. F. Oliinyk, S. V. Volkov, A. A. Konchits, I. B. Yanchuk, V. S. Yefanov, S. P. Kolesnik and M. V. Karpets, Electrolytic synthesis of carbon nanotubes from carbon dioxide in molten salts and their characterization, Phys. E, 2008, 40, 2231-2237, DOI: 10.1016/j.physe.2007.10.069.

109 H. Dai, Carbon nanotubes: opportunities and challenges, Surf. Sci., 2002, 500, 218-241.

110 N. Saifuddin, A. Z. Raziah and A. R. Junizah, Carbon nanotubes: A review on structure and their interaction with proteins, J. Chem., 2013, 2013, 676815, DOI: 10.1155/ 2013/676815.

111 W. Wang, J. Y. Huang, D. Z. Wang and Z. F. Ren, Lowtemperature hydrothermal synthesis of multiwall carbon nanotubes, J. Mater. Res., 2000, 15, 2591-2594, DOI: 10.1016/j.carbon.2004.12.020.

112 R. B. Hye, H. Lim, J. S. Hyun and C. C. Hee, A synthesis of high purity single-walled carbon nanotubes from small diameters of cobalt nanoparticles by using oxygen-assisted chemical vapor deposition process, Bull. Korean Chem. Soc., 2007, 28, 2056-2060, DOI: 10.5012/bkcs.2007.28.11.2056.

113 B. Brown, C. B. Parker, B. R. Stoner and J. T. Glass, Growth of vertically aligned bamboo-like carbon nanotubes from ammonia/methane precursors using a platinum catalyst, Carbon, 2011, 49, 266-274, DOI: 10.1016/j.carbon.2010. 09.018 .

114 Y. Xu, E. Dervishi, A. R. Biris and A. S. Biris, Chiralityenriched semiconducting carbon nanotubes synthesized on high surface area MgO-supported catalyst, Mater. Lett., 2011, 65, 1878-1881, DOI: 10.1016/j.matlet.2011.03.040.

115 D. Varshney, B. R. Weiner and G. Morell, Growth and field emission study of a monolithic carbon nanotube/diamond composite, Carbon, 2010, 48, 3353-3358, DOI: 10.1016/ j.carbon.2010.05.025.

116 Y. Li, X. Zhang, X. Tao, J. Xu, F. Chen, W. Huang and F. Liu, Growth mechanism of multi-walled carbon nanotubes with or without bundles by catalytic deposition of methane on Mo/MgO, Chem. Phys. Lett., 2004, 386, 105-110, DOI: 10.1016/j.cplett.2003.12.128.

117 K. Varshney, Carbon Nanotubes: A Review on Synthesis, Properties and Applications, Int. J. Eng. Res., 1991, 1, 660-677.

118 M. S. Hasnain and A. K. Nayak, Applications of carbon nanotubes, SpringerBriefs Appl. Sci. Technol., Springer, 2019, pp. 33-36, DOI: 10.1007/978-981-15-0910-0_6.

119 W. A. De Heer, Nanotubes and the Pursuit of Applications, MRS Bull., 2004, 29, 281-285, DOI: 10.1557/mrs2004.81.

120 A. Rashidi, M. K. Abbasabadi and S. Khodabakhshi, Allylamide-grafted multiwall carbon nanotubes as a new type of nanoadsorbent for the H2S removal from gas stream, J. Nat. Gas Sci. Eng., 2016, 36, 13-19, DOI: 10.1016/j.jngse.2016.10.001.

121 O. Duman, S. Tunç, T. G. Polat and B. K. I. Bozoğlan, Synthesis of magnetic oxidized multiwalled carbon nanotube- $\kappa$-carrageenan-Fe3O4 nanocomposite adsorbent and its application in cationic Methylene Blue dye adsorption, Carbohydr. Polym., 2016, 147, 79-88, DOI: 10.1016/ j.carbpol.2016.03.099.

122 Z. Shi, L. Wang, L. Deng, X. Peng and M. Yuan, Adsorptive removal of $\mathrm{Cr}(\mathrm{VI})$ from aqueous solution using NiFe2O4/ ZnAl-LDH, Chin. J. Environ. Eng., 2016, 10, 4635-4642, DOI: 10.12030/j.cjee.201601192.

123 R. Karimi, F. Yousefi, M. Ghaedi and K. Dashtian, Back propagation artificial neural network and central composite design modeling of operational parameter impact for sunset yellow and azur (II) adsorption onto MWCNT and MWCNT-Pd-NPs: Isotherm and kinetic study, Chemom. Intell. Lab. Syst., 2016, 159, 127-137, DOI: 10.1016/ j.chemolab.2016.10.012.

124 K. Xiao and T. He, Adsorption behavior of methylene blue on polyethylene-active carbon, Chongqing Daxue Xuebao, 2013, 36, 127-132, DOI: 10.11835/j.issn.1000-582X.2013.11.020.

125 M. Shirmardi, A. Mesdaghinia, A. H. Mahvi, S. Nasseri and R. Nabizadeh, Kinetics and equilibrium studies on 
adsorption of acid red 18 (Azo-Dye) using multiwall carbon nanotubes (MWCNTs) from aqueous solution, E-J. Chem., 2012, 9, 2371-2383, DOI: 10.1155/2012/541909.

126 S. Zohre, S. G. Ataallah and A. Mehdi, Experimental study of methylene blue adsorption from aqueous solutions onto carbon nano tubes, Int. J. Water Resour. Environ. Eng., 2010, 2, 16-28.

127 B. He, X. Wang, H. Xue and X. Hao, Adsorption of direct dyes from aqueous solutions by gelatin microspheres: Kinetics and equilibrium, Adv. Mater. Res., 2011, 332-334, 1577-1581, DOI: 10.4028/www.scientific.net/AMR.332334.1577.

128 F. M. Machado, C. P. Bergmann, T. H. M. Fernandes, E. C. Lima, B. Royer, T. Calvete and S. B. Fagan, Adsorption of Reactive Red M-2BE dye from water solutions by multiwalled carbon nanotubes and activated carbon, J. Hazard. Mater., 2011, 192, 1122-1131, DOI: 10.1016/j.jhazmat. 2011.06.020.

129 A. K. Mishra, T. Arockiadoss and S. Ramaprabhu, Study of removal of azo dye by functionalized multi walled carbon nanotubes, Chem. Eng. J., 2010, 162, 1026-1034, DOI: 10.1016/j.cej.2010.07.014.

130 J. P. Wang, H. C. Yang and C. Te, Hsieh, Adsorption of phenol and basic dye on carbon nanotubes/carbon fabric composites from aqueous solution, Sep. Sci. Technol., 2011, 46, 340-348, DOI: 10.1080/01496395.2010.508066.

131 W. Konicki, I. Pełech, E. Mijowska and I. Jasińska, Adsorption of anionic dye Direct Red 23 onto magnetic multiwalled carbon nanotubes-Fe 3C nanocomposite: Kinetics, equilibrium and thermodynamics, Chem. Eng. J., 2012, 210, 87-95, DOI: 10.1016/j.cej.2012.08.025.

132 E. Alipanahpour Dil, M. Ghaedi, A. Asfaram, F. Mehrabi and F. Sadeghfar, Efficient adsorption of Azure B onto CNTs/Zn:ZnO@Ni2P-NCs from aqueous solution in the presence of ultrasound wave based on multivariate optimization, J. Ind. Eng. Chem., 2019, 74, 55-62, DOI: 10.1016/ j.jiec.2018.12.050.

133 A. Mohammadi and P. Veisi, High adsorption performance of $\beta$-cyclodextrin-functionalized multi-walled carbon nanotubes for the removal of organic dyes from water and industrial wastewater, J. Environ. Chem. Eng., 2018, 6, 4634-4643, DOI: 10.1016/j.jece.2018.07.002.

134 G. Bhanjana, N. Dilbaghi, K. H. Kim and S. Kumar, Carbon nanotubes as sorbent material for removal of cadmium, J. Mol. Liq., 2017, 242, 966-970, DOI: 10.1016/j.molliq. 2017.07.072.

135 J. Gong, J. Feng, J. Liu, Z. Jiang, X. Chen, E. Mijowska, $\mathrm{X}$. Wen and T. Tang, Catalytic carbonization of polypropylene into cup-stacked carbon nanotubes with high performances in adsorption of heavy metallic ions and organic dyes, Chem. Eng. J., 2014, 248, 27-40, DOI: 10.1016/j.cej.2014.01.107.

136 A. Gupta, S. R. Vidyarthi and N. Sankararamakrishnan, Enhanced sorption of mercury from compact fluorescent bulbs and contaminated water streams using functionalized multiwalled carbon nanotubes, J. Hazard. Mater., 2014, 274, 132-144, DOI: 10.1016/j.jhazmat.2014.03.020.
137 H. Alijani and Z. Shariatinia, Synthesis of high growth rate SWCNTs and their magnetite cobalt sulfide nanohybrid as super-adsorbent for mercury removal, Chem. Eng. Res. Des., 2018, 129, 132-149, DOI: 10.1016/j.cherd.2017.11.014.

138 H. Sadegh, G. A. M. Ali, A. S. H. Makhlouf, K. F. Chong, N. S. Alharbi, S. Agarwal and V. K. Gupta, MWCNTs-Fe3O4 nanocomposite for $\mathrm{Hg}$ (II) high adsorption efficiency, J. Mol. Liq., 2018, 258, 345-353, DOI: 10.1016/j.molliq. 2018.03.012.

139 Z. F. Yang, L. Y. Li, C. Te Hsieh and R. S. Juang, Coprecipitation of magnetic $\mathrm{Fe} 3 \mathrm{O} 4$ nanoparticles onto carbon nanotubes for removal of copper ions from aqueous solution, J. Taiwan Inst. Chem. Eng., 2018, 82, 56-63, DOI: 10.1016/j.jtice.2017.11.009.

140 Ihsanullah, F. A. Al-Khaldi, B. Abu-Sharkh, A. M. Abulkibash, M. I. Qureshi, T. Laoui and M. A. Atieh, Effect of acid modification on adsorption of hexavalent chromium (Cr(VI)) from aqueous solution by activated carbon and carbon nanotubes, Desalin. Water Treat., 2016, 57, 7232-7244, DOI: 10.1080/19443994.2015.1021847.

141 S. Yang, J. Li, D. Shao, J. Hu and X. Wang, Adsorption of $\mathrm{Ni}(\mathrm{II})$ on oxidized multi-walled carbon nanotubes: Effect of contact time, $\mathrm{pH}$, foreign ions and PAA, J. Hazard. Mater., 2009, 166, 109-116, DOI: 10.1016/j.jhazmat.2008.11.003.

142 H. Wang, T. Maiyalagan and X. Wang, Review on recent progress in nitrogen-doped graphene: Synthesis, characterization, and its potential applications, ACS Catal., 2012, 2, 781-794, DOI: 10.1021/cs200652y.

143 X. Jia, J. Campos-Delgado, M. Terrones, V. Meunier and M. S. Dresselhaus, Graphene edges: A review of their fabrication and characterization, Nanoscale, 2011, 3, 86-95, DOI: 10.1039/c0nr00600a.

144 K. M. Manesh, H. T. Kim, P. Santhosh, A. I. Gopalan and K. P. Lee, A novel glucose biosensor based on immobilization of glucose oxidase into multiwall carbon nanotubespolyelectrolyte-loaded electrospun nanofibrous membrane, Biosens. Bioelectron., 2008, 23, 771-779, DOI: 10.1016/ j.bios.2007.08.016.

145 P. Xia, B. Zhu, J. Yu, S. Cao and M. Jaroniec, Ultra-thin nanosheet assemblies of graphitic carbon nitride for enhanced photocatalytic $\mathrm{CO} 2$ reduction, J. Mater. Chem. A, 2017, 5, 3230-3238, DOI: 10.1039/c6ta08310b.

146 R. Rostamian and H. Behnejad, A comprehensive adsorption study and modeling of antibiotics as a pharmaceutical waste by graphene oxide nanosheets, Ecotoxicol. Environ. Saf., 2018, 147, 117-123, DOI: 10.1016/j.ecoenv.2017. 08.019.

147 T. S. Anirudhan, F. Shainy and J. Christa, Synthesis and characterization of polyacrylic acid- grafted-carboxylic graphene/titanium nanotube composite for the effective removal of enrofloxacin from aqueous solutions: Adsorption and photocatalytic degradation studies, J. Hazard. Mater., 2017, 324, 117-130, DOI: 10.1016/j.jhazmat. 2016.09.073.

148 C. Chen, K. Xu, X. Ji, L. Miao and J. Jiang, Enhanced adsorption of acidic gases (CO2, NO2 and SO2) on light 
metal decorated graphene oxide, Phys. Chem. Chem. Phys., 2014, 16, 11031-11036, DOI: 10.1039/c4cp00702f.

149 K. Yang, B. Chen, X. Zhu and B. Xing, Aggregation, Adsorption, and Morphological Transformation of Graphene Oxide in Aqueous Solutions Containing Different Metal Cations, Environ. Sci. Technol., 2016, 50, 11066-11075, DOI: 10.1021/acs.est.6b04235.

$150 \mathrm{X}$. Wang, Y. Liang, W. An, J. Hu, Y. Zhu and W. Cui, Removal of chromium(VI) by a self-regenerating and metal free g-C3N4/graphene hydrogel system via the synergy of adsorption and photo-catalysis under visible light, Appl. Catal., B, 2017, 219, 53-62, DOI: 10.1016/j.apcatb.2017. 07.008.

151 H. C. Vu, A. D. Dwivedi, T. T. Le, S. H. Seo, E. J. Kim and Y. S. Chang, Magnetite graphene oxide encapsulated in alginate beads for enhanced adsorption of $\mathrm{Cr}(\mathrm{VI})$ and $\mathrm{As}(\mathrm{V})$ from aqueous solutions: Role of crosslinking metal cations in pH control, Chem. Eng. J., 2017, 307, 220-229, DOI: 10.1016/j.cej.2016.08.058.

152 L. Yu, L. Wang, W. Xu, L. Chen, M. Fu, J. Wu and D. Ye, Adsorption of VOCs on reduced graphene oxide, J. Environ. Sci., 2018, 67, 171-178, DOI: 10.1016/j.jes.2017.08.022.

153 S. Matsuyama, T. Sugiyama, T. Ikoma and J. S. Cross, Fabrication of 3D Graphene and 3D Graphene Oxide Devices for Sensing VOCs, MRS Adv., 2016, 1, 1359-1364, DOI: $10.1557 /$ adv.2016.151.

154 D. Gaber, M. Abu Haija, A. Eskhan and F. Banat, Graphene as an Efficient and Reusable Adsorbent Compared to Activated Carbons for the Removal of Phenol from Aqueous Solutions, Water, Air, Soil Pollut., 2017, 228, 320, DOI: 10.1007/s11270-017-3499-x.

155 C. C. Fu, R. S. Juang, M. M. Huq and C. Te Hsieh, Enhanced adsorption and photodegradation of phenol in aqueous suspensions of titania/graphene oxide composite catalysts, J. Taiwan Inst. Chem. Eng., 2016, 67, 338-345, DOI: 10.1016/j.jtice.2016.07.043.

156 S. Bele, V. Samanidou and E. Deliyanni, Effect of the reduction degree of graphene oxide on the adsorption of Bisphenol A, Chem. Eng. Res. Des., 2016, 109, 573-585, DOI: 10.1016/j.cherd.2016.03.002.

157 H. Zhu, D. Chen, N. Li, Q. Xu, H. Li, J. He and J. Lu, Graphene foam with switchable oil wettability for oil and organic solvents recovery, Adv. Funct. Mater., 2015, 25, 597-605, DOI: 10.1002/adfm.201403864.

158 R. Wu, B. Yu, X. Liu, H. Li, W. Wang, L. Chen, Y. Bai, Z. Ming and S. T. Yang, One-pot hydrothermal preparation of graphene sponge for the removal of oils and organic solvents, Appl. Surf. Sci., 2016, 362, 56-62, DOI: 10.1016/ j.apsusc.2015.11.215.

159 D. N. H. Tran, S. Kabiri, T. R. Sim and D. Losic, Selective adsorption of oil-water mixtures using polydimethylsiloxane (PDMS)-graphene sponges, Environ. Sci.: Water Res. Technol., 2015, 1, 298-305, DOI: 10.1039/c5ew00035a.

160 K. Shrivas, A. Ghosale, N. Nirmalkar, A. Srivastava, S. K. Singh and S. S. Shinde, Removal of endrin and dieldrin isomeric pesticides through stereoselective adsorption behavior on the graphene oxide-magnetic nanoparticles, Environ. Sci. Pollut. Res., 2017, 24, 24980-24988, DOI: 10.1007/s11356-017-0159-z.

161 D. Koushik, S. Sen Gupta, S. M. Maliyekkal and T. Pradeep, Rapid dehalogenation of pesticides and organics at the interface of reduced graphene oxide-silver nanocomposite, J. Hazard. Mater., 2016, 308, 192-198, DOI: 10.1016/ j.jhazmat.2016.01.004.

162 S. Agarwal, N. Sadeghi, I. Tyagi, V. K. Gupta and A. Fakhri, Adsorption of toxic carbamate pesticide oxamyl from liquid phase by newly synthesized and characterized graphene quantum dots nanomaterials, J. Colloid Interface Sci., 2016, 478, 430-438, DOI: 10.1016/j.jcis.2016.06.029.

$163 \mathrm{Z}$. Wu and B. Sundén, Convective heat transfer performance of aggregate-laden nanofluids, Int. J. Heat Mass Transfer, 2016, 93, 1107-1115, DOI: 10.1016/j.ijheatmass transfer.2015.11.032.

164 D. Robati, B. Mirza, M. Rajabi, O. Moradi, I. Tyagi, S. Agarwal and V. K. Gupta, Removal of hazardous dyesBR 12 and methyl orange using graphene oxide as an adsorbent from aqueous phase, Chem. Eng. J., 2016, 284, 687-697, DOI: 10.1016/j.cej.2015.08.131.

165 Y. Qi, M. Yang, W. Xu, S. He and Y. Men, Natural polysaccharides-modified graphene oxide for adsorption of organic dyes from aqueous solutions, J. Colloid Interface Sci., 2017, 486, 84-96, DOI: 10.1016/j.jcis.2016.09.058.

166 Y. Chao, W. Zhu, X. Wu, F. Hou, S. Xun, P. Wu, H. Ji, H. Xu and $\mathrm{H}$. Li, Application of graphene-like layered molybdenum disulfide and its excellent adsorption behavior for doxycycline antibiotic, Chem. Eng. J., 2014, 243, 60-67, DOI: 10.1016/j.cej.2013.12.048.

167 Ö. Kerkez-Kuyumcu, Ş. S. Bayazit and M. A. Salam, Antibiotic amoxicillin removal from aqueous solution using magnetically modified graphene nanoplatelets, J. Ind. Eng. Chem., 2016, 36, 198-205, DOI: 10.1016/j.jiec.2016.01.040.

168 L. Liu, S. Liu, Q. Zhang, C. Li, C. Bao, X. Liu and P. Xiao, Adsorption of $\mathrm{Au}(\mathrm{III}), \mathrm{Pd}$ (II), and Pt (IV) from aqueous solution onto graphene oxide, J. Chem. Eng. Data, 2012, 58, 209-216.

169 L. Cui, Y. Wang, L. Gao, L. Hu, L. Yan, Q. Wei and B. Du, EDTA functionalized magnetic graphene oxide for removal of $\mathrm{Pb}(\mathrm{II}), \mathrm{Hg}$ (II) and $\mathrm{Cu}(\mathrm{II})$ in water treatment: Adsorption mechanism and separation property, Chem. Eng. J., 2015, 281, 1-10, DOI: 10.1016/j.cej.2015.06.043.

170 F. Yu, J. Ma and D. Bi, Enhanced adsorptive removal of selected pharmaceutical antibiotics from aqueous solution by activated graphene, Environ. Sci. Pollut. Res., 2015, 22, 4715-4724, DOI: 10.1007/s11356-014-3723-9.

171 R. Sitko, M. Musielak, B. Zawisza, E. Talik and A. Gagor, Graphene oxide/cellulose membranes in adsorption of divalent metal ions, RSC Adv., 2016, 6, 96595-96605, DOI: 10.1039/c6ra21432k.

172 L. Liu, C. Li, C. Bao, Q. Jia, P. Xiao, X. Liu and Q. Zhang, Preparation and characterization of chitosan/graphene oxide composites for the adsorption of $\mathrm{Au}(\mathrm{III})$ and Pd(II), Talanta, 2012, 93, 350-357, DOI: 10.1016/j.talanta. 2012.02.051. 
173 L. P. Lingamdinne, J. R. Koduru, Y. L. Choi, Y. Y. Chang and J. K. Yang, Studies on removal of $\mathrm{Pb}$ (II) and $\mathrm{Cr}$ (III) using graphene oxide based inverse spinel nickel ferrite nano-composite as sorbent, Hydrometallurgy, 2016, 165, 64-72, DOI: 10.1016/j.hydromet.2015.11.005.

$174 \mathrm{~J} . \mathrm{Xu}, \mathrm{L}$. Wang and Y. Zhu, Decontamination of bisphenol A from aqueous solution by graphene adsorption, Langmuir, 2012, 28, 8418-8425, DOI: 10.1021/la301476p.

175 R. Sitko, E. Turek, B. Zawisza, E. Malicka, E. Talik, J. Heimann, A. Gagor, B. Feist and R. Wrzalik, Adsorption of divalent metal ions from aqueous solutions using graphene oxide, Dalton Trans., 2013, 42, 5682-5689, DOI: 10.1039/c3dt33097d.

176 P. K. Boruah, B. Sharma, N. Hussain and M. R. Das, Magnetically recoverable $\mathrm{Fe} 3 \mathrm{O} 4 /$ graphene nanocomposite towards efficient removal of triazine pesticides from aqueous solution: Investigation of the adsorption phenomenon and specific ion effect, Chemosphere, 2017, 168, 1058-1067, DOI: 10.1016/j.chemosphere.2016.10.103.

177 L. P. Lingamdinne, J. R. Koduru, H. Roh, Y. L. Choi, Y. Y. Chang and J. K. Yang, Adsorption removal of Co(II) from waste-water using graphene oxide, Hydrometallurgy, 2016, 165, 90-96, DOI: 10.1016/j.hydromet.2015.10.021.

178 W. Konicki, M. Aleksandrzak, D. Moszyński and E. Mijowska, Adsorption of anionic azo-dyes from aqueous solutions onto graphene oxide: Equilibrium, kinetic and thermodynamic studies, J. Colloid Interface Sci., 2017, 496, 188-200, DOI: 10.1016/j.jcis.2017.02.031.

179 W. Konicki, M. Aleksandrzak and E. Mijowska, Equilibrium, kinetic and thermodynamic studies on adsorption of cationic dyes from aqueous solutions using graphene oxide, Chem. Eng. Res. Des., 2017, 123, 35-49, DOI: 10.1016/ j.cherd.2017.03.036.

180 F. Sharif, L. R. Gagnon, S. Mulmi and E. P. L. Roberts, Electrochemical regeneration of a reduced graphene oxide/ magnetite composite adsorbent loaded with methylene blue, Water Res., 2017, 114, 237-245, DOI: 10.1016/j.watres. 2017.02.042.

181 M. Yari, M. Rajabi, O. Moradi, A. Yari, M. Asif, S. Agarwal and V. K. Gupta, Kinetics of the adsorption of $\mathrm{Pb}$ (II) ions from aqueous solutions by graphene oxide and thiol functionalized graphene oxide, J. Mol. Liq., 2015, 209, 50-57, DOI: 10.1016/j.molliq.2015.05.022.

182 F. Najafi, O. Moradi, M. Rajabi, M. Asif, I. Tyagi, S. Agarwal and V. K. Gupta, Thermodynamics of the adsorption of nickel ions from aqueous phase using graphene oxide and glycine functionalized graphene oxide, J. Mol. Liq., 2015, 208, 106-113, DOI: 10.1016/j.molliq.2015.04.033.

183 H. Xu, G. Li, J. Li, C. Chen and X. Ren, Interaction of Th(IV) with graphene oxides: Batch experiments, XPS investigation, and modeling, J. Mol. Liq., 2016, 213, 58-68, DOI: 10.1016/j.molliq.2015.11.022.

184 W. Yu, S. Zhan, Z. Shen, Q. Zhou and D. Yang, Efficient removal mechanism for antibiotic resistance genes from aquatic environments by graphene oxide nanosheet, Chem. Eng. J., 2017, 313, 836-846, DOI: 10.1016/j.cej.2016.10.107.
185 Z. Guo, J. Huang, Z. Xue and X. Wang, Electrospun graphene oxide/carbon composite nanofibers with welldeveloped mesoporous structure and their adsorption performance for benzene and butanone, Chem. Eng. J., 2016, 306, 99-106, DOI: 10.1016/j.cej.2016.07.048.

186 Z. Gong, S. Li, W. Han, J. Wang, J. Ma and X. Zhang, Recyclable graphene oxide grafted with poly $(\mathrm{N}-$ isopropylacrylamide) and its enhanced selective adsorption for phenols, Appl. Surf. Sci., 2016, 362, 459-468, DOI: 10.1016/j.apsusc.2015.11.251.

187 S. Yang, L. Chen, L. Mu and P. C. Ma, Magnetic graphene foam for efficient adsorption of oil and organic solvents, J. Colloid Interface Sci., 2014, 430, 337-344, DOI: 10.1016/ j.jcis.2014.05.062.

188 L. Fan, C. Luo, M. Sun, H. Qiu and X. Li, Synthesis of magnetic $\beta$-cyclodextrin-chitosan/graphene oxide as nanoadsorbent and its application in dye adsorption and removal, Colloids Surf., B, 2013, 103, 601-607, DOI: 10.1016/j.colsurfb.2012.11.023.

189 S. Peng, L. Li, J. Kong Yoong Lee, L. Tian, M. Srinivasan, S. Adams and S. Ramakrishna, Electrospun carbon nanofibers and their hybrid composites as advanced materials for energy conversion and storage, Nano Energy, 2016, 22, 361-395, DOI: 10.1016/j.nanoen.2016.02.001.

190 S. Peng, G. Jin, L. Li, K. Li, M. Srinivasan, S. Ramakrishna and J. Chen, Multi-functional electrospun nanofibres for advances in tissue regeneration, energy conversion \& storage, and water treatment, Chem. Soc. Rev., 2016, 45, 1225-1241, DOI: 10.1039/c5cs00777a.

191 S. Erdem, S. Hanbay and M. A. Blankson, Self-sensing damage assessment and image-based surface crack quantification of carbon nanofibre reinforced concrete, Constr. Build. Mater., 2017, 134, 520-529, DOI: 10.1016/j.conbuild mat.2016.12.197.

192 A. D’Alessandro, M. Rallini, F. Ubertini, A. L. Materazzi, J. M. Kenny and S. Laflamme, A comparative study between carbon nanotubes and carbon nanofibers as nanoinclusions in self-sensing concrete, in IEEE-NANO 2015 - 15th Int. Conf. Nanotechnol., IEEE, 2015, pp. 698-701, DOI: 10.1109/NANO.2015.7388702.

193 C. J. Lee, J. Park, J. M. Kim, Y. Huh, J. Y. Lee and K. S. No, Low-temperature growth of carbon nanotubes by thermal chemical vapor deposition using $\mathrm{Pd}, \mathrm{Cr}$, and $\mathrm{Pt}$ as co-catalyst, Chem. Phys. Lett., 2000, 327, 277-283, DOI: 10.1016/S0009-2614(00)00877-0.

194 G. Che, B. B. Lakshmi, C. R. Martin, E. R. Fisher and R. S. Ruoff, Chemical Vapor Deposition Based Synthesis of Carbon Nanotubes and Nanofibers Using a Template Method, Chem. Mater., 1998, 10, 260-267, DOI: 10.1021/cm970412f.

195 F. Miao, C. Shao, X. Li, K. Wang and Y. Liu, Flexible solidstate supercapacitors based on freestanding nitrogendoped porous carbon nanofibers derived from electrospun polyacrylonitrile@polyaniline nanofibers, J. Mater. Chem. A, 2016, 4, 4180-4187, DOI: 10.1039/c6ta00015k.

196 W. Li, L. Zeng, Z. Yang, L. Gu, J. Wang, X. Liu, J. Cheng and $\mathrm{Y}$. Yu, Free-standing and binder-free sodium-ion electrodes 
with ultralong cycle life and high rate performance based on porous carbon nanofibers, Nanoscale, 2014, 6, 693-698, DOI: 10.1039/c3nr05022j.

197 T. Chen, Y. Liu, L. Pan, T. Lu, Y. Yao, Z. Sun, D. H. C. Chua and Q. Chen, Electrospun carbon nanofibers as anode materials for sodium ion batteries with excellent cycle performance, J. Mater. Chem. A, 2014, 2, 4117-4121, DOI: 10.1039/c3ta14806h.

198 C. I. Su, Y. X. Huang, J. W. Wong, C. H. Lu and C. M. Wang, PAN-based carbon nanofiber absorbents prepared using electrospinning, Fibers Polym., 2012, 13, 436-442, DOI: 10.1007/s12221-012-0436-x.

199 Z. S. Metaxa, M. S. Konsta-Gdoutos and S. P. Shah, Mechanical properties and nanostructure of cement-based materials reinforced with carbon nanofibers and Polyvinyl Alcohol (PVA) microfibers, Am. Concr. Inst., SP, 2010, 270, 115-126.

200 B. O. Lee, W. J. Woo and M. S. Kim, EMI Shielding Effectiveness of Carbon Nanofiber Filled Poly(vinyl alcohol) Coating Materials, Macromol. Mater. Eng., 2001, 286, 114-118, DOI: 10.1002/1439-2054(20010201)286:2<114::AID-MAME $114>3.0 . \mathrm{CO} ; 2-8$.

201 C. Lai, Z. Zhou, L. Zhang, X. Wang, Q. Zhou, Y. Zhao, Y. Wang, X. F. Wu, Z. Zhu and H. Fong, Free-standing and mechanically flexible mats consisting of electrospun carbon nanofibers made from a natural product of alkali lignin as binder-free electrodes for high-performance supercapacitors, J. Power Sources, 2014, 247, 134-141, DOI: 10.1016/j.jpowsour.2013.08.082.

202 Y. Zhang, H. Ou, H. Liu, Y. Ke, W. Zhang, G. Liao and D. Wang, Polyimide-based carbon nanofibers: A versatile adsorbent for highly efficient removals of chlorophenols, dyes and antibiotics, Colloids Surf., A, 2018, 537, 92-101, DOI: 10.1016/j.colsurfa.2017.10.014.

203 W. Xu, Y. Feng, Y. Ding, S. Jiang, H. Fang and H. Hou, Short electrospun carbon nanofiber reinforced polyimide composite with high dielectric permittivity, Mater. Lett., 2015, 161, 431-434, DOI: 10.1016/j.matlet.2015.09.014.

204 T. Le, Y. Yang, Z. Huang and F. Kang, Preparation of microporous carbon nanofibers from polyimide by using polyvinyl pyrrolidone as template and their capacitive performance, J. Power Sources, 2015, 278, 683-692, DOI: 10.1016/j.jpowsour.2014.12.055.

205 K. H. Jung and J. P. Ferraris, Preparation of porous carbon nanofibers derived from PBI/PLLA for supercapacitor electrodes, Nanotechnology, 2016, 27, 425708, DOI: 10.1088/ 0957-4484/27/42/425708.

206 K. H. Jung and J. P. Ferraris, Preparation and electrochemical properties of carbon nanofibers derived from polybenzimidazole/polyimide precursor blends, Carbon, 2012, 50, 5309-5315, DOI: 10.1016/j.carbon.2012.07.019.

207 F. H. Anka and K. J. Balkus Jr, Electrospun polybenzimidazole $/ \mathrm{TiO}_{2}$ nanotube composite fiber mats for the adsorption of heavy metals and organic pollutants, Electrospun Nanofibers Water Filtr. Sens. Appl., 2013, 41.

208 S. M. Hong, S. W. Choi, S. H. Kim and K. B. Lee, Porous carbon based on polyvinylidene fluoride: Enhancement of
$\mathrm{CO}_{2}$ adsorption by physical activation, Carbon, 2016, 99, 354-360, DOI: 10.1016/j.carbon.2015.12.012.

209 S. A. C. Carabineiro, M. F. R. Pereira, J. N. Pereira, C. Caparros, V. Sencadas and S. Lanceros-Mendez, Effect of the carbon nanotube surface characteristics on the conductivity and dielectric constant of carbon nanotube/ poly(vinylidene fluoride) composites, Nanoscale Res. Lett., 2011, 6, 302, DOI: 10.1186/1556-276X-6-302.

210 Y. Cao, J. Huang, X. Peng, D. Cao, A. Galaska, S. Qiu, J. Liu, M. A. Khan, D. P. Young, J. E. Ryu, H. Feng, N. Yerra and Z. Guo, Poly(vinylidene fluoride) derived fluorine-doped magnetic carbon nanoadsorbents for enhanced chromium removal, Carbon, 2017, 115, 503-514, DOI: 10.1016/ j.carbon.2017.01.033.

211 D. Nan, J. Liu and W. Ma, Electrospun phenolic resinbased carbon ultrafine fibers with abundant ultra-small micropores for CO2 adsorption, Chem. Eng. J., 2015, 276, 44-50, DOI: 10.1016/j.cej.2015.04.081.

212 Y. Chen, M. Yue, Z. H. Huang and F. Kang, Electrospun carbon nanofiber networks from phenolic resin for capacitive deionization, Chem. Eng. J., 2014, 252, 30-37, DOI: 10.1016/j.cej.2014.04.099.

213 Y. Bai, Z. H. Huang and F. Kang, Electrospun preparation of microporous carbon ultrafine fibers with tuned diameter, pore structure and hydrophobicity from phenolic resin, Carbon, 2014, 66, 705-712, DOI: 10.1016/j.carbon.2013. 09.074.

214 R. Ruiz-Rosas, J. Bedia, M. Lallave, I. G. Loscertales, A. Barrero, J. Rodríguez-Mirasol and T. Cordero, The production of submicron diameter carbon fibers by the electrospinning of lignin, Carbon, 2010, 48, 696-705, DOI: 10.1016/j.carbon.2009.10.014.

215 M. Fujii, X. Zhang, H. Xie, H. Ago, K. Takahashi, T. Ikuta, H. Abe and T. Shimizu, Measuring the thermal conductivity of a single carbon nanotube, Phys. Rev. Lett., 2005, 95, 65502, DOI: 10.1103/PhysRevLett.95.065502.

216 P. Costa, J. Silva, A. Ansón-Casaos, M. T. Martinez, M. J. Abad, J. Viana and S. Lanceros-Mendez, Effect of carbon nanotube type and functionalization on the electrical, thermal, mechanical and electromechanical properties of carbon nanotube/styrene-butadiene-styrene composites for large strain sensor applications, Composites, Part B, 2014, 61, 136-146, DOI: 10.1016/j.compositesb.2014. 01.048.

217 P. Wang, R. Xiang and S. Maruyama, Thermal Conductivity of Carbon Nanotubes and Assemblies, Adv. Heat Transfer, 2018, 50, 43-122, DOI: 10.1016/bs.aiht.2018.07.004.

218 E. Zussman, X. Chen, W. Ding, L. Calabri, D. A. Dikin, J. P. Quintana and R. S. Ruoff, Mechanical and structural characterization of electrospun PAN-derived carbon nanofibers, Carbon, 2005, 43, 2175-2185, DOI: 10.1016/ j.carbon.2005.03.031.

219 G. Wang, J. Zhang, S. Kuang, J. Zhou, W. Xing and S. Zhuo, Nitrogen-doped hierarchical porous carbon as an efficient electrode material for supercapacitors, Electrochim. Acta, 2015, 153, 273-279, DOI: 10.1016/j.electacta.2014.12.006. 
220 M. Ali Atieh, Removal of Zinc from Water Using Modified and Non-Modified Carbon Nanofibers, in 2nd Int. Conf. Environ. Sci. Technol., 2011, pp. 220-223.

221 J. W. Lee, H. C. Kang, W. G. Shim, C. Kim, K. S. Yang and H. Moon, Heterogeneous adsorption of activated carbon nanofibers synthesized by electrospinning polyacrylonitrile solution, J. Nanosci. Nanotechnol., 2006, 6, 3577-3582, DOI: 10.1166/jnn.2006.060.

222 Y. Si, T. Ren, B. Ding, J. Yu and G. Sun, Synthesis of mesoporous magnetic Fe 3O 4@carbon nanofibers utilizing in situ polymerized polybenzoxazine for water purification, J. Mater. Chem., 2012, 22, 4619-4622, DOI: 10.1039/ c2jm00036a.

223 E. Díaz, S. Ordóñez and A. Vega, Adsorption of volatile organic compounds onto carbon nanotubes, carbon nanofibers, and high-surface-area graphites, J. Colloid Interface Sci., 2007, 305, 7-16, DOI: 10.1016/j.jcis.2006.09.036.

224 M. Bikshapathi, S. Singh, B. Bhaduri, G. N. Mathur, A. Sharma and N. Verma, Fe-nanoparticles dispersed carbon micro and nanofibers: Surfactant-mediated preparation and application to the removal of gaseous VOCs, Colloids Surf., A, 2012, 399, 46-55, DOI: 10.1016/ j.colsurfa.2012.02.023.

225 A. Chakraborty, D. Deva, A. Sharma and N. Verma, Adsorbents based on carbon microfibers and carbon nanofibers for the removal of phenol and lead from water, J. Colloid Interface Sci., 2011, 359, 228-239, DOI: 10.1016/j.jcis.2011.03.057.

226 R. Behnam, M. Morshed, H. Tavanai and M. Ghiaci, Destructive adsorption of diazinon pesticide by activated carbon nanofibers containing $\mathrm{Al} 2 \mathrm{O} 3$ and $\mathrm{MgO}$ nanoparticles, Bull. Environ. Contam. Toxicol., 2013, 91, 475-480, DOI: 10.1007/s00128-013-1064-x.

227 M. Bikshapathi, G. N. Mathur, A. Sharma and N. Verma, Surfactant-enhanced multiscale carbon webs including nanofibers and Ni-nanoparticles for the removal of gaseous persistent organic pollutants, Ind. Eng. Chem. Res., 2012, 51, 2104-2112, DOI: 10.1021/ie200741e.

228 P. Sullivan, J. Moate, B. Stone, J. D. Atkinson, Z. Hashisho and M. J. Rood, Physical and chemical properties of PANderived electrospun activated carbon nanofibers and their potential for use as an adsorbent for toxic industrial chemicals, Adsorption, 2012, 18, 265-274, DOI: 10.1007/ s10450-012-9399-x.

229 C. Park, E. S. Engel, A. Crowe, T. R. Gilbert and N. M. Rodriguez, Use of carbon nanofibers in the removal of organic solvents from water, Langmuir, 2000, 16, 8050-8056, DOI: $10.1021 /$ la9916068.

230 P. Serp, Carbon Nanotubes and Nanofibers in Catalysis, Carbon Mater. Catal., 2008, 253, 309-372, DOI: 10.1002/ 9780470403709.ch9.

231 E. C. Landis, K. L. Klein, A. Liao, E. Pop, D. K. Hensley, A. V. Melechko and R. J. Hamers, Covalent functionalization and electron-transfer properties of vertically aligned carbon nanofibers: The importance of edge-plane sites, Chem. Mater., 2010, 22, 2357-2366, DOI: 10.1021/ cm9036132.
232 B. M. Thamer, A. Aldalbahi, M. Moydeen, A. M. Al-Enizi, H. El-Hamshary, M. Singh, V. Bansal and M. H. El-Newehy, Alkali-activated electrospun carbon nanofibers as an efficient bifunctional adsorbent for cationic and anionic dyes, Colloids Surf., A, 2019, 582, 123835, DOI: 10.1016/ j.colsurfa.2019.123835.

233 S. Imaizumi, H. Matsumoto, M. Ashizawa, M. Minagawa and A. Tanioka, Nanosize effects of sulfonated carbon nanofiber fabrics for high capacity ion-exchanger, $R S C$ Adv., 2012, 2, 3109-3114, DOI: 10.1039/c2ra20103h.

234 A. S. Ibupoto, U. A. Qureshi, F. Ahmed, Z. Khatri, M. Khatri, M. Maqsood, R. Z. Brohi and I. S. Kim, Reusable carbon nanofibers for efficient removal of methylene blue from aqueous solution, Chem. Eng. Res. Des., 2018, 136, 744-752, DOI: 10.1016/j.cherd.2018.06.035.

235 M. Teng, J. Qiao, F. Li and P. K. Bera, Electrospun mesoporous carbon nanofibers produced from phenolic resin and their use in the adsorption of large dye molecules, Carbon, 2012, 50, 2877-2886, DOI: 10.1016/j.carbon. 2012.02.056.

236 W. Xiong, J. Tong, Z. Yang, G. Zeng, Y. Zhou, D. Wang, P. Song, R. Xu, C. Zhang and M. Cheng, Adsorption of phosphate from aqueous solution using iron-zirconium modified activated carbon nanofiber: Performance and mechanism, J. Colloid Interface Sci., 2017, 493, 17-23, DOI: 10.1016/j.jcis.2017.01.024.

$237 \mathrm{X}$. Zhao, X. Ma and P. Zheng, The preparation of carboxylic-functional carbon-based nanofibers for the removal of cationic pollutants, Chemosphere, 2018, 202, 298-305, DOI: 10.1016/j.chemosphere.2018.03.131.

238 M. Ahmad, J. Wang, J. Xu, Q. Zhang and B. Zhang, Magnetic tubular carbon nanofibers as efficient $\mathrm{Cu}(\mathrm{II})$ ion adsorbent from wastewater, J. Cleaner Prod., 2020, 252, 119825, DOI: 10.1016/j.jclepro.2019.119825.

239 Y. Sun, Z. Y. Wu, X. Wang, C. Ding, W. Cheng, S. H. Yu and $\mathrm{X}$. Wang, Macroscopic and Microscopic Investigation of $\mathrm{U}(\mathrm{VI})$ and Eu(III) Adsorption on Carbonaceous Nanofibers, Environ. Sci. Technol., 2016, 50, 4459-4467, DOI: 10.1021/ acs.est.6b00058.

240 X. Pan, H. Nan, P. Yang, L. Yang, G. Wang, H. Chen, H. Lin and $\mathrm{X}$. Zhao, Low-temperature and large-scale synthesis of carbon nanofiber web via electrospinning and their efficient removal of $\mathrm{Cr}(\mathrm{VI})$ ions, ChemistrySelect, 2018, 3, 10543-10548, DOI: 10.1002/slct.201802844.

241 M. Ahmad, K. Yang, L. Li, Y. Fan, T. Shah, Q. Zhang and B. Zhang, Modified Tubular Carbon Nanofibers for Adsorption of Uranium(VI) from Water, ACS Appl. Nano Mater., 2020, 3, 6394-6405, DOI: 10.1021/acsanm.0c00837.

242 P. Kampalanonwat and P. Supaphol, Preparation and adsorption behavior of aminated electrospun polyacrylonitrile nanofiber mats for heavy metal ion removal, ACS Appl. Mater. Interfaces, 2010, 2, 3619-3627, DOI: 10.1021/ am1008024.

243 K. J. Lee, N. Shiratori, G. H. Lee, J. Miyawaki, I. Mochida, S. H. Yoon and J. Jang, Activated carbon nanofiber produced from electrospun polyacrylonitrile nanofiber as a 
highly efficient formaldehyde adsorbent, Carbon, 2010, 48, 4248-4255, DOI: 10.1016/j.carbon.2010.07.034.

244 X. Li, S. Chen, X. Fan, X. Quan, F. Tan, Y. Zhang and J. Gao, Adsorption of ciprofloxacin, bisphenol and 2-chlorophenol on electrospun carbon nanofibers: In comparison with powder activated carbon, J. Colloid Interface Sci., 2015, 447, 120-127, DOI: 10.1016/j.jcis.2015.01.042.

245 Q. Liu, L. Bin Zhong, Q. B. Zhao, C. Frear and Y. M. Zheng, Synthesis of Fe3O4/Polyacrylonitrile Composite Electrospun Nanofiber Mat for Effective Adsorption of Tetracycline, ACS Appl. Mater. Interfaces, 2015, 7, 14573-14583, DOI: 10.1021/acsami.5b04598.

246 Y. Bai, Z. H. Huang, M. X. Wang and F. Kang, Adsorption of benzene and ethanol on activated carbon nanofibers prepared by electrospinning, Adsorption, 2013, 19, 1035-1043, DOI: 10.1007/s10450-013-9524-5.

247 Y. Bai, Z. H. Huang and F. Kang, Surface oxidation of activated electrospun carbon nanofibers and their adsorption performance for benzene, butanone and ethanol, Colloids Surf., A, 2014, 443, 66-71, DOI: 10.1016/ j.colsurfa.2013.10.057.

248 S. Schneiderman, L. Zhang, H. Fong and T. J. Menkhaus, Surface-functionalized electrospun carbon nanofiber mats as an innovative type of protein adsorption/purification medium with high capacity and high throughput, J. Chromatogr. A, 2011, 1218, 8989-8995, DOI: 10.1016/ j.chroma.2011.10.024.

249 G. Y. Oh, Y. W. Ju, M. Y. Kim, H. R. Jung, H. J. Kim and W. J. Lee, Adsorption of toluene on carbon nanofibers prepared by electrospinning, Sci. Total Environ, 2008, 393, 341-347, DOI: 10.1016/j.scitotenv.2008.01.005.

250 G. Y. Oh, Y. W. Ju, H. R. Jung and W. J. Lee, Preparation of the novel manganese-embedded PAN-based activated carbon nanofibers by electrospinning and their toluene adsorption, J. Anal. Appl. Pyrolysis, 2008, 81, 211-217, DOI: 10.1016/j.jaap.2007.11.006.

251 W. G. Shim, C. Kim, J. W. Lee, J. J. Yun, Y. I. Jeong, H. Moon and K. S. Yang, Adsorption characteristics of benzene on electrospun-derived porous carbon nanofibers, J. Appl. Polym. Sci., 2006, 102, 2454-2462, DOI: 10.1002/app.24554.

252 H. Liu, C. Y. Cao, F. F. Wei, P. P. Huang, Y. Bin Sun, L. Jiang and W. G. Song, Flexible macroporous carbon nanofiber film with high oil adsorption capacity, J. Mater. Chem. A, 2014, 2, 3557-3562, DOI: 10.1039/c3ta14468b.

253 H. Peng, P. Gao, G. Chu, B. Pan, J. Peng and B. Xing, Enhanced adsorption of $\mathrm{Cu}(\mathrm{II})$ and $\mathrm{Cd}(\mathrm{II})$ by phosphoric acid-modified biochars, Environ. Pollut., 2017, 229, 846-853, DOI: 10.1016/j.envpol.2017.07.004.

254 J. H. Kwak, M. S. Islam, S. Wang, S. A. Messele, M. A. Naeth, M. G. El-Din and S. X. Chang, Biochar properties and lead(II) adsorption capacity depend on feedstock type, pyrolysis temperature, and steam activation, Chemosphere, 2019, 231, 393-404, DOI: 10.1016/j.chemosphere.2019.05.128.

255 N. Grünewald and G. Rullander, Charcoal vertical gardens as treatment of drainwater for irrigation reuse: a performance evaluation in Kibera slum, Nairobi, 2020.
256 S. Fan, Y. Wang, Z. Wang, J. Tang, J. Tang and X. Li, Removal of methylene blue from aqueous solution by sewage sludgederived biochar: Adsorption kinetics, equilibrium, thermodynamics and mechanism, J. Environ. Chem. Eng., 2017, 5, 601-611, DOI: 10.1016/j.jece.2016.12.019.

257 C. Li, X. Zhu, H. He, Y. Fang, H. Dong, J. Lü, J. Li and Y. Li, Adsorption of two antibiotics on biochar prepared in aircontaining atmosphere: Influence of biochar porosity and molecular size of antibiotics, J. Mol. Liq., 2019, 274, 353-361, DOI: 10.1016/j.molliq.2018.10.142.

258 X. Zhu, B. Chen, L. Zhu and B. Xing, Effects and mechanisms of biochar-microbe interactions in soil improvement and pollution remediation: A review, Environ. Pollut., 2017, 227, 98-115, DOI: 10.1016/j.envpol.2017.04.032.

259 L. Wang, Y. Wang, F. Ma, V. Tankpa, S. Bai, X. Guo and $\mathrm{X}$. Wang, Mechanisms and reutilization of modified biochar used for removal of heavy metals from wastewater: A review, Sci. Total Environ, 2019, 668, 1298-1309, DOI: 10.1016/j.scitotenv.2019.03.011.

260 A. Mandal, N. Singh and T. J. Purakayastha, Characterization of pesticide sorption behaviour of slow pyrolysis biochars as low cost adsorbent for atrazine and imidacloprid removal, Sci. Total Environ., 2017, 577, 376-385, DOI: 10.1016/j.scitotenv.2016.10.204.

261 B. Jiang, Y. Lin and J. C. Mbog, Biochar derived from swine manure digestate and applied on the removals of heavy metals and antibiotics, Bioresour. Technol., 2018, 270, 603-611, DOI: 10.1016/j.biortech.2018.08.022.

262 N. Zhu, T. Yan, J. Qiao and H. Cao, Adsorption of arsenic, phosphorus and chromium by bismuth impregnated biochar: Adsorption mechanism and depleted adsorbent utilization, Chemosphere, 2016, 164, 32-40, DOI: 10.1016/ j.chemosphere.2016.08.036.

263 J. H. Park, Y. S. Ok, S. H. Kim, J. S. Cho, J. S. Heo, R. D. Delaune and D. C. Seo, Competitive adsorption of heavy metals onto sesame straw biochar in aqueous solutions, Chemosphere, 2016, 142, 77-83, DOI: 10.1016/ j.chemosphere.2015.05.093.

264 M. A. P. Kelm, M. J. da Silva Júnior, S. H. de Barros Holanda, C. M. B. de Araujo, R. B. de Assis Filho, E. J. Freitas, D. R. dos Santos and M. A. da Motta, Sobrinho, Removal of azo dye from water via adsorption on biochar produced by the gasification of wood wastes, Environ. Sci. Pollut. Res., 2019, 26, 28558-28573, DOI: 10.1007/s11356-018-3833-x.

265 H. Cederlund, E. Börjesson, D. Lundberg and J. Stenström, Adsorption of Pesticides with Different Chemical Properties to a Wood Biochar Treated with Heat and Iron, Water, Air, Soil Pollut., 2016, 227, 203, DOI: 10.1007/s11270-016-2894-z.

266 M. B. Ahmed, J. L. Zhou, H. H. Ngo, W. Guo, M. A. H. Johir and K. Sornalingam, Single and competitive sorption properties and mechanism of functionalized biochar for removing sulfonamide antibiotics from water, Chem. Eng. J., 2017, 311, 348-358, DOI: 10.1016/j.cej.2016.11.106.

267 S. S. Yang, Y. di Chen, J. H. Kang, T. R. Xie, L. He, D. F. Xing, N. Q. Ren, S. H. Ho and W. M. Wu, Generation 
of high-efficient biochar for dye adsorption using frass of yellow mealworms (larvae of Tenebrio molitor Linnaeus)fed with wheat straw for insect biomass production, J. Cleaner Prod., 2019, 227, 33-47, DOI: 10.1016/j.jclepro.2019.04.005.

268 A. S. Eltaweil, H. Ali Mohamed, E. M. Abd El-Monaem and G. M. El-Subruiti, Mesoporous magnetic biochar composite for enhanced adsorption of malachite green dye: Characterization, adsorption kinetics, thermodynamics and isotherms, Adv. Powder Technol., 2020, 31, 1253-1263, DOI: 10.1016/j.apt.2020.01.005.

269 S. Chen, C. Qin, T. Wang, F. Chen, X. Li, H. Hou and M. Zhou, Study on the adsorption of dyestuffs with different properties by sludge-rice husk biochar: Adsorption capacity, isotherm, kinetic, thermodynamics and mechanism, J. Mol. Liq., 2019, 285, 62-74, DOI: 10.1016/j.molliq.2019.04.035.

270 J. H. Park, J. J. Wang, Y. Meng, Z. Wei, R. D. DeLaune and D. C. Seo, Adsorption/desorption behavior of cationic and anionic dyes by biochars prepared at normal and high pyrolysis temperatures, Colloids Surf., A, 2019, 572, 274-282, DOI: 10.1016/j.colsurfa.2019.04.029.

271 H. N. Tran, Comments on "High-efficiency removal of dyes from wastewater by fully recycling litchi peel biochar, Chemosphere, 2020, 257, 125734, DOI: 10.1016/j.chemosphere.2020.126444.

272 M. Choudhary, R. Kumar and S. Neogi, Activated biochar derived from Opuntia ficus-indica for the efficient adsorption of malachite green dye, $\mathrm{Cu}+2$ and $\mathrm{Ni}+2$ from water, J. Hazard. Mater., 2020, 392, 122441, DOI: 10.1016/ j.jhazmat.2020.122441.

273 J. Liang, X. Li, Z. Yu, G. Zeng, Y. Luo, L. Jiang, Z. Yang, Y. Qian and $\mathrm{H}$. Wu, Amorphous MnO2 Modified Biochar Derived from Aerobically Composted Swine Manure for Adsorption of $\mathrm{Pb}(\mathrm{II})$ and $\mathrm{Cd}(\mathrm{II})$, ACS Sustain, Chem. Eng., 2017, 5, 5049-5058, DOI: 10.1021/acssuschemeng. $7 \mathrm{~b} 00434$.

274 L. L. Ling, W. J. Liu, S. Zhang and H. Jiang, Magnesium Oxide Embedded Nitrogen Self-Doped Biochar Composites: Fast and High-Efficiency Adsorption of Heavy Metals in an Aqueous Solution, Environ. Sci. Technol., 2017, 51, 10081-10089, DOI: 10.1021/acs.est.7b02382.

275 Y. Deng, S. Huang, D. A. Laird, X. Wang and Z. Meng, Adsorption behaviour and mechanisms of cadmium and nickel on rice straw biochars in single- and binary-metal systems, Chemosphere, 2019, 218, 308-318, DOI: 10.1016/ j.chemosphere.2018.11.081.

276 X. Wang, X. Li, G. Liu, Y. He, C. Chen, X. Liu, G. Li, Y. Gu and $Y$. Zhao, Mixed heavy metal removal from wastewater by using discarded mushroom-stick biochar: Adsorption properties and mechanisms, Environ. Sci.: Processes Impacts, 2019, 21, 584-592, DOI: 10.1039/c8em00457a.

277 F. Xiao, J. Cheng, W. Cao, C. Yang, J. Chen and Z. Luo, Removal of heavy metals from aqueous solution using chitosan-combined magnetic biochars, J. Colloid Interface Sci., 2019, 540, 579-584, DOI: 10.1016/j.jcis.2019.01.068.

278 W. Yu, F. Lian, G. Cui and Z. Liu, N-doping effectively enhances the adsorption capacity of biochar for heavy metal ions from aqueous solution, Chemosphere, 2018, 193, 8-16, DOI: 10.1016/j.chemosphere.2017.10.134.

279 D. W. Schaefer and K. D. Keefer, Structure of random porous materials: Silica aerogel, Phys. Rev. Lett., 1986, 56, 2199-2202, DOI: 10.1103/PhysRevLett.56.2199.

280 A. C. Pierre and G. M. Pajonk, Chemistry of aerogels and their applications, Chem. Rev., 2002, 102, 4243-4265, DOI: 10.1021/cr0101306.

281 L. Hu, R. He, H. Lei and D. Fang, Carbon Aerogel for Insulation Applications: A Review, Int. J. Thermophys., 2019, 40, 39, DOI: 10.1007/s10765-019-2505-5.

282 W. C. Li, A. H. Lu and S. C. Guo, Control of mesoporous structure of aerogels derived from cresol-formaldehyde, J. Colloid Interface Sci., 2002, 254, 153-157, DOI: 10.1006/ jcis.2002.8573.

283 H. J. Fecht, K. Brühne and P. Gluche, Carbon-based nano materials and hybrids - synthesis, properties and commercial applications, Carbon-Based Nanomater. Hybrids Synth. Prop. Commer. Appl., 2014, 4, 1-205, DOI: 10.4032/ 9789814411417.

284 A. Szczurek, K. Jurewicz, G. Amaral-Labat, V. Fierro, A. Pizzi and A. Celzard, Structure and electrochemical capacitance of carbon cryogels derived from phenol-formaldehyde resins, Carbon, 2010, 48, 3874-3883, DOI: 10.1016/ j.carbon.2010.06.053.

285 Y. Q. Li, Y. A. Samad, K. Polychronopoulou, S. M. Alhassan and K. Liao, Carbon aerogel from winter melon for highly efficient and recyclable oils and organic solvents absorption, ACS Sustain, Chem. Eng., 2014, 2, 1492-1497, DOI: 10.1021/sc500161b.

286 Z. Xu, X. Jiang, S. Tan, W. Wu, J. Shi, H. Zhou and P. Chen, Preparation and characterisation of $\mathrm{CNF} / \mathrm{MWCNT}$ carbon aerogel as efficient adsorbents, IET Nanobiotechnol., 2018, 12, 500-504, DOI: 10.1049/iet-nbt.2017.0234.

$287 \mathrm{M}$. Yu, J. Li and L. Wang, KOH-activated carbon aerogels derived from sodium carboxymethyl cellulose for highperformance supercapacitors and dye adsorption, Chem. Eng. J., 2017, 310, 300-306, DOI: 10.1016/j.cej.2016.10.121.

288 T. Horikawa, J. Hayashi and K. Muroyama, Controllability of pore characteristics of resorcinol-formaldehyde carbon aerogel, Carbon, 2004, 42, 1625-1633, DOI: 10.1016/ j.carbon.2004.02.016.

289 W. C. Li, A. H. Lu and S. C. Guo, Characterization of the microstructures of organic and carbon aerogels based upon mixed cresol-formaldehyde, Carbon, 2001, 39, 1989-1994, DOI: 10.1016/S0008-6223(01)00029-X.

290 D. Wu, R. Fu, Z. Sun and Z. Yu, Low-density organic and carbon aerogels from the sol-gel polymerization of phenol with formaldehyde, J. Non-Cryst. Solids, 2005, 351, 915-921, DOI: 10.1016/j.jnoncrysol.2005.02.008.

291 H. J. Kim, J. H. Kim, W. Il Kim and D. J. Suh, Nanoporous Phloroglucinol-Formaldehyde carbon aerogels for electrochemical use, Korean J. Chem. Eng., 2005, 22, 740-744, DOI: 10.1007/BF02705792.

292 F. Pérez-Caballero, A. L. Peikolainen, M. Uibu, R. Kuusik, O. Volobujeva and M. Koel, Preparation of carbon aerogels 
from 5-methylresorcinol-formaldehyde gels, Microporous Mesoporous Mater., 2008, 108, 230-236, DOI: 10.1016/ j.micromeso.2007.04.006.

293 W. Li, G. Reichenauer and J. Fricke, Carbon aerogels derived from cresol-resorcinol-formaldehyde for supercapacitors, Carbon, 2002, 40, 2955-2959, DOI: 10.1016/ S0008-6223(02)00243-9.

294 R. W. Pekala, Organic aerogels from the polycondensation of resorcinol with formaldehyde, J. Mater. Sci., 1989, 24, 3221-3227, DOI: 10.1007/BF01139044.

295 P. Hao, Z. Zhao, Y. Leng, J. Tian, Y. Sang, R. I. Boughton, C. P. Wong, H. Liu and B. Yang, Graphene-based nitrogen self-doped hierarchical porous carbon aerogels derived from chitosan for high performance supercapacitors, Nano Energy, 2015, 15, 9-23, DOI: 10.1016/j.nanoen.2015.02.035.

296 X. Xu, J. Zhou, D. H. Nagaraju, L. Jiang, V. R. Marinov, G. Lubineau, H. N. Alshareef and M. Oh, Flexible, highly graphitized carbon aerogels based on bacterial cellulose/ lignin: Catalyst-free synthesis and its application in energy storage devices, Adv. Funct. Mater., 2015, 25, 3193-3202, DOI: 10.1002/adfm.201500538.

$297 \mathrm{X}$. Wu and W. Jia, Biomass-derived multifunctional magnetite carbon aerogel nanocomposites for recyclable sequestration of ionizable aromatic organic pollutants, Chem. Eng. J., 2014, 245, 210-216, DOI: 10.1016/j.cej. 2014.02.032.

298 W. Zhang, M. Zhao, R. Liu, X. Wang and H. Lin, Hierarchical porous carbon derived from lignin for high performance supercapacitor, Colloids Surf., A, 2015, 484, 518-527, DOI: 10.1016/j.colsurfa.2015.08.030.

299 S. Yang, L. Chen, L. Mu, B. Hao and P. C. Ma, Low cost carbon fiber aerogel derived from bamboo for the adsorption of oils and organic solvents with excellent performances, RSC Adv., 2015, 5, 38470-38478, DOI: 10.1039/ c5ra03701h.

300 H. Bi, Z. Yin, X. Cao, X. Xie, C. Tan, X. Huang, B. Chen, F. Chen, Q. Yang, X. Bu, X. Lu, L. Sun and H. Zhang, Carbon fiber aerogel made from raw cotton: A novel, efficient and recyclable sorbent for oils and organic solvents, Adv. Mater., 2013, 25, 5916-5921, DOI: 10.1002/adma. 201302435.

301 X. Chang, D. Chen and X. Jiao, Starch-derived carbon aerogels with high-performance for sorption of cationic dyes, Polymer, 2010, 51, 3801-3807, DOI: 10.1016/ j.polymer.2010.06.018.

302 J. Han, J. Ge, Z. Ren, J. Tu, Z. Sun, S. Chen and G. Xie, Facile green synthesis of $3 \mathrm{D}$ porous glucose-based carbon aerogels for high-performance supercapacitors, Electrochim. Acta, 2017, 258, 951-958, DOI: 10.1016/j.electacta.2017. 11.146.

303 G. Zu, J. Shen, L. Zou, F. Wang, X. Wang, Y. Zhang and X. Yao, Nanocellulose-derived highly porous carbon aerogels for supercapacitors, Carbon, 2016, 99, 203-211, DOI: 10.1016/j.carbon.2015.11.079.

304 H. C. Chien, W. Y. Cheng, Y. H. Wang and S. Y. Lu, Ultrahigh specific capacitances for supercapacitors achieved by nickel cobaltite/carbon aerogel composites, Adv. Funct. Mater., 2012, 22, 5038-5043, DOI: 10.1002/adfm.201201176.

305 L. Li, T. Hu, H. Sun, J. Zhang and A. Wang, PressureSensitive and Conductive Carbon Aerogels from Poplars Catkins for Selective Oil Absorption and Oil/Water Separation, ACS Appl. Mater. Interfaces, 2017, 9, 18001-18007, DOI: $10.1021 /$ acsami.7b04687.

306 R. Gosalawit-Utke, T. K. Nielsen, K. Pranzas, I. Saldan, C. Pistidda, F. Karimi, D. Laipple, J. Skibsted, T. R. Jensen, T. Klassen and M. Dornheim, 2LiBH 4-MgH 2 in a resorcinol-furfural carbon aerogel scaffold for reversible hydrogen storage, J. Phys. Chem. C, 2012, 116, 1526-1534, DOI: $10.1021 /$ jp2088127.

307 T. He, Y. Zhang, Y. Chen, Z. Zhang, H. Wang, Y. Hu, M. Liu, C. W. Pao, J. L. Chen, L. Y. Chang, Z. Sun, J. Xiang, Y. Zhang and S. Chen, Single iron atoms stabilized by microporous defects of biomass-derived carbon aerogels as high-performance cathode electrocatalysts for aluminumair batteries, J. Mater. Chem. A, 2019, 7, 20840-20846, DOI: 10.1039/c9ta05981d.

308 H. Zhao, Q. Wang, Y. Chen, Q. Tian and G. Zhao, Efficient removal of dimethyl phthalate with activated iron-doped carbon aerogel through an integrated adsorption and electro-Fenton oxidation process, Carbon, 2017, 124, 111-122, DOI: 10.1016/j.carbon.2017.08.034.

309 J. Yang, Y. Chen, P. Xu, Y. Li, X. Jia and H. Song, Fabrication of compressible and underwater superoleophobic carbon/g-C3N4 aerogel for wastewater purification, Mater. Lett., 2019, 254, 210-213, DOI: 10.1016/j.matlet.2019. 07.069.

310 C. Gao, Z. Dong, X. Hao, Y. Yao and S. Guo, Preparation of Reduced Graphene Oxide Aerogel and Its Adsorption for Pb(II), ACS Omega, 2020, 5, 9903-9911, DOI: 10.1021/ acsomega.0c00183.

311 K. Kadirvelu, J. Goel and C. Rajagopal, Sorption of lead, mercury and cadmium ions in multi-component system using carbon aerogel as adsorbent, J. Hazard. Mater., 2008, 153, 502-507, DOI: 10.1016/j.jhazmat.2007.08.082.

312 J. Li, L. Zheng and H. Liu, A novel carbon aerogel prepared for adsorption of copper(II) ion in water, J. Porous Mater., 2017, 24, 1575-1580, DOI: 10.1007/s10934-017-0397-y.

313 X. Jiang, X. Xiang, S. Peng and L. Hou, Facile preparation of nitrogen-doped activated mesoporous carbon aerogel from chitosan for methyl orange adsorption from aqueous solution, Cellulose, 2019, 26, 4515-4527, DOI: 10.1007/ s10570-019-02368-2.

314 Y. F. Lin and C. Y. Chang, Magnetic mesoporous iron oxide/carbon aerogel photocatalysts with adsorption ability for organic dye removal, RSC Adv., 2014, 4, 28628-28631, DOI: 10.1039/c4ra03436h.

315 G. Aylaz, M. Okan, M. Duman and H. M. Aydin, Study on Cost-Efficient Carbon Aerogel to Remove Antibiotics from Water Resources, ACS Omega, 2020, 5, 16635-16644, DOI: 10.1021/acsomega.0c01479.

316 X. Tian, J. Liu, Y. Wang, F. Shi, Z. Shan, J. Zhou and J. Liu, Adsorption of antibiotics from aqueous solution by 
different aerogels, J. Non-Cryst. Solids, 2019, 505, 72-78, DOI: 10.1016/j.jnoncrysol.2018.10.033.

317 F. J. Maldonado-Hódar, C. Moreno-Castilla, F. CarrascoMarín and A. F. Pérez-Cadenas, Reversible toluene adsorption on monolithic carbon aerogels, J. Hazard. Mater., 2007, 148, 548-552, DOI: 10.1016/j.jhazmat.2007.03.007.

318 J. Gao, X. Zhang, J. Yang, J. Zhou, M. Tong, Q. Jin, F. Dai and G. Li, Ethylenediamine-catalyzed preparation of nitrogen-doped hierarchically porous carbon aerogel under hypersaline condition for high-performance supercapacitors and organic solvent absorbents, Nanomaterials, 2019, 9, 771, DOI: 10.3390/nano9050771.

319 Y. Liu, T. Shi, T. Zhang, D. Yuan, Y. Peng and F. Qiu, Cellulose-derived multifunctional nano-CuO/carbon aerogel composites as a highly efficient oil absorbent, Cellulose, 2019, 26, 5381-5394, DOI: 10.1007/s10570-019-02484-z.

320 Y. Hu, X. Tong, H. Zhuo, L. Zhong, X. Peng, S. Wang and R. Sun, 3D hierarchical porous $\mathrm{N}$-doped carbon aerogel from renewable cellulose: An attractive carbon for highperformance supercapacitor electrodes and $\mathrm{CO} 2$ adsorption, $R S C A d v$., 2016, 6, 15788-15795, DOI: 10.1039/ c6ra00822d.

321 H. Tian, J. Wu, W. Zhang, S. Yang, F. Li, Y. Qi, R. Zhou, X. Qi, L. Zhao and X. Wang, High performance of Fe nanoparticles/carbon aerogel sorbents for H2S Removal, Chem. Eng. J., 2017, 313, 1051-1060, DOI: 10.1016/ j.cej.2016.10.135.

322 T. Ahamad, M. Naushad, Ruksana, A. N. Alhabarah and S. M. Alshehri, N/S doped highly porous magnetic carbon aerogel derived from sugarcane bagasse cellulose for the removal of bisphenol-A, Int. J. Biol. Macromol., 2019, 132, 1031-1038, DOI: 10.1016/j.ijbiomac.2019.04.004.

323 M. Yu, Y. Han, J. Li and L. Wang, Magnetic N-doped carbon aerogel from sodium carboxymethyl cellulose/ collagen composite aerogel for dye adsorption and electrochemical supercapacitor, Int. J. Biol. Macromol., 2018, 115, 185-193, DOI: 10.1016/j.ijbiomac.2018.04.012.

324 Y. F. Lin and J. L. Chen, Magnetic mesoporous Fe/carbon aerogel structures with enhanced arsenic removal efficiency, J. Colloid Interface Sci., 2014, 420, 74-79, DOI: 10.1016/ j.jcis.2014.01.008.

325 Y. Wang, Y. Li and H. Zheng, Equilibrium, kinetic and thermodynamic studies on methylene blue adsorption by Trichosanthes kirilowii Maxim shell activated carbon, Pol. J. Chem. Technol., 2020, 21, 89-97, DOI: 10.2478/pjct2019-0044.

326 Z. Li, Z. Jia, T. Ni and S. Li, Adsorption of methylene blue on natural cotton based flexible carbon fiber aerogels activated by novel air-limited carbonization method, J. Mol. Liq., 2017, 242, 747-756, DOI: 10.1016/j.molliq. 2017.07.062.

327 Y. Shen, X. Zhu, L. Zhu and B. Chen, Synergistic effects of 2D graphene oxide nanosheets and 1D carbon nanotubes in the constructed 3D carbon aerogel for high performance pollutant removal, Chem. Eng. J., 2017, 314, 336-346, DOI: 10.1016/j.cej.2016.11.132.
328 Z. Li, L. Shao, Z. Ruan, W. Hu, L. Lu and Y. Chen, Converting untreated waste office paper and chitosan into aerogel adsorbent for the removal of heavy metal ions, Carbohydr. Polym., 2018, 193, 221-227, DOI: 10.1016/ j.carbpol.2018.04.003.

329 S. Abolhasani, A. Ahmadpour, T. Rohani Bastami and A. Yaqubzadeh, Facile synthesis of mesoporous carbon aerogel for the removal of ibuprofen from aqueous solution by central composite experimental design (CCD), J. Mol. Liq., 2019, 281, 261-268, DOI: 10.1016/j.molliq. 2019.02.084.

$330 \mathrm{X}$. Wu, D. Wu and R. Fu, Studies on the adsorption of reactive brilliant red $\mathrm{X}-3 \mathrm{~B}$ dye on organic and carbon aerogels, J. Hazard. Mater., 2007, 147, 1028-1036, DOI: 10.1016/j.jhazmat.2007.01.139.

331 K. Li, M. Zhou, L. Liang, L. Jiang and W. Wang, Ultrahighsurface-area activated carbon aerogels derived from glucose for high-performance organic pollutants adsorption, J. Colloid Interface Sci., 2019, 546, 333-343, DOI: 10.1016/ j.jcis.2019.03.076.

332 E. Lei, W. Li, J. Sun, Z. Wu and S. Liu, N-doped carbon aerogels obtained from APMP fiber aerogels saturated with rhodamine dye and their application as supercapacitor electrodes, Appl. Sci., 2019, 9, 618, DOI: 10.3390/ app9040618.

333 H. Wang, Y. Gong and Y. Wang, Cellulose-based hydrophobic carbon aerogels as versatile and superior adsorbents for sewage treatment, RSC Adv., 2014, 4, 45753-45759, DOI: 10.1039/c4ra08446b.

334 A. K. Meena, C. Rajagopal, Kiran and G. K. Mishra, Removal of heavy metal ions from aqueous solutions using chemically (Na2S) treated granular activated carbon as an adsorbent, J. Sci. Ind. Res., 2010, 69, 449-453.

335 J. Goel, K. Kadirvelu, C. Rajagopal and V. K. Garg, Investigation of adsorption of lead, mercury and nickel from aqueous solutions onto carbon aerogel, J. Chem. Technol. Biotechnol., 2005, 80, 469-476, DOI: 10.1002/jctb.1212.

336 J. Goel, K. Kadirvelu, C. Rajagopal and V. K. Garg, Cadmium(II) uptake from aqueous solution by adsorption onto carbon aerogel using a response surfaced methodological approach, Ind. Eng. Chem. Res., 2006, 45, 6531-6537, DOI: 10.1021/ie060010u.

337 J. Goel, K. Kadirvelu, C. Rajagopal and V. K. Garg, Removal of mercury(II) from aqueous solution by adsorption on carbon aerogel: Response surface methodological approach, Carbon, 2005, 43, 197-200, DOI: 10.1016/j.carbon. 2004.08.002.

338 W. Zhu, Y. Li, Y. Yu, T. Duan, D. Zhou, L. Wang, J. Zhou and M. Kuang, Environment-friendly bio-materials based on cotton-carbon aerogel for strontium removal from aqueous solution, J. Radioanal. Nucl. Chem., 2018, 316, 553-560, DOI: 10.1007/s10967-018-5782-8.

339 G. Liu, H. Mei, X. Tan, H. Zhang, H. Liu, M. Fang and $\mathrm{X}$. Wang, Enhancement of $\mathrm{Rb}+$ and $\mathrm{Cs}+$ removal in $3 \mathrm{D}$ carbon aerogel-supported Na2Ti3O7, J. Mol. Liq., 2018, 262, 476-483, DOI: 10.1016/j.molliq.2018.04.117. 
340 D. F. Molina-Campos, D. P. V. Delgadillo, L. Giraldo and J. C. Moreno-Piraján, Removal of metal ions CD(II), $\mathrm{CR}(\mathrm{VI})$ and NI(II) from aqueous solution using an organic aerogel and carbon aerogel obtained by acid catalysis, Mater. Express, 2020, 10, 127-139, DOI: 10.1166/mex. 2020.1623.

341 Y. Liu, Q. Xiong, H. Song, Y. Peng, L. Liu and C. Jiang, Preparation of LDH-modified cotton fabric based carbon aerogel as a highly efficient adsorbent for tellurium recovery, Cellulose, 2019, 26, 2573-2585, DOI: 10.1007/ s10570-019-02266-7.

342 O. M. Yaghi, M. O’Keeffe, N. W. Ockwig, H. K. Chae, M. Eddaoudi and J. Kim, Reticular synthesis and the design of new materials, Nature, 2003, 423, 705-714, DOI: 10.1038/ nature 01650.

343 J. Wang and S. Zhuang, Covalent organic frameworks (COFs) for environmental applications, Coord. Chem. Rev., 2019, 400, 213046, DOI: 10.1016/j.ccr.2019.213046. 